\title{
Models of the cardiac L-type calcium current: a quantitative comparison
}

\author{
Aditi Agrawal ${ }^{1}$, Ken Wang ${ }^{2}$, Liudmila Polonchuk ${ }^{2}$, Jonathan Cooper ${ }^{3}$, \\ Gary R. Mirams ${ }^{4}$, David J. Gavaghan ${ }^{1}$, Michael Clerx ${ }^{4, *}$ \\ ${ }^{1}$ Computational Biology \& Health Informatics, Dept. of Computer Science, University of Oxford, Oxford OX1 3QD, UK. \\ 2 Pharma Research and Early Development, Innovation Center Basel, F. Hoffmann-La Roche Ltd., Basel CH-4070, Switzerland. \\ ${ }^{3}$ Centre for Advanced Research Computing, University College London, Gower Street, London WC1E 6BT, UK. \\ ${ }^{4}$ Centre for Mathematical Medicine \& Biology, School of Mathematical Sciences, University of Nottingham, Nottingham NG7 \\ $2 \mathrm{RD}, \mathrm{UK}$. \\ * Corresponding author: michael.clerx@nottingham.ac.uk
}

\begin{abstract}
The L-type calcium current $\left(\mathrm{I}_{\mathrm{CaL}}\right)$ plays a critical role in cardiac electrophysiology, and models of $\mathrm{I}_{\mathrm{CaL}}$ are vital tools to predict arrhythmogenicity of drugs and mutations. Five decades of measuring and modelling $\mathrm{I}_{\mathrm{CaL}}$ have resulted in several competing theories (encoded in mathematical equations). However, the introduction of new models has not typically been accompanied by a data-driven critical comparison with previous work, so that it is unclear where predictions overlap or conflict, or which model is best suited for any particular application. We gathered 71 mammalian $\mathrm{I}_{\mathrm{CaL}}$ models, compared their structure, and reproduced simulated experiments to show that there is a large variability in their predictions, which was not substantially diminished when grouping by species or other categories. By highlighting the differences in these competing theories, listing major data sources, and providing simulation code, we have laid strong foundations for the development of a consensus model of $\mathrm{I}_{\mathrm{CaL}}$.
\end{abstract}




\section{Contents}

$\begin{array}{ll}\text { Introduction } & 3\end{array}$

$\begin{array}{ll}\text { Qualitative comparison } & 6\end{array}$

Literature survey . . . . . . . . . . . . . . . . . . . . . 6

Model provenance . . . . . . . . . . . . . . . . . . . . 6 6

Local $\left[\mathrm{Ca}^{2+}\right]$ and other variables . . . . . . . . . . . . . . . . . . . 9

Gating mechanisms . . . . . . . . . . . . . . . . . . . . . 12

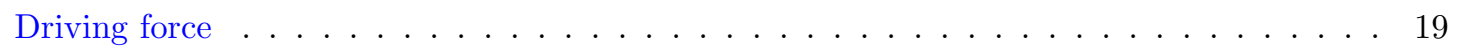

$\begin{array}{lr}\text { Quantitative comparison } & 24\end{array}$

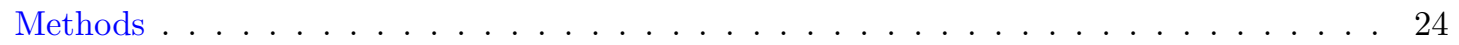

Model annotations . . . . . . . . . . . . . . . . . . . 24

Ionic Concentrations . . . . . . . . . . . . . . . . . . 25

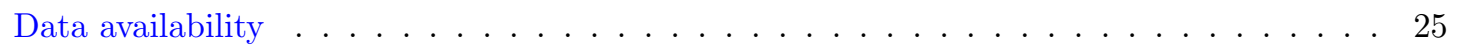

Activation . . . . . . . . . . . . . . . . . . . . 26

Voltage-dependent inactivation . . . . . . . . . . . . . . . . . . . 28

Recovery from voltage-dependent inactivation . . . . . . . . . . . . . . . . . . . . 29

Calcium-dependent inactivation . . . . . . . . . . . . . . . . . . . . 30

Action potential clamp . . . . . . . . . . . . . . . . . . . . . 32

$\begin{array}{lr}\text { Discussion } & 36\end{array}$

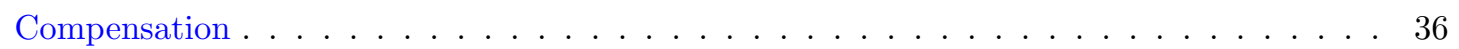

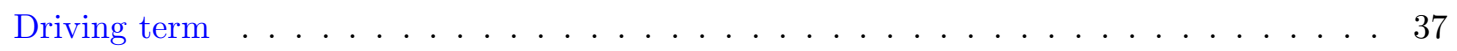

CDI and calcium dynamics . . . . . . . . . . . . . . . . . . . 37

Voltage-dependent kinetics . . . . . . . . . . . . . . . . . . . 38

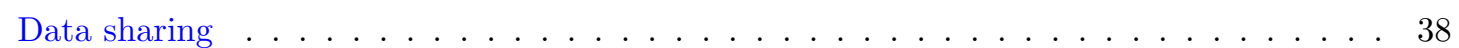

$\begin{array}{lr}\text { Conclusion } & 39\end{array}$

$\begin{array}{lr}\text { Additional information } & 39\end{array}$

$\begin{array}{lr}\text { References } & 40\end{array}$ 


\section{Introduction}

The "long-lasting" or L-type calcium current $\left(\mathrm{I}_{\mathrm{CaL}}\right)$ is an ionic current found in cardiomyocytes, neurons, endocrine cells, and other cell types throughout the body (Striessnig et al., 2014). It plays a crucial part in critical functions such as hormone secretion, regulation of gene expression, and contraction of cardiac and smooth muscle (Hofmann et al., 2014). Its critical role in cardiac cellular electrophysiology has led to extensive modelling efforts, and a large number of models of cardiac $\mathrm{I}_{\mathrm{CaL}}$ electrophysiology have been published since the 1970s. Incorporated into models of the cardiac action potential (AP), $\mathrm{I}_{\mathrm{CaL}}$ models have a long and successful history of application in fundamental electrophysiology research (Noble and Rudy, 2001). More recently, they have been used or proposed for use in drug safety assessment (Mirams et al., 2012) and risk stratification in cohorts with ion channel mutations (Hoefen et al., 2012). Choosing an $\mathrm{I}_{\mathrm{CaL}}$ model for such safety-critical applications is not an easy task, as models are spread out over the literature, vary widely in their structure and assumptions, and are often published in a paper form which does not lend itself to quantitative comparison without considerable effort (Cooper et al., 2011). On a more fundamental level, each model of $\mathrm{I}_{\mathrm{CaL}}$ represents a testable theory of its physiology, and the existence of so many competing theories reveals both gaps in our knowledge and an urgent need for their comparison and synthesis. In this study, we take the first major steps to facilitate a critical reassessment by the community, by collecting $\mathrm{I}_{\mathrm{CaL}}$ models, analysing their qualitative differences, and providing quantitative comparisons based on simulations with freely reusable code. We start with a brief description of $\mathrm{I}_{\mathrm{CaL}}$ physiology and the common structure of its models.

The L-type calcium channels through which $\mathrm{I}_{\mathrm{CaL}}$ flows consist of a pore formed by four $\alpha_{1}$ subunits and one each of the auxiliary subunits $\beta$ and $\alpha_{2} \delta$ (Dolphin, 2016). The most common $\alpha_{1}$ subunit in Purkinje fibres and ventricular and atrial cardiomyocytes is Cav1.2 (encoded by the gene CACNA1C), while $\mathrm{Ca}_{\mathrm{V}} 1.3(C A C N A 1 D)$ is more prevalent in the sinoatrial node (SAN) and atrio-ventricular node (AVN) (Gaborit et al., 2007; Zamponi et al., 2015). Electrically, $\mathrm{I}_{\mathrm{CaL}}$ is characterised by fast, membrane voltage $\left(V_{m}\right)$-dependent activation at relatively depolarised potentials (around $0 \mathrm{mV}$ ) and slower inactivation that also depends on the $V_{m}$ (voltage-dependent inactivation, VDI) and on the intracellular calcium concentration (calcium-dependent inactivation, CDI). Although predominantly carried by calcium ions, smaller potassium and sodium components have also been reported (Hess et al., 1986) and included in models.

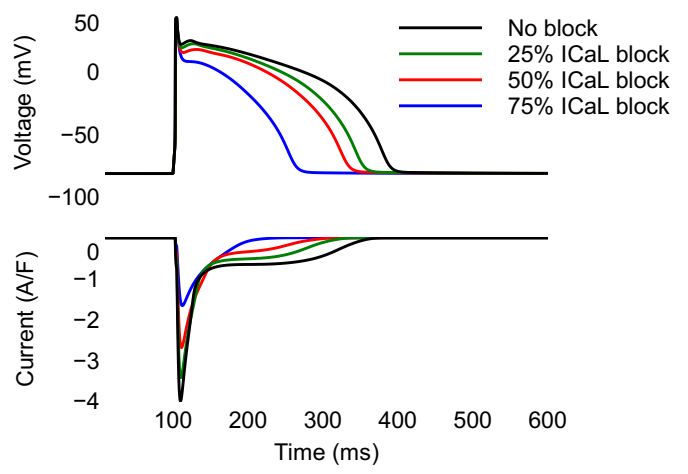

Figure 1: Blocking the L-type calcium current $\left(\mathrm{I}_{\mathrm{CaL}}\right)$ shortens the AP duration. Top: AP and Bottom: $\mathrm{I}_{\mathrm{CaL}}$ during $1 \mathrm{~Hz}$ simulation of the AP model by Grandi et al. (2010).

In ventricular and atrial cardiomyocytes, $\mathrm{I}_{\mathrm{CaL}}$ is the major inward current responsible for maintaining the "plateau" of the AP (Catterall, 2011). Figure 1 shows the shortening of the AP duration when the $\mathrm{I}_{\mathrm{CaL}}$ is blocked in the AP model by Grandi et al. (2010). The calcium influx during the plateau phase 
initiates the process of calcium-induced-calcium release (CICR): calcium flowing through L-type calcium channels triggers a further (much larger) release of calcium from the sarcoplasmic reticulum (SR), the major calcium store inside the cell. The resulting increase of calcium concentration in the cytosol allows formation of cross-bridges between myosin heads and actin filaments, causing contraction (Eisner et al., 2017).

The crucial role of calcium channels in maintaining healthy cardiac function is borne out by clinical evidence. For example, reduction of the expression of the Cav $1.2 \alpha_{1}$ subunit by less than half can lead to heart failure (Goonasekera et al., 2012). Mutations in CACNA1C and in its subunits have been linked to Brugada syndrome, Timothy's syndrome, arrhythmia, and structural heart defects (Hofmann et al., 2014).

As a result of its role in cardiac physiology, the L-type calcium channel is an important target for pharmacological antiarrhythmic therapy. For example, nifedipine, verapamil, and diltiazem are known to inhibit $\mathrm{I}_{\mathrm{CaL}}$ (Ortner and Striessnig, 2016). Conversely, unintended pharmacological modulation of $\mathrm{I}_{\mathrm{CaL}}$ may lead to drug-induced arrhythmias or other adverse cardiovascular effects. Initiatives like the comprehensive in vitro proarrhythmia assay $(\mathrm{CiPA})$ therefore take $\mathrm{I}_{\mathrm{CaL}}$ into account when attempting to predict or evaluate pro-arrhythmic risk (Ridder et al., 2020).

Models of a cardiac calcium current first appeared in the early 1970s (Bassingthwaithe and Reuter, 1972; McAllister et al., 1975), only a few years after the first calcium current recordings in cardiac preparations. Although Bassingthwaithe and Reuter (1972) confidently referred to it as a "calcium current whose role is primarily in the maintenance of the plateau [and in] regenerative depolarisation in low-sodium medium", the exact nature of the current and the species it was carried by was controversial at the time, so that the more cautious names "secondary inward" and "slow inward current" were more commonly used (Fozzard, 2002).

Although the complexity of $\mathrm{I}_{\mathrm{CaL}}$ models has increased over time (keeping pace with new discoveries about the current and its role in cardiac function), all models we assess in this manuscript can be expressed in a common form:

$$
I_{\mathrm{CaL}}=(\bar{g} \text { or } \bar{P}) \cdot O\left(V_{m},\left[\mathrm{Ca}^{2+}\right], t\right) \cdot D\left(V_{m},\left[\mathrm{Ca}^{2+}\right]\right) .
$$

Here, $O$ is the fraction of open channels (or the open probability of a single channel). The time-varying behaviour, i.e. the kinetics (or gating), of the channel(s) is captured by $O$, which is voltage- and timedependent and may also depend on $\left[\mathrm{Ca}^{2+}\right]$. The term $D$ represents the "driving term" accounting for the electrochemical forces driving the ionic movement. $D$ can depend on $V_{m}$ as well as the ionic concentrations on either side of the membrane. The current is scaled by either a maximal conductance $\bar{g}$ or a maximum permeability $\bar{P}$, depending on the choice of driving force model (see 'Driving force'). Conductance and permeability are functions of the total number of channels in the membrane (Schulz et al., 2006), which can vary over longer periods (hours to days); however, they are treated as constants in all of the models we surveyed.

For many ionic currents, the driving force at physiological membrane potentials is well described by an Ohmic driving force and a reversal potential given by the Nernst equation (see 'Driving force'), so that most modelling efforts are concentrated on the time-variant (and often transient) kinetic effects described by the $O$ term. For $\mathrm{I}_{\mathrm{CaL}}$, however, even the earliest publications showed that these assumptions are problematic, which led to the introduction of more complex driving terms, but also to the postulation of intracellular subspaces with elevated $\left[\mathrm{Ca}^{2+}\right]$ (Bassingthwaithe and Reuter, 1972) and to $\mathrm{I}_{\mathrm{CaL}}$ current formulations with sodium and potassium components (Reuter and Scholz, 1977; DiFrancesco and Noble, 1985). When gating terms began to include CDI (DiFrancesco and Noble, 1985), this led modellers to 
the inclusion of intracellular subspaces in their models (often connected to the SR) where $\left[\mathrm{Ca}^{2+}\right.$ ] could differ from the 'bulk' cytosolic level (Nordin, 1993). As a result, comparing models of $\mathrm{I}_{\mathrm{CaL}}$ requires consideration of the modellers' assumptions about channel localisation and cell structure in addition to the driving force and gating. Examples of early (McAllister et al., 1975) and more recent model equations (Faber and Rudy, 2000) can be viewed in the online repository accompanying this paper, at https://github.com/CardiacModelling/ical-model-comparison.

In this study we present an overview of the models that have been used in cardiac, mammalian $\mathrm{I}_{\mathrm{CaL}}$ modelling to date. We first describe the process by which we have identified models to be included in the study. We classify 71 of such models identified by their origins, the assumptions made by their authors about channel localisation and calcium-dependent effects, and the equations for their gating and driving force. We then compare the 60 models for which we could find the full equations by simulating the application of several experimental protocols. These include voltage-clamp protocols for activation, inactivation, and recovery, as well as an AP-clamp protocol and a protocol in which AP and calcium transient $(\mathrm{CaT})$ are both clamped. To understand the observed variability in predictions, we then test whether we can explain quantitative model differences by grouping models according to the qualitative aspects identified earlier. Finally, we discuss the implications of our findings for simulation studies including $\mathrm{I}_{\mathrm{CaL}}$ and for the process of building new $\mathrm{I}_{\mathrm{CaL}}$ models. 


\section{Part 1. Qualitative comparison}

\section{Literature survey}

To find papers that contained models of $\mathrm{I}_{\mathrm{CaL}}$ we searched on PubMed for the term "L-type calcium channel". Because many $\mathrm{I}_{\mathrm{CaL}}$ models are presented as part of a larger modelling effort, we also included the term "cardiac cell model", and scanned lists of models such as those given in Noble et al. (2012) and Heijman (2012). To restrict our search, we only included $\mathrm{I}_{\mathrm{CaL}}$ models that were presented by the authors as representing $\mathrm{I}_{\mathrm{CaL}}$ from healthy human or mammalian cells.

Next, we selected modern calcium models only where the authors indicated that it was an L-type current. Older models of "calcium current" and "slow" or "second inward" current were included if they modelled atrial, ventricular, or Purkinje cells, in which L-type is the dominant calcium current (Gaborit et al., 2007). The models included this way were by Bassingthwaithe and Reuter (1972), McAllister et al. (1975), Beeler and Reuter (1977), DiFrancesco and Noble (1985), Hilgemann and Noble (1987), and Noble et al. (1991). Some older models were excluded if they modelled the sino-atrial node, in which the dominant calcium current is of the T-type (Mesirca et al., 2014).

Some studies included several model variants. The models by Pandit et al. (2001), Ten Tusscher et al. (2004), Ten Tusscher and Panfilov (2006), O'Hara et al. (2011), and Tomek et al. (2019) have epi-, endo-, or mid-myocardial variants but the $\mathrm{I}_{\mathrm{CaL}}$ kinetics are the same. The epicardial cell model was chosen for these models. Similarly, the apical cell model was chosen for Bondarenko et al. (2004). The $\mathrm{I}_{\mathrm{CaL}}$ kinetics varies among the different versions presented for Inada et al. (2009), Paci et al. (2013), and Varela et al. (2016), for which we chose the atrio-nodal, atrial-like, and right-atrial model respectively.

The next selection was based on the model equations. Models were included in our overview if they introduced changes to equations in a pre-existing model, or if they included reparameterisation of equations determining either the open probability or driving force. We did not include models that changed only the maximum conductance or permeability. Models for which the equations were not (fully) given in the publication or an online addendum were also excluded in this step (9 models in total), as were models for which the equations were suspected to contain typesetting errors ( 1 model). Due to its historic importance, an exception was made for Bassingthwaithe and Reuter (1972) for which the published equations did not match the accompanying figures. This model is included in our qualitative, but not quantitative, analysis.

Finally, studies that calculated the current by considering the sum of all individual $\mathrm{I}_{\mathrm{CaL}}$ channels stochastically were only included for qualitative analysis. These included the studies by Greenstein and Winslow (2002), Restrepo et al. (2008), Hashambhoy et al. (2009), and Nivala et al. (2012). The studies by Hinch et al. (2004), Greenstein et al. (2006), Asakura et al. (2014), and Himeno et al. (2015) described $\mathrm{I}_{\mathrm{CaL}}$ using a model in which the gating was linked to the ryanodine receptor, and were also included for qualitative analysis only.

Applying these criteria we found a total of 71 distinct $\mathrm{I}_{\mathrm{CaL}}$ models, spanning more than five decades of research.

\section{Model provenance}

Models are not created in isolation, but inherit ideas, equations, and parameter values from previous models. Figure 2 presents a tentative 'phylogeny' of $\mathrm{I}_{\mathrm{CaL}}$ models, showing how the models that are in use today were derived from one another over time. To establish these relationships, we searched the model publications for explicit references to parent models. In some cases (e.g. Rasmusson et al. (1990)) 
the parent models did not meet the selection criteria used in this study, which is indicated in the figure by a dashed line. In other cases (e.g. Lindblad et al., 1996; Demir et al., 1999; Bondarenko et al., 2004), the parent model was not mentioned explicitly but could be inferred from the equations.

In constructing the figure, we attempted to limit each model to a single parent where possible. This is a simplification, and the figure should not be read as a statement on originality. For the models up to around 1995 it is likely that each model 'inherited' in some way from all other models published up to that time.

The phylogeny shows that many models have encountered species switches over the course of their development. For example, Grandi et al. (2010) (human) inherits from Shannon 2004 (rabbit), Luo-Rudy 1994 (guinea pig), and Rasmusson 1990 (bullfrog). Similarly, the histories of the O'Hara et al. (2011) and Paci et al. (2013) models also contain several species switches. Note that this does not necessarily suggest re-use of data, as models are frequently re-parameterised to new data sets. However, inheritance of parameter values (and thereby indirectly of data sources) is also very common in electrophysiology models (Niederer et al., 2009). 


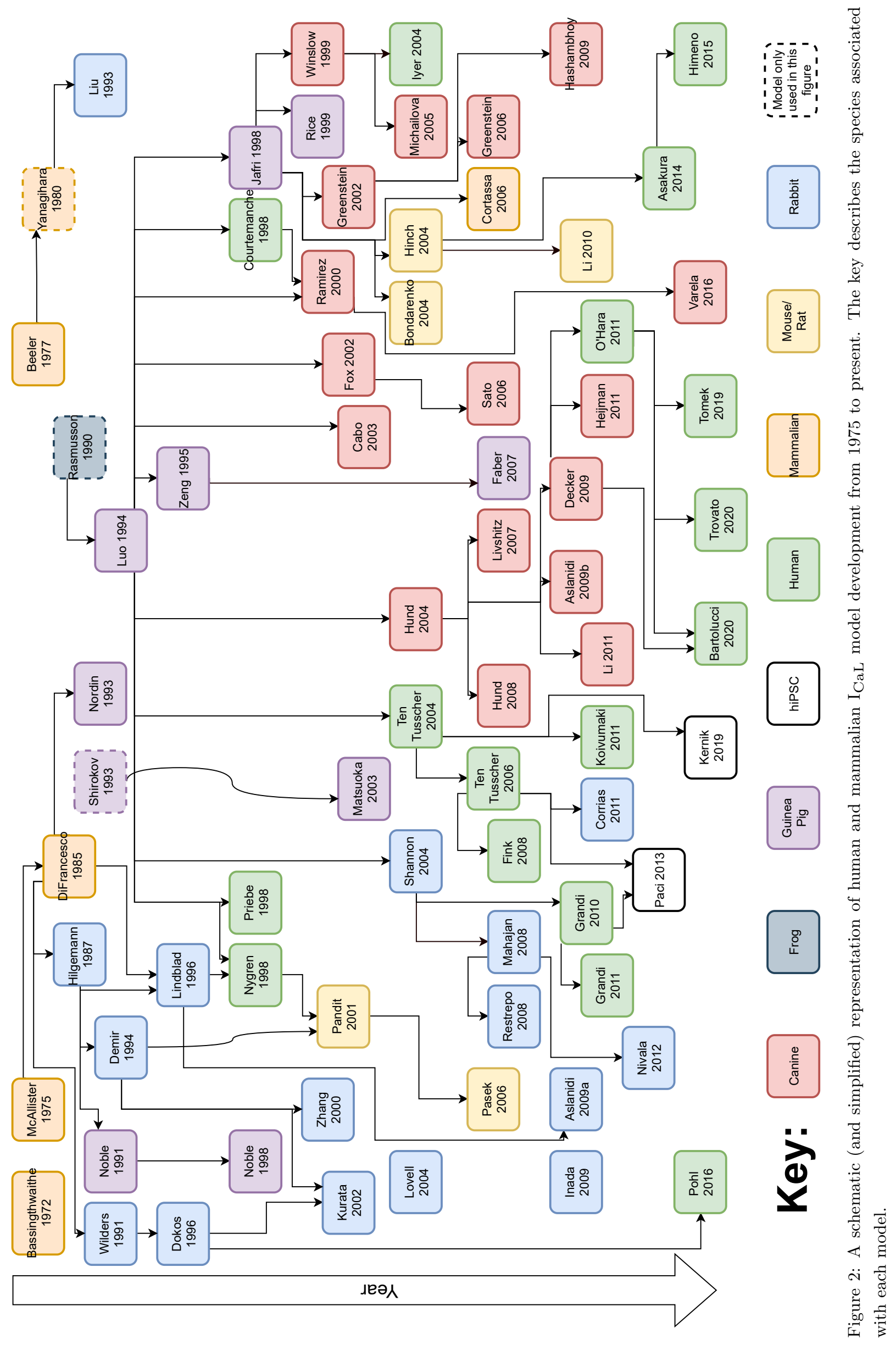




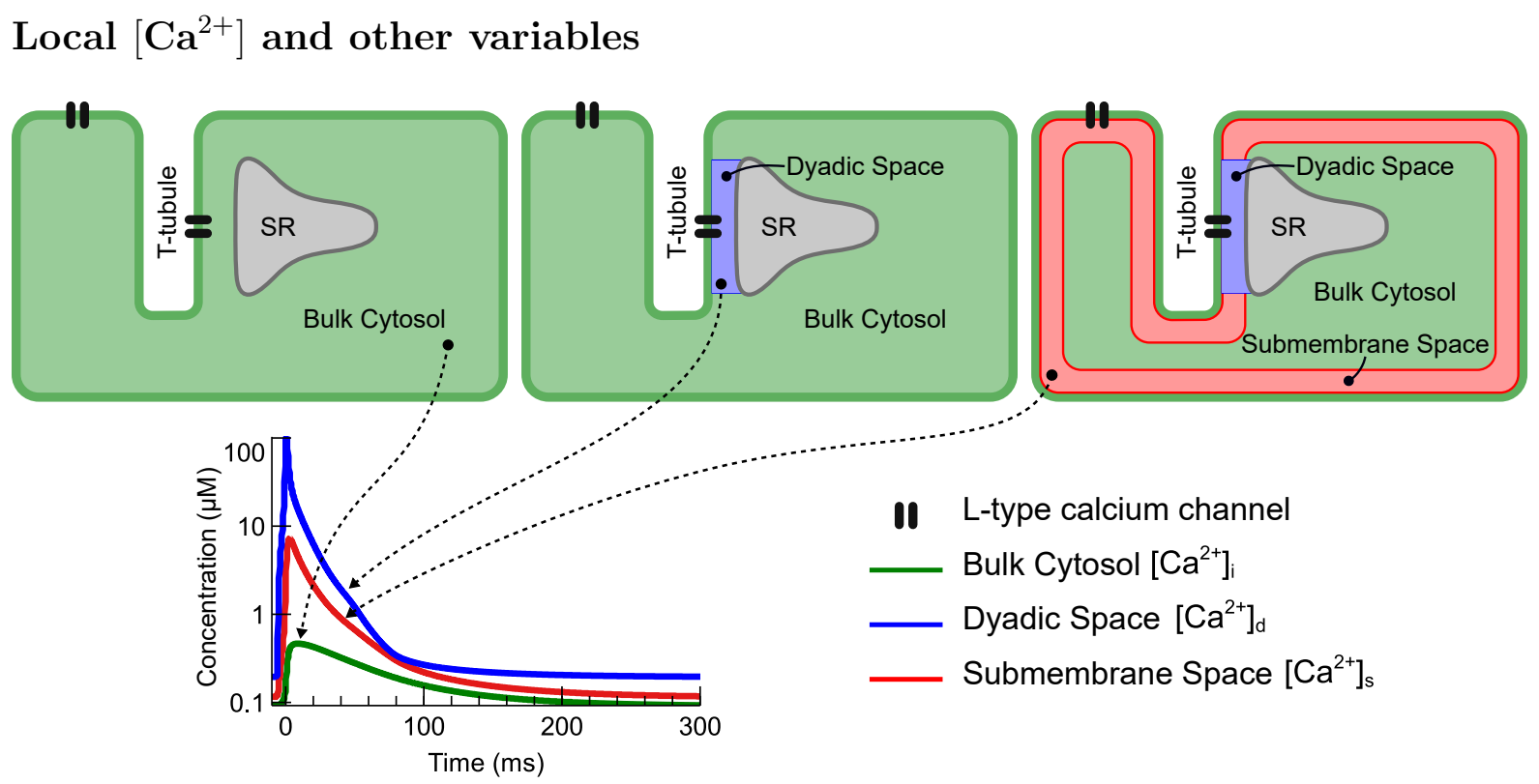

Figure 3: Schematic representations of a cardiomyocyte illustrating three common models of subcellular subspaces and L-type calcium channel localisation. In small subspaces, $\left[\mathrm{Ca}^{2+}\right]$ can differ from the bulk cytosolic concentration by orders of magnitude, as illustrated in the lower panel, which shows calcium transients from the Grandi et al. (2010) action potential model at $1 \mathrm{~Hz}$ simulation.

The calcium concentration at the intracellular side of the $\mathrm{I}_{\mathrm{CaL}}$ channel is known to affect the channel's gating, as well as the electrochemical force. Modellers as early as Bassingthwaithe and Reuter (1972) suggested that the size of these effects is inconsistent with the low (micromolar) calcium concentration of the 'bulk' cytosol. Instead, many action potential (AP) models have divided the cell into smaller volume 'subspaces' in which calcium ions, carried in by $\mathrm{I}_{\mathrm{CaL}}$ or released from the $\mathrm{SR}$, can cause $\left[\mathrm{Ca}^{2+}\right]$ to transiently rise to much higher levels than are seen in the bulk cytosolic space.

Figure 3 shows three commonly used subspace configurations. Here, we use $\left[\mathrm{Ca}^{2+}\right]_{i}$ to denote the bulk cytosolic concentration, $\left[\mathrm{Ca}^{2+}\right]_{s}$ for the submembrane space concentration, and $\left[\mathrm{Ca}^{2+}\right]_{d}$ for the dyadic space concentration. In the simplest type of AP model, shown on the left, there are no subspaces and $\mathrm{I}_{\mathrm{CaL}}$ flows directly into the bulk cytosol (e.g. DiFrancesco and Noble (1985)). The second type of cardiac model adds a 'dyadic' or 'junctional' space, located near the t-tubules adjacent to the SR. In this illustration, $\mathrm{I}_{\mathrm{CaL}}$ channels are connected to the dyadic space and also directly to the bulk cytosol (as some cardiac models have a small fraction $(\sim 10 \%)$ of $\mathrm{I}_{\mathrm{CaL}}$ flowing directly into the cytosol, e.g. Tomek et al. (2019)). The third type of cardiac model retains the dyadic space, but adds a 'submembrane' or 'subsarcolemmal' space just below the remainder of the cell membrane, so that $\mathrm{I}_{\mathrm{CaL}}$ flows either into the dyadic or the submembrane space. An example of this configuration, including compartment sizes and experimental references, is given in Shannon et al. (2004).

The subspaces, as defined above, are not separated from the bulk cytosol by any physical barrier. Rather, they represent a first approximation to more complex 'local control' models where $\left[\mathrm{Ca}^{2+}\right]$ can vary smoothly throughout the cell (Stern, 1992; Rice and Jafri, 2001). Such models may be implemented using partial differential equations for subcellular diffusion of $\left[\mathrm{Ca}^{2+}\right]$ (Stern, 1992), but are more commonly simulated using a fine-grained grid of "functional release units", each with their own calcium concentration (Rice et al., 1999; Nivala et al., 2012). Alternative approaches have been used by e.g. Nordin (1993), who define a 'superficial, middle, and deep myoplasm', and Koivumäki et al. (2011), who modelled the myocyte as a series of concentric shells. 
bioRxiv preprint doi: https://doi.org/10.1101/2021.10.04.462988; this version posted October 7, 2021. The copyright holder for this preprint (which was not certified by peer review) is the author/funder, who has granted bioRxiv a license to display the preprint in perpetuity. It is made available under aCC-BY 4.0 International license.

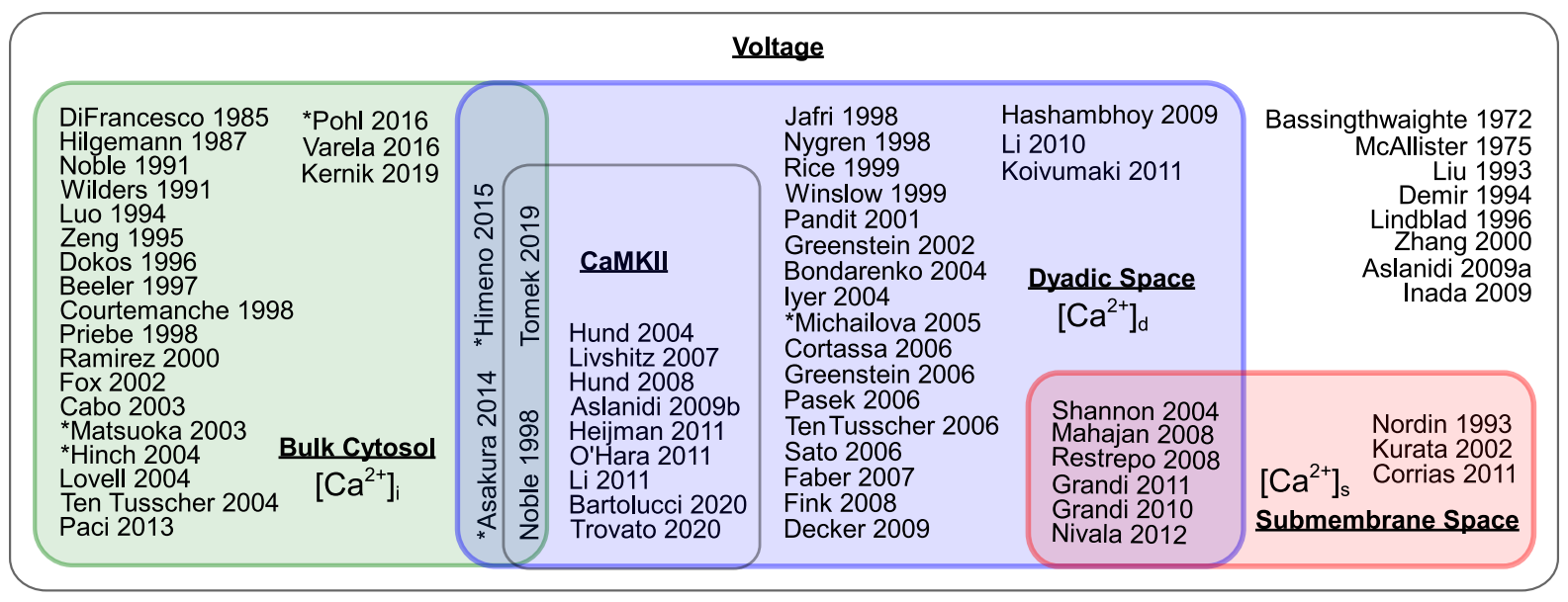

Figure 4: A venn diagram showing the dependency of $\mathrm{I}_{\mathrm{CaL}}$ gating and driving force on $\left[\mathrm{Ca}^{2+}\right]$ and $[\mathrm{CaMKII}]$. All models shown here depend on voltage. $\mathrm{I}_{\mathrm{CaL}}$ models inside the geen, blue, and red boxes depend on bulk cytosolic calcium, dyadic space calcium, and submembrane space calcium respectively, and models inside the black-edged central box also depend on the concentration of CaMKII. Models marked with an asterisk depend on additional variables, as described in the text.

These different models of cell geometry and $\left[\mathrm{Ca}^{2+}\right]$ concentrations complicate the task of comparing $\mathrm{I}_{\mathrm{CaL}}$ models in an AP model. Different assumptions about channel localisation in an AP model will lead to $\mathrm{I}_{\mathrm{CaL}}$ channels experiencing different intracellular calcium concentrations. $\mathrm{I}_{\mathrm{CaL}}$ models subsequently have different assumptions about CDI and driving force. Furthermore, since $\mathrm{I}_{\mathrm{CaL}}$ gating models are often calibrated in the context of an AP model, several more parameters in the $\mathrm{I}_{\mathrm{CaL}}$ model will be sensitive to the chosen localisation.

In addition to the membrane potential $\left(V_{m}\right)$ and (local) intracellular $\left[\mathrm{Ca}^{2+}\right], \mathrm{I}_{\mathrm{CaL}}$ models have been developed that are sensitive to several other variables. The most common of these is the CaMKII concentration, which is assumed to affect CDI in models such as Noble et al. (1998). Effects of ATP concentration on channel gating are accounted for in the models by Matsuoka et al. (2003), Asakura et al. (2014), and Himeno et al. (2015); Michailova et al. (2005) incorporates an effect of [MgATP], and ACh-inhibition of $\mathrm{I}_{\mathrm{CaL}}$ is modelled by Pohl et al. (2016). Finally, the work by Hinch et al. (2004) uses a single model to describe the L-type calcium channels and ryanodine receptors, leading to a dependency on the state of the SR (interestingly, this model uses the $\left[\mathrm{Ca}^{2+}\right]_{i}$ to estimate the concentration in the dyadic space). An overview of the dependencies of each $\mathrm{I}_{\mathrm{CaL}}$ model is provided in Figure 4.

We next grouped the $71 \mathrm{I}_{\mathrm{CaL}}$ models by the calcium concentrations assumed to affect $\mathrm{I}_{\mathrm{CaL}}$ gating $(O)$ and driving force $(D)$, leading to the twelve categories shown in Table 1. Note that not all models shown in this table fit neatly into the three subspace configurations shown in Figure 3: the studies by Asakura et al. (2014) and Himeno et al. (2015) both define an extra intermediate subspace, between dyadic and bulk cytosolic; while the models by Noble et al. (1998), Mahajan et al. (2008), and Restrepo et al. (2008) use different concentrations for the gating and driving force, which means they cannot be neatly assigned a position in Figure 3.

The naming of spaces varies between studies, and sometimes overlaps or conflicts. In preparing Figure 4 and Table 1, we classified a subspace as 'dyadic' if its primary role was in calcium handling (e.g. if it contained $\mathrm{I}_{\mathrm{CaL}}$ channels and connected to the SR) while we used the term 'submembrane' space only if several ion species flowed in and out of it, and it covered all or most of the (outer and t-tubular) membrane. An example where this conflicts is Sato et al. (2006), where we classified as 'dyadic' a 
subspace termed 'submembrane' by the authors.

\begin{tabular}{|c|c|c|c|}
\hline No. & Models & $O$ & $D$ \\
\hline 1 & $\begin{array}{l}\text { Bassingthwaithe and Reuter (1972), McAllister et al. (1975), Liu et } \\
\text { al. (1993), Demir et al. (1994), Lindblad et al. (1996), Zhang et al. } \\
\text { (2000), Aslanidi et al. (2009a) and Inada et al. (2009) }\end{array}$ & - & - \\
\hline 2 & $\begin{array}{l}\text { Beeler and Reuter (1977), Noble et al. (1991), and Wilders et al. } \\
\text { (1991) }\end{array}$ & - & {$\left[\mathrm{Ca}^{2+}\right]_{i}$} \\
\hline 3 & $\begin{array}{l}\text { Courtemanche et al. (1998), Ramirez et al. (2000), Lovell et al. (2004), } \\
\text { and Varela et al. (2016) }\end{array}$ & {$\left[\mathrm{Ca}^{2+}\right]_{i}$} & - \\
\hline 4 & Kurata et al. (2002) & {$\left[\mathrm{Ca}^{2+}\right]_{s}$} & - \\
\hline 5 & $\begin{array}{l}\text { Jafri et al. (1998), Rice et al. (1999), Nygren et al. (1998), Winslow } \\
\text { et al. (1999), Pandit et al. (2001), Bondarenko et al. (2004), Iyer et } \\
\text { al. (2004), Michailova et al. (2005), Cortassa et al. (2006), Pásek et } \\
\text { al. (2006), and Koivumäki et al. (2011) }\end{array}$ & {$\left[\mathrm{Ca}^{2+}\right]_{d}$} & - \\
\hline 6 & $\begin{array}{l}\text { DiFrancesco and Noble (1985), Hilgemann and Noble (1987), Luo and } \\
\text { Rudy (1994), Zeng et al. (1995), Dokos et al. (1996), Priebe and } \\
\text { Beuckelmann (1998), Fox et al. (2002), Cabo and Boyden (2003), } \\
\text { Matsuoka et al. (2003), Ten Tusscher et al. (2004), Paci et al. (2013), } \\
\text { Pohl et al. (2016), and Kernik et al. (2019) }\end{array}$ & {$\left[\mathrm{Ca}^{2+}\right]_{i}$} & {$\left[\mathrm{Ca}^{2+}\right]_{i}$} \\
\hline 7 & Nordin (1993), Sato et al. (2006), and Corrias et al. (2011) & {$\left[\mathrm{Ca}^{2+}\right]_{s}$} & {$\left[\mathrm{Ca}^{2+}\right]_{s}$} \\
\hline 8 & $\begin{array}{l}\text { Hinch et al. (2004), Hund and Rudy (2004), Greenstein and Winslow } \\
\text { (2002), Greenstein et al. (2006), Ten Tusscher and Panfilov (2006), } \\
\text { Faber et al. (2007), Livshitz and Rudy (2007), Fink et al. (2008), Hund } \\
\text { et al. (2008), Aslanidi et al. (2009b), Decker et al. (2009), Hashambhoy } \\
\text { et al. (2009), Li et al. (2010), Rovetti et al. (2010), Heijman et al. } \\
\text { (2011), O'Hara et al. (2011), Li and Rudy (2011), Nivala et al. (2012), } \\
\text { Bartolucci et al. (2020), and Trovato et al. (2020) }\end{array}$ & {$\left[\mathrm{Ca}^{2+}\right]_{d}$} & {$\left[\mathrm{Ca}^{2+}\right]_{d}$} \\
\hline 9 & Tomek et al. (2019), Asakura et al. (2014), and Himeno et al. (2015) & $\begin{array}{l}{\left[\mathrm{Ca}^{2+}\right]_{i}} \\
{\left[\mathrm{Ca}^{2+}\right]_{d}}\end{array}$ & $\begin{array}{l}{\left[\mathrm{Ca}^{2+}\right]_{i}} \\
{\left[\mathrm{Ca}^{2+}\right]_{d}}\end{array}$ \\
\hline 10 & Shannon et al. (2004), Grandi et al. (2010), and Grandi et al. (2011) & $\begin{array}{l}{\left[\mathrm{Ca}^{2+}\right]_{s}} \\
{\left[\mathrm{Ca}^{2+}\right]_{d}}\end{array}$ & $\begin{array}{l}{\left[\mathrm{Ca}^{2+}\right]_{s}} \\
{\left[\mathrm{Ca}^{2+}\right]_{d}}\end{array}$ \\
\hline 11 & Noble et al. (1998) & {$\left[\mathrm{Ca}^{2+}\right]_{d}$} & {$\left[\mathrm{Ca}^{2+}\right]_{i}$} \\
\hline 12 & Mahajan et al. (2008) and Restrepo et al. (2008) & {$\left[\mathrm{Ca}^{2+}\right]_{d}$} & {$\left[\mathrm{Ca}^{2+}\right]_{s}$} \\
\hline
\end{tabular}

Table 1: $\mathrm{I}_{\mathrm{CaL}}$ models grouped according to the $\left[\mathrm{Ca}^{2+}\right]$ they are assumed to depend on in their open probability $(O)$ and driving force $(D)$; extending the illustration in Figure 4. 


\section{Gating mechanisms}

The feature that varies most between $\mathrm{I}_{\mathrm{CaL}}$ models is the set of equations used to describe the fraction of open channels, $O$. This part of the model determines how the current changes over time i.e. it describes the current kinetics or gating. In this section we present a further classification of $\mathrm{I}_{\mathrm{CaL}}$ models into 15 distinct groups based on their gating equations.

$\mathrm{I}_{\mathrm{CaL}}$ gating is commonly modelled using either Hodgkin-Huxley models (HHMs) or Markov models (MMs). In HHMs (Hodgkin and Huxley, 1952) the open probability is calculated as the product of several independent 'gates', e.g. one gate representing voltage-dependent activation, one representing VDI, and one representing CDI. The opening and closing of each gate is modelled using a single ordinary differential equation (ODE), although CDI gates are frequently assumed to be very fast and therefore as instantaneously reaching their steady states (e.g. using a Hill equation). In Markov models the channel is postulated to be in one of a finite number of states, and transition rates are defined between the states that can depend on $V_{m}$ or $\left[\mathrm{Ca}^{2+}\right]$. In contrast to HHMs, where each process (activation, VDI, CDI) is independent, MMs allow a more general structure where e.g. activation and VDI are coupled (Rudy and Silva, 2006).

In the most common formulation, where the open probability $(O)$ of an HHM is the product of a number of independent gates, an equivalent MM can be written for each HHM (Keener and Sneyd, 1998). However, many $\mathrm{I}_{\mathrm{CaL}}$ models use an extension to the classical HH scheme, e.g. by introducing a non-inactivating fraction of channels (McAllister et al., 1975), or by modelling the current as if arising from two separate channel families (Nygren et al., 1998) (Table 2). Such models have no obvious MM equivalent. Taking this into account, we identified 15 distinct gating models, as shown schematically in Figure 5 . Where possible, we have shown models in an MM representation.

Each gating type is described briefly below. Some models have an $O$ defined in the phosphorylated and non-phosphorylated states because of CAMKII dependence, or have $\mathrm{I}_{\mathrm{CaL}}$ channels localised in different biological compartments; we do not focus on these properties in this section and are only concerned with the gating kinetics.

Type $\mathbf{A}$ is the earliest and most straightforward gating mechanism, consisting of voltage-dependent activation $(d)$ and inactivation $(f)$, modelled as independent gates that are not affected by $\left[\mathrm{Ca}^{2+}\right]$ (Bassingthwaithe and Reuter, 1972). Wilders et al. (1991) is a unique model within this group because its time constant of inactivation is not voltage-dependent but rather depends on the fraction of inactivation $f$. Type B extends type A by adding a non-inactivating fraction of channels $d^{\prime}$, leading to an open probability $O=d \cdot f+d^{\prime}$ (McAllister et al., 1975).

The type $\mathbf{C}$ gating mechanism extends type A by adding a CDI gate, usually written as $f_{\mathrm{Ca}}$. In type C1 this is modelled using as an instantaneous process, so that the fraction of open $f_{\mathrm{Ca}}$ gates is given by a Hill equation with Hill coefficient 2 in Luo and Rudy (1994) but 1 in the remaining models in this class. Types C2 and C3 use an ODE to model the evolution of $f_{\mathrm{Ca}}$, but differ in that C2 models have calcium-independent recovery from inactivation (DiFrancesco and Noble, 1985), while in C3 models both inactivation and recovery depend on $\left[\mathrm{Ca}^{2+}\right]$ as shown in Figure 5 (C2 and C3). Finally, type C4 has an instantaneous $f_{\text {Ca }}$ gate, but also incorporates calcium-sensitivity in its gate for VDI, making it a dual voltage-calcium-dependent inactivation gate.

Gating type D is similar to type $\mathrm{C}$ in its $\mathrm{HH}$ form, except that the activation gate $d$ is cubed (Nordin, 1993). In the MM structure, this equates to adding several closed states, as shown in Figure 5D.

An ever larger Markov scheme is used by models of type E1, in which five steps are required to fully 
A

D
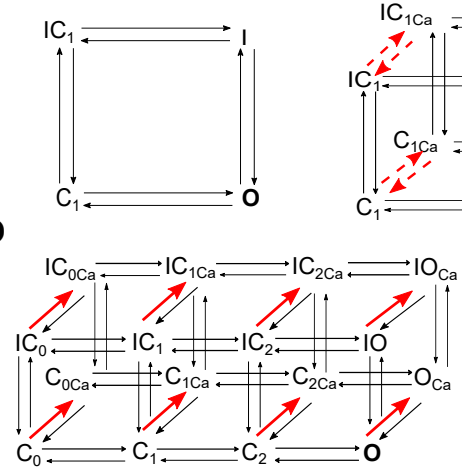

E2

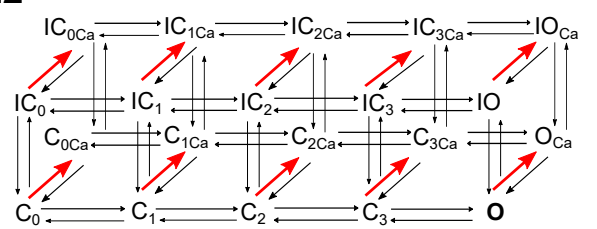

E5

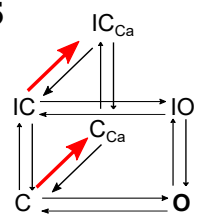

I

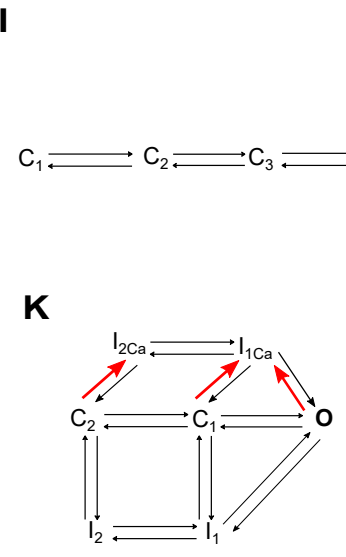

B $d \cdot f+d^{\prime}$

C4 $d \cdot f(V, C a) \cdot f_{C a_{\infty}}$

F1 $d \cdot\left(x_{C a, \infty} \cdot f_{f}+\left(1-x_{C a, \infty}\right) \cdot f_{s}\right)$

F2 $d \cdot\left(x_{C a} \cdot f_{f}+\left(1-x_{C a}\right) \cdot f_{s}\right)$

F3 $d \cdot\left(x \cdot f_{f}+(1-x) \cdot f_{s}\right) \cdot f_{C a}$

O $d \cdot\left(1-f_{C a}\right) \cdot\left(x \cdot f_{1 f}+(1-x)\right.$

$\mathbf{N}$
C2

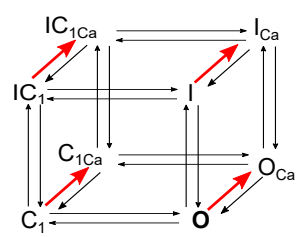

C3

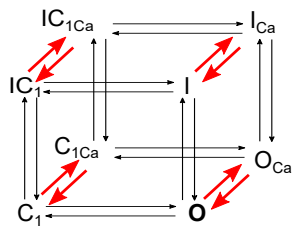

E1

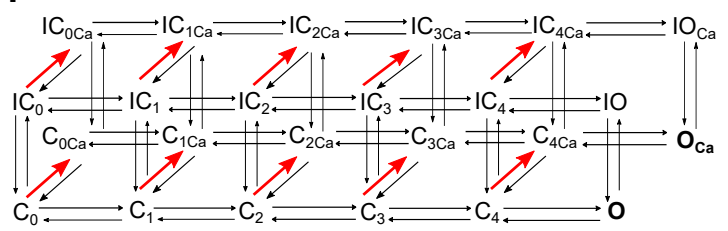

E3

E4

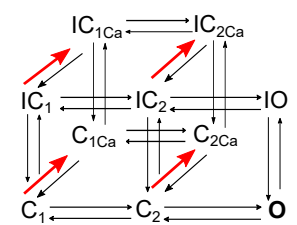

G

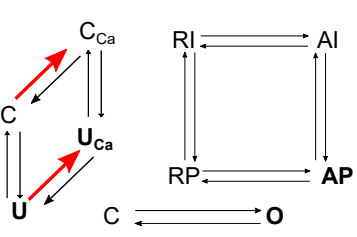

H
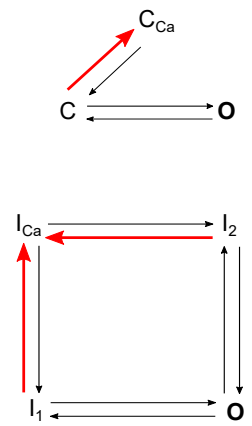

J
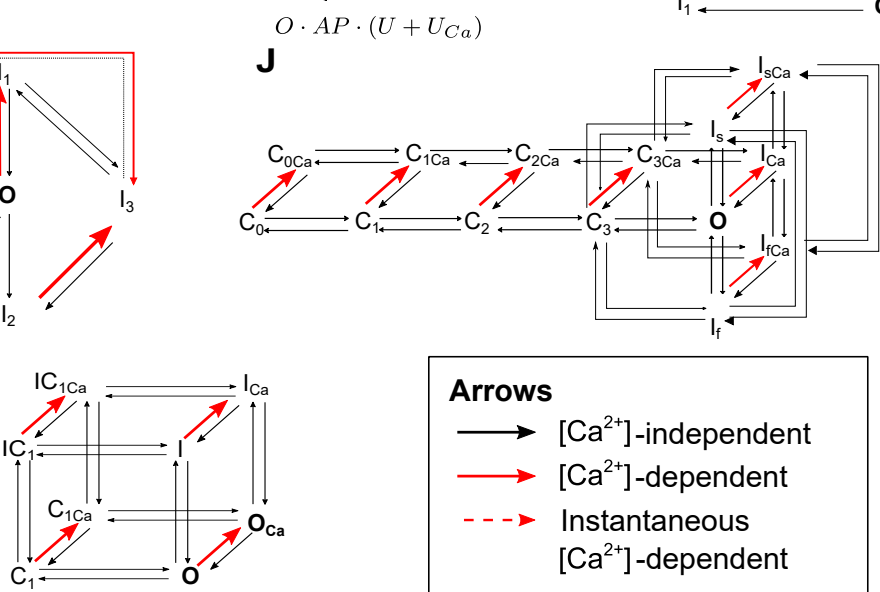

Arrows

$\longrightarrow\left[\mathrm{Ca}^{2+}\right]$-independent

$\longrightarrow\left[\mathrm{Ca}^{2+}\right]$-dependent

- - Instantaneous

$\left[\mathrm{Ca}^{2+}\right]$-dependent

Figure 5: Models of $\mathbf{I}_{\mathbf{C a L}}$ gating. Each label in this figure (A, C1, C2, ...) indicates a distinct gating mechanism, as described in detail in the text. Where possible, models are shown in an MM representation. MM state labels include Closed, Inactivated, Open, Activated, Uncovered, Resting, and Primed. Subscripts $s$ and $f$ are used to indicate states involved in "slow" and "fast" transitions, while the $C a$ subscripts indicate states involved in calcium-dependent transitions. The conducting states in each Markov structure are shown in bold. Where models have more than one conducting state, the total open fraction is found by adding the occupancy of all conducting states together. The open probability equation for $\mathrm{G}$ is shown within the Figure. In the $\mathrm{HH}$ equations, $d$ and $f$ denote activation and inactivation gates respectively, and $f_{C a}$ gates are calcium-dependent. 
activate (similar to a fifth power in HH terms). In the original implementation, this model was written as a combination between an HHM (for VDI) and an MM for activation and CDI (Jafri et al., 1998). The mechanism for CDI in this model is a switch to a "Calcium mode" in which transitions to the open state are extremely slow (Imredy and Yue, 1994). A slight variation, which we still classified as E1, is given by Iyer et al. (2004) in which the $O_{\mathrm{Ca}}$ and $O I_{\mathrm{Ca}}$ states are omitted altogether. Several simplifications of the E1 scheme have been proposed, reducing it from 24 to 20 states (type E2, Michailova et al., 2005), 10 states (type E3, Greenstein and Winslow, 2002), and even 3 states (type E4, Hinch et al., 2004). Note that, to arrive at the representation of the E2 type shown here, we have reinterpreted the model by Michailova et al. (2005) as an MM and omitted the term accounting for [MgATP] effects and a constant factor $x$. The study by Li et al. (2010) extended the E4 type by re-adding VDI, creating the 6-state type E5. Similarly, Asakura et al. (2014) extended E4 with a fourth state to create type E6.

Type $\mathbf{F}$ gating mechanisms assume that $\mathrm{I}_{\mathrm{CaL}}$ has fast and slow modes. In type F1, the fraction of channels in slow mode is determined by an instantaneous calcium binding process (Nygren et al., 1998), while in type F2 this process is modelled with an ODE (Pandit et al., 2001). Type F3 separates fast and slow kinetics from calcium by fixing the fraction of channels with fast VDI to $73 \%$ and introducing a separate CDI process (Pohl et al., 2016). A similar two-component model without CDI was introduced by Inada et al. (2009), which we have labelled as type F4.

The type $\mathbf{G}$ gating mechanism consists of three independent MMs for activation, VDI, and CDI. In the MM for CDI, the binding of a $\mathrm{Ca}^{2+}$ ion brings the system into a state where recovery from inactivation is much slower.

A new type $\mathbf{H}$ gating mechanism was introduced by Lovell et al. (2004), consisting of a four state MM with activation, VDI and CDI. More complex MMs were introduced by Bondarenko et al. (2004), Faber et al. (2007), and Mahajan et al. (2008) to create types I, J, and K respectively. The unusual scheme in type I was inspired by structure-function relationships in a homology model based on Shaker $B$ voltagegated $K^{+}$models. Type J was the first model to incorporate fast and slow VDI in MM kinetics. Type $\mathrm{K}$ used barium as a charge carrier for $\mathrm{I}_{\mathrm{CaL}}$ to determine the rate constants associated with VDI.

The type L1 gating mechanism consists of activation, fast and slow VDI, and fast and slow CDI (dependent on both $\left[\mathrm{Ca}^{2+}\right]$ and $\mathrm{I}_{\mathrm{CaL}}$ ). Unusually, the activation variable is raised to a power $n$ with time-variant behaviour, also modelled as an ODE (Hund and Rudy, 2004). In type L2 this is simplified to use a constant $n=1$ (Aslanidi et al., 2009b), and type L3 simplifies this further by combining fast and slow VDI into a single gate (Hund et al., 2008).

The study by Ten Tusscher and Panfilov (2006) extended their previous C3 type model with an extra gate, leading to type M. Note that this can also be seen as a simplification of type L2.

Type $\mathbf{N}$ gating uses a similar MM to C2, but with different rates on the transitions, and an increased number of conducting states so that this MM can no longer be reduced to an equivalent HHM. As in type E1, the MM has a 'slow' and a 'fast' side, between which it transitions based on [Ca $\left.{ }^{2+}\right]$. Unlike $\mathrm{C} 2$, the total probability is given by $\mathrm{O}+\mathrm{O}_{\mathrm{Ca}}$.

Like the F-type mechanisms, type $\mathbf{O}$ gating splits the channels into several fractions. First, a $\left[\mathrm{Ca}^{2+}\right]$ dependent variable splits the channels into a fraction with VDI and a fraction with CDI. In turn, each inactivation type is split into a fast and slow fraction, with a fixed ratio between fast and slow VDI and a voltage-dependent ratio between fast and slow CDI.

Table 2 shows how each model fits into this classification. In addition to the gating type, this table also lists each model's cell type, species, and simulated temperature (if stated). The final column provides 

made available under aCC-BY 4.0 International license.

an indication of the major data sources used in the model's construction. For the earlier generation of models, this data source is often hard to establish, as parameters were commonly set by hand to create a model that was acceptably close to a wide range of observations (typically measured in tissue preparations, and sometimes spanning several species). A full list of data sources is available online at https://github.com/CardiacModelling/ical-model-comparison. 
Table 2: Models classified by their gating type, with additional information of cell type, species, temperature (T) and the major data sources used in each model's construction. The equivalent MM schematic/equation for each gating class is shown in Figure 5. Minor variants within each class are indicated with $\left(^{*}\right)$ and explained in text.

\begin{tabular}{|c|c|c|c|c|c|}
\hline & Models & Cell & Species & $\mathbf{T}$ & Major data sources \\
\hline \multirow[t]{6}{*}{$\mathrm{A}$} & Bassingthwaithe and Reuter (1972) & Ventricle & Mammalian & & Beeler and Reuter (1970) \\
\hline & Beeler and Reuter (1977) & Ventricle & Mammalian & & Beeler and Reuter (1970); Reuter \\
\hline & & & & & $\begin{array}{l}\text { (1973, 1974); Gettes and Reuter } \\
(1974)\end{array}$ \\
\hline & Noble et al. (1991) & Ventricle & Guinea Pig & 37 & - \\
\hline & *Wilders et al. (1991) & SAN & Rabbit & 37.5 & $\begin{array}{l}\text { Nakayama et al. (1984); Hagiwara } \\
\text { et al. (1988) }\end{array}$ \\
\hline & Liu et al. (1993) & AVN & Rabbit & 35 & Liu et al. (1993) \\
\hline \multirow[t]{5}{*}{$\mathrm{B}$} & McAllister et al. (1975) & Purkinje & Mammalian & & $\begin{array}{l}\text { Reuter (1968); Vitek and } \\
\text { Trautwein (1971) }\end{array}$ \\
\hline & Demir et al. (1994) & SAN & Rabbit & 37 & $\begin{array}{l}\text { Nilius (1986); Hagiwara et al. } \\
\text { (1988); Fermini and Nathan } \\
\text { (1991) }\end{array}$ \\
\hline & Lindblad et al. (1996) & Atrium & Rabbit & 35 & $\begin{array}{l}\text { Nilius (1986); Hagiwara et al. } \\
\text { (1988); Kawano and Hiraoka } \\
(1991)\end{array}$ \\
\hline & Zhang et al. (2000) & SAN & Rabbit & 37 & $\begin{array}{l}\text { Nilius (1986); Hagiwara et al. } \\
\text { (1988); Fermini and Nathan } \\
\text { (1991); Demir et al. (1994) }\end{array}$ \\
\hline & Aslanidi et al. (2009a) & Atrium & Rabbit & 35 & Ko et al. (2006) \\
\hline \multirow[t]{4}{*}{$\mathrm{C} 1$} & *Luo and Rudy (1994) & Ventricle & Guinea Pig & 37 & - \\
\hline & Zeng et al. (1995) & Ventricle & Guinea Pig & 37 & - \\
\hline & Priebe and Beuckelmann (1998) & Ventricle & Human & 37 & Beuckelmann et al. $(1991,1992)$ \\
\hline & Cabo and Boyden (2003) & Ventricle & Canine & 37 & $\begin{array}{l}\text { Aggarwal and Boyden (1995, } \\
1996)\end{array}$ \\
\hline \multirow[t]{5}{*}{$\overline{\mathrm{C}} \overline{2}$} & DiFrancesco and Noble (1985) & Purkinje- & Mammalian & $3 \overline{7}$ & \\
\hline & Dokos et al. (1996) & SAN & Rabbit & 37 & $\begin{array}{l}\text { Nakayama et al. (1984); Hagi- } \\
\text { wara et al. (1988); Habuchi et al. } \\
(1990) \text {; Satoh (1994) }\end{array}$ \\
\hline & Shannon et al. (2004) & Ventricle & Rabbit & 37 & - \\
\hline & Grandi et al. (2010) & Ventricle & Human & 37 & $\begin{array}{l}\text { Pelzmann et al. (1998); Li et al. } \\
\text { (1999); Magyar et al. (2002) }\end{array}$ \\
\hline & Grandi et al. (2011) & Atrial & Human & 37 & $\begin{array}{l}\text { Li and Nattel (1997); Shannon et } \\
\text { al. (2005) }\end{array}$ \\
\hline \multirow[t]{5}{*}{$\overline{\mathrm{C}} 3$} & Courtemanche et al. (1998) & Atrium & Human & $3 \overline{7}$ & $\begin{array}{l}\text { Friedman et al. (1996); Li and } \\
\text { Nattel (1997); Sun et al. (1997) }\end{array}$ \\
\hline & Noble et al. (1998) & Ventricle & Guinea Pig & 37 & Linz and Meyer (1997) \\
\hline & Ramirez et al. (2000) & Atrium & Canine & 37 & Yue et al. (1997) \\
\hline & Fox et al. (2002) & Ventricle & Canine & 37 & - \\
\hline & Kurata et al. (2002) & SAN & Rabbit & 37 & $\begin{array}{l}\text { Nakayama et al. (1984); Hagiwara } \\
\text { et al. (1988); Kawano and Hi- } \\
\text { raoka (1991); Fermini and Nathan } \\
(1991)\end{array}$ \\
\hline
\end{tabular}


Table 2 continued from previous page

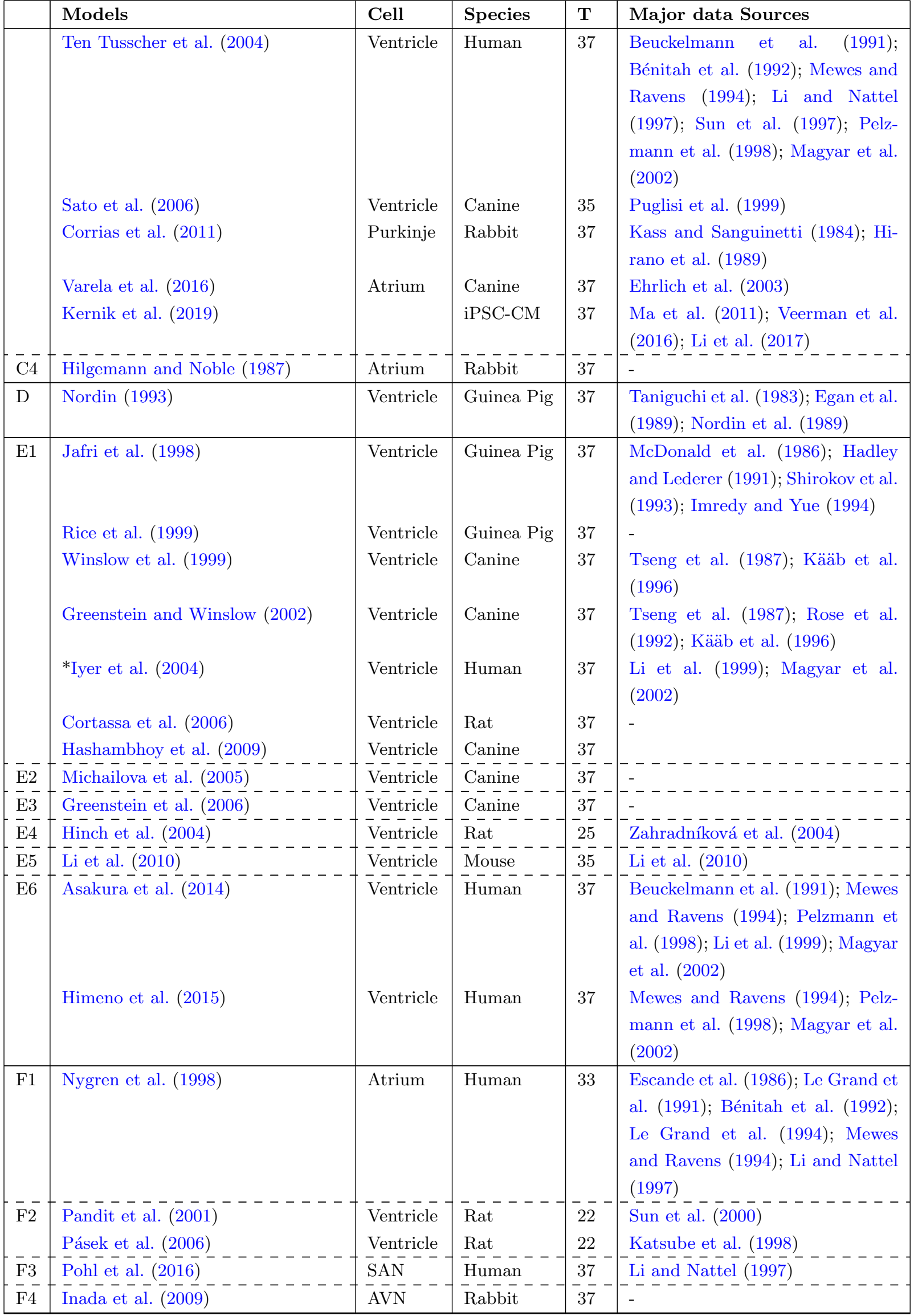


Table 2 continued from previous page

\begin{tabular}{|c|c|c|c|c|c|}
\hline & Models & Cell & Species & $\mathbf{T}$ & Major data Sources \\
\hline G & Matsuoka et al. (2003) & Ventricle & Guinea Pig & 37 & $\begin{array}{l}\text { Noma and Shibasaki (1985); Hagi- } \\
\text { wara et al. (1988); Boyett et al. } \\
\text { (1994); Takagi et al. (1998) }\end{array}$ \\
\hline $\mathrm{H}$ & Lovell et al. (2004) & SAN & Rabbit & 37 & Kodama et al. (1999) \\
\hline I & Bondarenko et al. (2004) & Ventricle & Mouse & 25 & Bondarenko et al. (2004) \\
\hline $\mathrm{J}$ & Faber et al. (2007) & Ventricle & Guinea Pig & 37 & $\begin{array}{l}\text { Cavalié et al. (1986); Rose et al. } \\
\text { (1992); Höfer et al. (1997); Vorna- } \\
\text { nen and Shepherd (1997); Findlay } \\
(2002,2004)\end{array}$ \\
\hline \multirow[t]{3}{*}{ K } & Mahajan et al. (2008) & Ventricle & Rabbit & 35 & Mahajan et al. (2008) \\
\hline & Restrepo et al. (2008) & Ventricle & Rabbit & 35 & - \\
\hline & Nivala et al. (2012) & Ventricle & Rabbit & 37 & - \\
\hline \multirow[t]{2}{*}{ L1 } & Hund and Rudy (2004) & Ventricle & Canine & 37 & $\begin{array}{l}\text { Sun et al. (1997); Rubart et } \\
\text { al. (2000); Kamp et al. (2000); } \\
\text { Miyoshi et al. (2003) }\end{array}$ \\
\hline & Livshitz and Rudy (2007) & Ventricle & Canine & 37 & - \\
\hline \multirow[t]{2}{*}{ L2 } & Aslanidi et al. (2009b) & Purkinje & Canine & 35 & Han et al. (2001) \\
\hline & Li and Rudy (2011) & Purkinje & Canine & 37 & Han et al. (2001) \\
\hline L3 & Hund et al. (2008) & Ventricle & Canine & 37 & - \\
\hline \multirow[t]{4}{*}{ M } & Ten Tusscher and Panfilov (2006) & Ventricle & Human & 37 & Magyar et al. (2002) \\
\hline & Fink et al. (2008) & Ventricle & Human & 37 & - \\
\hline & Koivumäki et al. (2011) & Atrium & Human & 33 & Li and Nattel (1997) \\
\hline & Paci et al. (2013) & Atrium & iPSC-CM & 37 & Ma et al. (2011) \\
\hline \multirow[t]{3}{*}{$\mathrm{N}$} & Decker et al. (2009) & Ventricle & Canine & 37 & $\begin{array}{l}\text { Tseng (1988); Aggarwal and Boy- } \\
\text { den (1995); Rubart et al. (2000); } \\
\text { Szabó et al. (2005) }\end{array}$ \\
\hline & Heijman et al. (2011) & Ventricle & Canine & 37 & - \\
\hline & Bartolucci et al. (2020) & Ventricle & Human & 37 & $\begin{array}{l}\text { Magyar et al. (2002); Fülöp et al. } \\
\text { (2004); O'Hara et al. (2011) }\end{array}$ \\
\hline \multirow[t]{3}{*}{$\mathrm{O}$} & O'Hara et al. (2011) & Ventricle & Human & 37 & $\begin{array}{l}\text { Magyar et al. (2002); Fülöp et al. } \\
\text { (2004); O'Hara et al. (2011) }\end{array}$ \\
\hline & Tomek et al. (2019) & Ventricle & Human & 37 & Magyar et al. (2002) \\
\hline & Trovato et al. (2020) & Purkinje & Human & 37 & - \\
\hline
\end{tabular}




\section{Driving force}

Two types of driving force are common in $\mathrm{I}_{\mathrm{CaL}}$ models. An Ohmic driving force for a current carried by a single species takes the form

$$
D_{\mathrm{Ohmic}}=\left(V_{m}-E_{\mathrm{rev}}\right)
$$

where $E_{\text {rev }}$ is the reversal potential, at which the current reverses direction. For currents carried by a single species, the reversal potential can be calculated using the Nernst equation

$$
E_{\mathrm{rev}}=\frac{R T}{z_{X} F} \ln \frac{[X]_{o}}{[X]_{i}},
$$

where $R$ is the universal gas constant, $T$ is temperature, $F$ is the Faraday constant, $z_{x}$ is the valence of a single ion of species $X$ (2 for $\left.\left[\mathrm{Ca}^{2+}\right]\right)$, and $[X]_{o}$ and $[X]_{i}$ are the external and internal concentrations of $X$ respectively. Although commonly used in the form given above, a more accurate version uses $\gamma_{o}[X]_{o} / \gamma_{i}[X]_{i}$, where $\gamma_{o}$ and $\gamma_{i}$ are dimensionless activity coefficients that account for non-ideal behaviour of the solutes. The units of the gas constant are frequently chosen as $\mathrm{mJ} / \mathrm{K} / \mathrm{mol}$ to yield a reversal potential in $\mathrm{mV}$. A model with an Ohmic driving term is written $I=\bar{g} \cdot O \cdot\left(V-E_{\mathrm{rev}}\right)$, where $\bar{g}$ is in Siemens (S) for a current in Amperes (A).

A more complex model of the electrochemical driving force is given by the Goldman-Hodgkin-Katz (GHK) flux equation (Goldman, 1943; Hodgkin and Katz, 1949):

$$
D_{\mathrm{GHK}}=V_{m} \frac{z_{X}^{2} F^{2}}{R T}\left(\frac{\gamma_{i}[X]_{i}-\gamma_{o}[X]_{o} e^{-z_{X} V_{m} F /(R T)}}{1-e^{-z_{X} V_{m} F /(R T)}}\right) .
$$

Because its derivation involves assuming a constant electrical field throughout the channel, the GHK equation and its derivatives are also known as "constant field theory". Assuming concentrations in $\mathrm{mM}=\mathrm{mol} / \mathrm{m}^{3}$ and using matching units for $V$ and $R T / F$, a model with a GHK driving term is written as $I=\bar{P} \cdot O \cdot D_{\mathrm{GHK}}$, where $\bar{P}$ is in $\mathrm{L} / \mathrm{ms}\left(=\mathrm{m}^{3} / \mathrm{s}\right)$ for a current in $\mathrm{A}$, in $\mathrm{L} / \mathrm{F} / \mathrm{ms}$ for a current in $\mathrm{A} / \mathrm{F}$, or in $\mathrm{cm} / \mathrm{s}$ for a current in $\mu \mathrm{A} / \mathrm{cm}^{2}$.

A number of early studies used a modified GHK equation, which accounts for the (hypothesised) presence of a charged particle near the channel mouth, causing a change $V_{0}$ in the voltage across the channel (Frankenhaeuser, 1960):

$$
D_{\mathrm{GHK}},=\left(V_{m}-V_{0}\right) \frac{z_{X}^{2} F^{2}}{R T}\left(\frac{\gamma_{i}[X]_{i} e^{V_{0} \frac{z_{X} F}{R T}}-\gamma_{o}[X]_{o} e^{\left(V_{m}-V_{0}\right) \frac{-z_{X} F}{R T}}}{1-e^{\left(V_{m}-V_{0}\right) \frac{-z_{X} F}{R T}}}\right)
$$

The equations for $D_{\mathrm{Ohmic}}, D_{\mathrm{GHK}}$, and $D_{\mathrm{GHK}}$, all predict that the current carried by a single species $X$ reverses at $V_{m}=E_{\mathrm{rev}}$. For $\mathrm{I}_{\mathrm{CaL}}$, which is known to have calcium, potassium, and sodium components (Reuter and Scholz, 1977), the situation is more complex, and applying the Nernst equation for calcium as the only carrier leads to estimates for $E_{\mathrm{rev}}$ in the range $100-200 \mathrm{mV}$, which is significantly higher than experimental estimates of $40-70 \mathrm{mV}$. A simple model for currents with multiple carriers can be made by assuming that each species travels through the channel without affecting the others, so that the total current is simply a sum of single-species currents. With this assumption, equations for $E_{\text {rev }}$ can still be derived (see e.g. Campbell et al., 1988; Keener and Sneyd, 1998) but the predicted reversal potentials from Ohmic and GHK models are no longer the same. And crucially, the reversal potential of a multi-species current depends strongly on the ratio between the species' permeabilities $\bar{P}_{X}$ (or conductances $\bar{g}_{X}$, if an Ohmic term is used). A study by Campbell et al. (1988) measured the reversal potential of $\mathrm{I}_{\mathrm{CaL}}$ in bull-frog atrial myocytes, and compared this to predictions using different ratios of $\bar{P}_{\mathrm{K}}: \bar{P}_{\mathrm{Ca}}$. They found that good agreement with experiment could be found using a GHK equation (Equation 4), provided the channel was highly selective to $\left[\mathrm{Ca}^{2+}\right]$ ( $>95 \%$ of the $\mathrm{I}_{\mathrm{CaL}}$ is carried by $\left[\mathrm{Ca}^{2+}\right]$ at $0 \mathrm{mV}$ ). Similar 
estimates could be made using the modified GHK (Equation 5), regardless of the chosen value of $V_{0}$, leading e.g. Luo and Rudy (1994) to set $V_{0}=0$. A later study by Zhou and Bers (2000) used fluorescence microscopy to simultaneously measure $\left[\mathrm{Ca}^{2+}\right]$ influx and $\mathrm{I}_{\mathrm{CaL}}$ (all ionic current) independently. Stepping to potentials beyond the $I_{\mathrm{CaL}}$ reversal potential, they found continued $\left[\mathrm{Ca}^{2+}\right]$ influx, which continued until the predicted $\left[\mathrm{Ca}^{2+}\right]$ reversal potential was reached. This is consistent with the hypothesis that, at its reversal potential, $\mathrm{I}_{\mathrm{CaL}}$ is in a balanced equilibrium between opposing flows carried by different species.
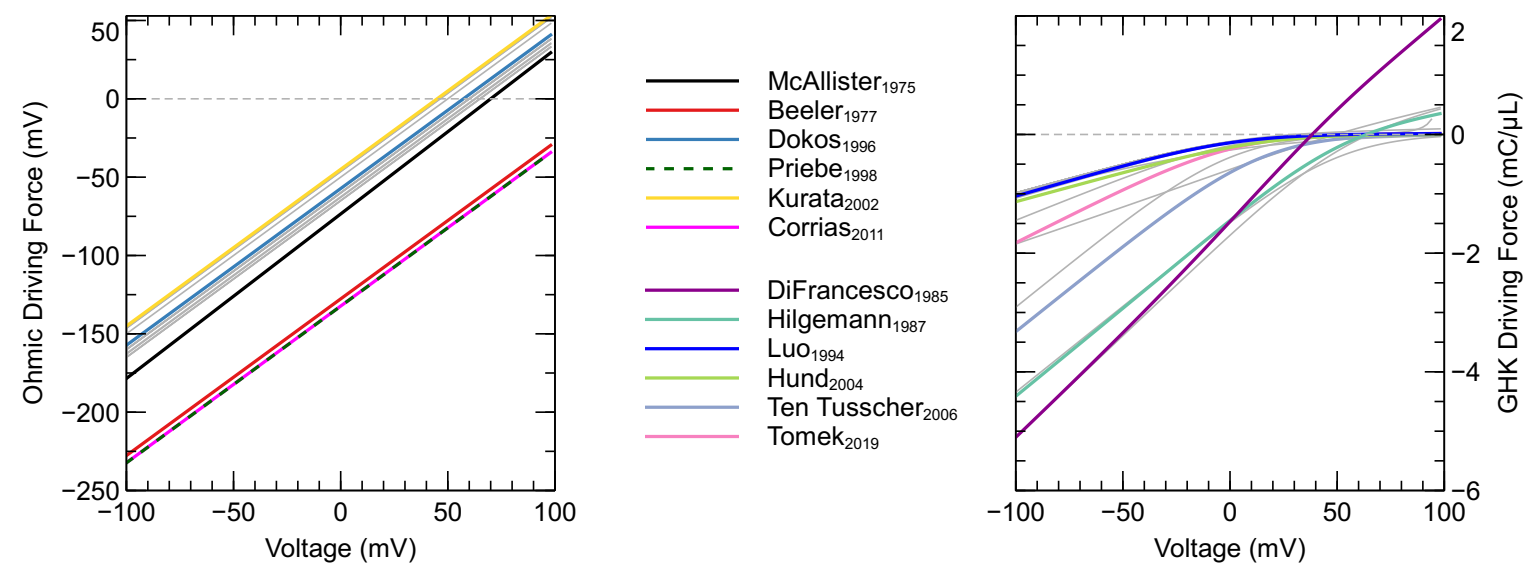

Figure 6: Driving term as a function of voltage for models with an Ohmic driving term (Left) and a (normal or modified) GHK driving term (Right). In the left panel, the majority of models are plotted in grey and are shown to form a tight cluster, reversing at around $65 \mathrm{mV}$. The lower and upper bounds for this cluster are marked by McAllister et al. (1975) and Kurata et al. (2002), which are indicated in colour, along with three outliers (Beeler and Reuter, 1977; Priebe and Beuckelmann, 1998; Corrias et al., 2011) that do not show a reversal potential within the physiological range. In the right panel, most currents are again shown in grey, but a selection of models are shown in colour to show the range of behaviours observable by varying the activity coefficients and voltage offset $V_{0}$ (DiFrancesco and Noble, 1985; Hilgemann and Noble, 1987; Luo and Rudy, 1994; Hund and Rudy, 2004; Ten Tusscher and Panfilov, 2006; Tomek et al., 2019). A full description of how this figure was constructed is given in the main text.

Assuming fixed internal and external concentrations, the driving term can be plotted as a function of voltage, as shown in Figure 6. To create this plot, we assumed values of $\left[\mathrm{Na}^{+}\right]_{o}=140 \mathrm{mM},\left[\mathrm{Na}^{+}\right]_{i}=$ $10 \mathrm{mM},\left[\mathrm{K}^{+}\right]_{o}=5 \mathrm{mM},\left[\mathrm{K}^{+}\right]_{i}=140 \mathrm{mM},\left[\mathrm{Cl}^{-}\right]_{o}=150 \mathrm{mM},\left[\mathrm{Cl}^{-}\right]_{i}=24 \mathrm{mM},\left[\mathrm{Ca}^{2+}\right]_{\mathrm{o}}=2 \mathrm{mM}$ and $\left[\mathrm{Ca}^{2+}\right]_{\mathrm{s}}=\left[\mathrm{Ca}^{2+}\right]_{\mathrm{i}}=\left[\mathrm{Ca}^{2+}\right]_{\mathrm{d}}=10^{-4} \mathrm{mM}$. In models where $\mathrm{I}_{\mathrm{CaL}}$ is carried by multiple species, we calculated the "net driving term" by summing up the contributions of each component, and weighting by the component's permeability relative to the calcium component (e.g. the calcium component has weight $\bar{P}_{\mathrm{Ca}} / \bar{P}_{\mathrm{Ca}}=1$, the potassium component has weight $\bar{P}_{\mathrm{K}} / \bar{P}_{\mathrm{Ca}}$, etc.).

The left panel of Figure 6 shows $D$ for the models in this study that used an Ohmic driving term (models for which we could not find the full equations are omitted). Rather than use the Nernst equation, most of these models set a constant reversal potential in the range of $45-70 \mathrm{mV}$. As expected, models that do use the single-species Nernst equation (Beeler and Reuter, 1970; Dokos et al., 1996; Priebe and Beuckelmann, 1998; Kurata et al., 2002) show a reversal potential well outside of the physiological range. The right panel in Figure 6 shows $D$ for models with a GHK (or GHK') driving term. Most of these models do not show a true 'reversal' of current, with the driving force approaching zero for high voltages. Only models with a high permeability for sodium and potassium ions (DiFrancesco and Noble, 1985; Hilgemann and Noble, 1987) show a positive driving force for high voltages. Finally, the model by Liu et al. (1993) uses 
neither an Ohmic nor a GHK driving term, but an exponentially increasing flux and is not included in this figure.

A list of models with Ohmic driving terms is given in Table 3. For models using a fixed $E_{\text {rev }}$, the numerical value is shown, while the equation used for $E_{\text {rev }}$ is shown for the remainder. None of the models with Ohmic driving terms in this study explicitly modelled potassium or sodium components of $\mathrm{I}_{\mathrm{CaL}}$ (although their existence is implicitly acknowledged in the models with a fixed reversal potential).

A similar list for models with GHK (and GHK') driving is given in Table 4, along with the offset $V_{0}$ (if used), the activity coefficients for internal and external calcium, and the ratio between the permeability coefficients of potassium and sodium with respect to calcium.

The earliest studies in this table all use a voltage shift parameter $V_{0}=50 \mathrm{mV}$, but this form is rarely seen in later models. Models with this large $V_{0}$ also assume a large contribution of sodium and potassium ions, consistent with the analysis by Campbell et al. (1988).

The model by Luo and Rudy (1994) abandons the use of $V_{0}$ and introduces the values $\gamma_{i}=1$ and $\gamma_{o}=0.341$ for the activity coefficients of internal and external calcium. These values can be calculated using the Pitzer equations (Pitzer and Mayorga, 1973), while the frequently used value $\gamma_{i}=1$ appears to arise from assuming that low internal $\left[\mathrm{Ca}^{2+}\right]$ leads to near-ideal behaviour. Instead of using constant values, the model by Tomek et al. (2019) calculates the activity coefficients using the Davies equation (Davies and Malpass, 1964), which is a precursor to Pitzer's work. Activity coefficients for sodium and potassium are usually taken to be 0.75 internally and externally, and are not shown in the table.

Although there is a common consensus that $\mathrm{I}_{\mathrm{CaL}}$ is carried by multiple ion species, the ratio of permeabilities between the different species varies greatly between models, and several studies have cited the low permeability to potassium and sodium as a reason to omit these components from the model altogether. In general, older models assume larger contributions from sodium and potassium, while more recent models assume a much more selective channel. Instead of fixed permeability ratios, a small number of models calculate the permeability to potassium as a function of the calcium driving force (Jafri et al., 1998; Winslow et al., 1999; Fox et al., 2002; Iyer et al., 2004; Cortassa et al., 2006). This is indicated with $f(V, C a)$ in the table.

Finally, some of the models in Table 4 use a slight variation of the (normal or modified) GHK equation. The model by Jafri et al. (1998) and many of its descendants, (Rice et al., 1999; Winslow et al., 1999; Iyer et al., 2004; Michailova et al., 2005; Cortassa et al., 2006) use a constant internal calcium activity $\gamma_{i}\left[\mathrm{Ca}^{2+}\right]_{i}=0.001 \mathrm{mM}$ (Smith, 1996). The model by Ten Tusscher and Panfilov (2006) uses a GHK equation in which $V$ is offset by $15 \mathrm{mV}$, but without the extra term $\left(\exp \left(V_{o} \frac{z_{X} F}{R T}\right)\right)$ used in Equation 5 . 


\begin{tabular}{|l|l|}
\hline Models & $\mathbf{E}_{\mathbf{r e v}}(\mathbf{m V})$ \\
\hline Bassingthwaithe and Reuter (1972) & $42 \mathrm{mV}$ \\
McAllister et al. (1975) & $70 \mathrm{mV}$ \\
Beeler and Reuter (1977) & $-82.3-13.0287 \ln \frac{\left[\mathrm{Ca}^{2+}\right]_{i}}{1000 \mathrm{mM}}$ \\
Demir et al. (1994) & $46.4 \mathrm{mV}$ \\
Lindblad et al. (1996) & $60 \mathrm{mV}$ \\
Dokos et al. (1996) & $-75 \mathrm{mV}+\frac{R T}{2 F} \ln \frac{\left[\mathrm{Ca}^{2+}\right]_{o}}{\left[\mathrm{Ca}^{2+}\right]_{i}}$ \\
Courtemanche et al. (1998) & $65 \mathrm{mV}$ \\
Nygren et al. (1998) & $60 \mathrm{mV}$ \\
Priebe and Beuckelmann (1998) & $\frac{R T}{2 F} \ln \frac{\left[\mathrm{Ca}^{2+}\right]_{o}}{\left[\mathrm{Ca}^{2+}\right]_{i}}$ \\
Ramirez et al. (2000) & $65 \mathrm{mV}$ \\
Zhang et al. (2000) & $46.4 \mathrm{mV}$ \\
Pandit et al. (2001) & $65 \mathrm{mV}$ \\
Kurata et al. (2002) & $45 \mathrm{mV}$ \\
Bondarenko et al. (2004) & $63 \mathrm{mV}$ \\
Lovell et al. (2004) & $49.72 \mathrm{mV}$ \\
Aslanidi et al. (2009a) & $50 \mathrm{mV}$ \\
Inada et al. (2009) & $62.5 \mathrm{mV}$ \\
Corrias et al. (2011) & $\frac{R T}{2 F} \ln \frac{\left[\mathrm{Ca}^{2+}\right]_{o}}{\left[\mathrm{Ca}^{2+}\right]_{i}}$ \\
Koivumäki et al. (2011) & $60 \mathrm{mV}$ \\
Pohl et al. (2016) & $-75 \mathrm{mV}+\frac{R T}{2 F} \ln \frac{\left[\mathrm{Ca}^{2+}\right]_{o}}{\left[\mathrm{Ca}^{2+}\right]_{i}}$ \\
Varela et al. (2016) & $60 \mathrm{mV}$ \\
\hline
\end{tabular}

Table 3: Reversal potentials for models using an Ohmic driving force (Equation 2). 

made available under aCC-BY 4.0 International license.

\begin{tabular}{|c|c|c|c|c|c|}
\hline Models & $\mathrm{V}_{\mathrm{o}}$ & $\gamma_{i}$ & $\gamma_{o}$ & $\bar{P}_{\mathrm{K}}: \bar{P}_{\mathrm{Ca}}$ & $\bar{P}_{\mathrm{Na}}: \bar{P}_{\mathrm{Ca}}$ \\
\hline DiFrancesco and Noble (1985) & 50 & 1 & 1 & $1: 100$ & $1: 100$ \\
\hline Hilgemann and Noble (1987) & 50 & 1 & 1 & $1: 500$ & $1: 100$ \\
\hline Noble et al. (1991) & 50 & 1 & 1 & $1: 500$ & $1: 100$ \\
\hline Wilders et al. (1991) & 50 & 1 & 1 & $1: 100$ & $1: 100$ \\
\hline Nordin (1993) & 50.1 & 1 & 1 & 1:197.3 & - \\
\hline Luo and Rudy (1994) & 0 & 1 & 0.341 & 1:2798 & $1: 800$ \\
\hline Zeng et al. (1995) & 0 & 1 & 0.341 & $1: 2798$ & $1: 800$ \\
\hline *Jafri et al. (1998) & 0 & 1 & 0.341 & $f(V, C a)$ & - \\
\hline Noble et al. (1998) & 50 & 1 & 1 & $1: 500$ & $1: 500$ \\
\hline *Rice et al. (1999) & 0 & 1 & 0.341 & - & - \\
\hline *Winslow et al. (1999) & 0 & 1 & 0.341 & $f(V, C a)$ & - \\
\hline Fox et al. (2002) & 0 & 1 & 0.341 & $f(V, C a)$ & - \\
\hline Greenstein and Winslow (2002) & 0 & 1 & 0.341 & - & - \\
\hline Cabo and Boyden (2003) & 0 & 1 & 0.341 & $1: 1554$ & $1: 444$ \\
\hline Matsuoka et al. (2003) & 0 & 1 & 1 & $1: 2730$ & $1: 54054$ \\
\hline Hinch et al. (2004) & 0 & 1 & 1 & - & - \\
\hline Hund and Rudy (2004) & 15 & 1 & 0.341 & - & - \\
\hline *Iyer et al. (2004) & 0 & 1 & 0.341 & $f(V, C a)$ & - \\
\hline Shannon et al. (2004) & 0 & 0.341 & 0.341 & $1: 2000$ & $1: 36000$ \\
\hline Ten Tusscher et al. (2004) & 0 & 1 & 0.341 & - & - \\
\hline *Michailova et al. (2005) & 0 & 1 & 0.341 & $1: 540$ & - \\
\hline *Cortassa et al. (2006) & 0 & 1 & 1 & $f(V, C a)$ & - \\
\hline Greenstein et al. (2006) & 0 & 1 & 0.341 & - & - \\
\hline Sato et al. (2006) & 0 & 1 & 0.341 & - & - \\
\hline Pásek et al. (2006) & 0 & 1 & 0.341 & - & - \\
\hline *Ten Tusscher and Panfilov (2006) & 15 & 0.25 & 1 & - & - \\
\hline Faber et al. (2007) & 0 & 0.01 & 0.341 & $1: 2780$ & $1: 800$ \\
\hline Livshitz and Rudy (2007) & 15 & 0.341 & 0.341 & - & - \\
\hline${ }^{*}$ Fink et al. $(2008)$ & 15 & 0.25 & 1 & - & - \\
\hline Hund et al. (2008) & 0 & 1 & 0.341 & - & - \\
\hline Mahajan et al. (2008) & 0 & 1 & 0.341 & - & - \\
\hline Restrepo et al. (2008) & 0 & 0.341 & 0.341 & - & - \\
\hline Aslanidi et al. (2009b) & 15 & 1 & 0.341 & - & - \\
\hline Decker et al. (2009) & 0 & 1 & 0.341 & - & - \\
\hline Hashambhoy et al. (2009) & 0 & 1 & 0.341 & - & - \\
\hline Grandi et al. (2010) & 0 & 0.341 & 0.341 & $1: 2022$ & $1: 36000$ \\
\hline Li et al. (2010) & 0 & 1 & 1 & - & - \\
\hline Grandi et al. (2011) & 0 & 0.341 & 0.341 & $1: 2000$ & $1: 36000$ \\
\hline Heijman et al. (2011) & 0 & 1 & 0.341 & - & - \\
\hline Li and Rudy (2011) & 15 & 1 & 0.341 & - & - \\
\hline O'Hara et al. (2011) & 0 & 1 & 0.341 & $1: 2798$ & $1: 800$ \\
\hline Nivala et al. (2012) & 0 & 1 & 0.341 & - & - \\
\hline Paci et al. (2013) & 0 & 1 & 0.341 & - & - \\
\hline Asakura et al. (2014) & 0 & 1 & 1 & $1: 682$ & $1: 54054$ \\
\hline Himeno et al. (2015) & 0 & 1 & 1 & $1: 2730$ & $1: 54054$ \\
\hline Kernik et al. (2019) & 0 & 0.341 & 0.341 & $1: 2000$ & $1: 36000$ \\
\hline Tomek et al. (2019) & 0 & $f$ & $f$ & $1: 2798$ & $1: 800$ \\
\hline Bartolucci et al. (2020) & 0 & 1.2 & 0.341 & $1: 2801$ & $1: 800$ \\
\hline Trovato et al. (2020) & 0 & 1 & 0.341 & $1: 2798$ & $1: 800$ \\
\hline
\end{tabular}

Table 4: GHK and GHK' parameters in models using GHK driving terms (Equation 5). Models marked with a (*) use variations of the GHK equation, as discussed in the main text. 


\section{Part 2. Quantitative comparison}

In this section, 60 models are compared functionally (Cooper et al., 2011) by studying their predicted $\mathrm{I}_{\mathrm{CaL}}$ responses to voltage-clamp protocols. Voltage-step experiments are simulated to compare activation, inactivation, and recovery from inactivation under a wide range of voltages and AP- and AP-CaT clamp are performed to show the predicted $\mathrm{I}_{\mathrm{CaL}}$ during an AP.

\section{Methods}

\section{Model implementation}

Where possible, models in CellML 1.0 or 1.1 format (Hedley et al., 2001) were obtained from the Physiome Model Repository (PMR) (Yu et al., 2011). Thirty-five (35) models obtained in this way could be used directly, while a further thirteen needed corrections to either units or equations. Five (5) of these corrected models were reduced to $\mathrm{I}_{\mathrm{CaL}}$-only models, and 7 were updated on PMR. For eleven (11) models no CellML files were available so new implementations were created based on published equations or code. A full model implementation was created for Heijman et al. (2011), while we made CellML models containing only $\mathrm{I}_{\mathrm{CaL}}$ for Wilders et al. (1991); Liu et al. (1993); Nordin (1993); Cabo and Boyden (2003); Cortassa et al. (2006); Sato et al. (2006); Faber et al. (2007); Hund et al. (2008); Li and Rudy (2011); Kernik et al. (2019). In the AP model by Pásek et al. (2006) (which we obtained from the PMR), the voltage across the T-tubular membrane can differ from the 'main' transmembrane potential. To compare the channel kinetics consistently, we set this secondary voltage to equal the transmembrane potential $V_{m}$.

\section{Simulation software}

Simulations were run using the Cardiac Electrophysiology Web Lab (Cooper et al., 2016; Daly et al., 2018). This is a resource developed to allow the characterisation and comparison of cardiac electrophysiology models in a wide range of experimental scenarios. It uses a novel protocol language that allows the user to separate the details of the mathematical model of the channel from the experimental protocol being simulated. We also performed simulations for calcium sensitivity (see "Calcium-dependent inactivation") by solving the model equations using CVODE version 3.1.2 as incorporated in Myokit (Clerx et al., 2016) version 1.28.4, using Python version 3.7.3.

\section{Model annotations}

To run simulations in the Web Lab, models are encoded in CellML format and annotated with metadata terms. These terms allow variables with the same physiological meaning to be identified in different models. This is a useful feature for this study as it allows the comparison of our 60 models - which do not use consistent naming for the same variables.

The following variables were annotated in all models: membrane potential $\left(V_{m}\right)$, the time for which the simulation is run, the total $\mathrm{I}_{\mathrm{CaL}}$, driving term $(D)$, and the open probability $(O)$. For models in which $\mathrm{I}_{\mathrm{CaL}}$ is split into multiple components (by ionic species, phosphorylated/non-phosphorylated fraction, or biological subcompartment) we selected the variable that represents the sum over all these aspects to annotate as $\mathrm{I}_{\mathrm{CaL}}$. For this purpose, a new variable was often introduced in the CellML files. Similarly, $O$ is sometimes split into components with or without phosphorylation, $D$ can be split by ionic species, and both $O$ and $D$ are occasionally split by the biological compartment. For all such cases, we introduced and annotated $O$ and $D$ as the weighted average over all these components (see e.g. the annotations in our file for Bartolucci et al., 2020). This weighting was made based on the fraction of phosphorylated 
channels, the relative permeability of each ionic species with respect to calcium, and/or the fraction of channels in each biological compartment. When annotating driving term variables, distinct terms were used for Ohmic and GHK formulations.

Finally, we annotated the variables representing ionic concentrations. Intra- and extracellular concentration variables were annotated for $\mathrm{Ca}^{2+}, \mathrm{Na}^{+}, \mathrm{K}^{+}$, and $\mathrm{Cl}^{-}$. For external concentrations, most models use a single constant-parameter but some make a distinction between a constant "bath concentration" and a time-varying "cleft concentration" near the cell. All three types of external concentration variable were annotated (and later fixed). Similarly, we annotated (and later fixed) intracellular concentrations for each ionic species with labels for bulk cytosol, submembrane space, or dyadic space concentration. Concentrations within subcompartments such as the sarcoplasmic reticulum were not annotated because they don't contribute to the total $\mathrm{I}_{\mathrm{CaL}}$.

\section{Ionic concentrations}

In all simulations in this study, extracellular concentrations were set to $\left[\mathrm{Na}^{+}\right]=140 \mathrm{mM},\left[\mathrm{K}^{+}\right]=5 \mathrm{mM}$, $\left[\mathrm{Cl}^{-}\right]=150 \mathrm{mM}$, and $\left[\mathrm{Ca}^{2+}\right]=2 \mathrm{mM}$, and kept constant at those values. Similarly, intracellular concentrations were fixed to $\left[\mathrm{Na}^{+}\right]=10 \mathrm{mM},\left[\mathrm{K}^{+}\right]=140 \mathrm{mM}$, and $\left[\mathrm{Cl}^{-}\right]=24 \mathrm{mM}$. This corresponds to a patch-clamp setting where these concentrations are well buffered by the bath and pipette solutions. Except where stated otherwise, the internal calcium concentrations for $\left[\mathrm{Ca}^{2+}\right]$ were fixed to $10^{-9} \mathrm{mM}$. These fixed concentrations allow the current kinetics to be compared in the absence of channel localisation effects; we will revisit the impact of this choice later. Where present, phosphorylation levels were allowed to vary as dictated by the model equations (the level of phosphorylation, however, depends on the internal calcium concentration, which was set to a fixed level in each simulation).

\section{Data availability}

All model and simulation files are available under an open source BSD 3 Clause license, and can be obtained from https://github.com/CardiacModelling/ical-model-comparison. 


\section{Activation}
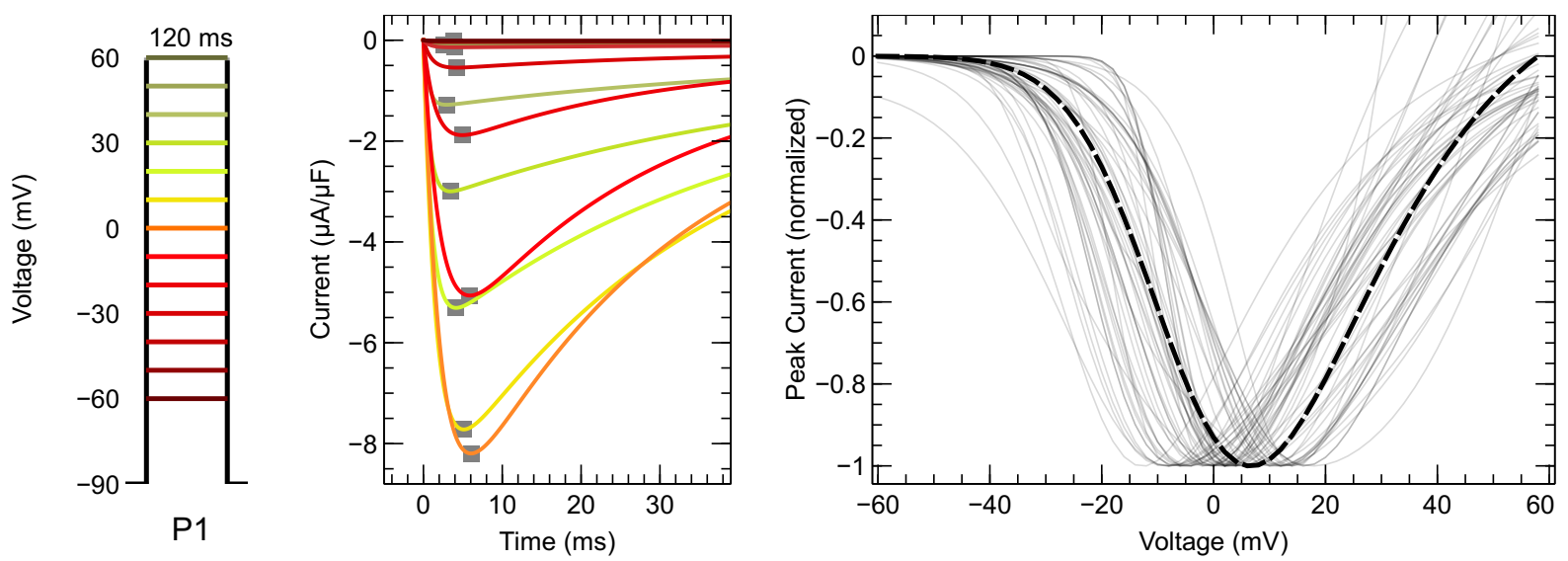

Figure 7: Left: Voltage-clamp protocol used to characterise activation (see main text for details). Centre: Simulated $\mathrm{I}_{\mathrm{CaL}}$ response using the model by Grandi et al. (2010). Traces from successive sweeps are overlaid and colour-coded to match the P1 steps in the first panel. The peak $\mathrm{I}_{\mathrm{CaL}}$ at each voltage step is marked with a grey square: these values are used to construct the I-V curves on the right. This process of constructing an I-V curve is shown in the animation online at https://github.com/CardiacModelling/ical-model-comparison. Right: Normalised peak $\mathrm{I}_{\mathrm{CaL}}$ versus step voltage for 55 (out of 60) models (the direction of the current was preserved during normalisation). The black dashed line shows the I-V curve from Faber et al. (2007), which is close to the median response. The models by McAllister et al. (1975), Beeler and Reuter (1970), Liu et al. (1993), Dokos et al. (1996), and Corrias et al. (2011) showed outlier responses, and are plotted separately in Figure 8. The simulation results for all of the models can be compared on the Cardiac Electrophysiology Web Lab at https://bit.1y/LtypeCa.

An activation protocol was adapted from O'Hara et al. (2011). It consists of repeating units called sweeps. Each sweep starts with stepping up the membrane voltage from a 20 s-long holding potential at $-90 \mathrm{mV}$ to a $120 \mathrm{~ms}$ step at the test potential, denoted by P1 in Figure 7 (left). The test potential at $\mathrm{P} 1$ is $-60 \mathrm{mV}$ for the first sweep and increases by $2 \mathrm{mV}$ per sweep (a subset of which is shown in the figure), up to $60 \mathrm{mV}$ in the final sweep.

Current was recorded during P1 to measure the peak $\mathrm{I}_{\mathrm{CaL}}(\mathrm{I})$ at each sweep (Figure 7, centre) which was normalised as $\overline{\mathrm{I}}=\mathrm{I} /|\min \mathrm{I}|$. The normalised peak $\mathrm{I}_{\mathrm{CaL}}(\overline{\mathrm{I}})$ was plotted against the test potential to construct an I-V curve.

This process was applied to all models, leading to the normalised I-V curves shown in Figure 7 (right). The I-V curve is useful to establish the activation kinetics for ion channels. Here we see that most $I_{C a L}$ models predict that channels begin to activate at membrane voltages around $-40 \mathrm{mV}$ and that $\mathrm{I}_{\mathrm{CaL}}$ reaches its maximum magnitude between -20 to $20 \mathrm{mV}$. We next calculated the voltage at which half of the maximum peak is simulated $\left(V_{0.5}\right)$ for each model, by finding the point where the I-V curve first crosses -0.5 . The $V_{0.5}$ varies between -48 to $1.1 \mathrm{mV}$ for the models in this study while the median $V_{0.5}$ is $-13.7 \mathrm{mV}$. By comparison, examples from the experimental (patch-clamp) literature show that $\mathrm{I}_{\mathrm{CaL}}$ channels start to activate at around $-30 \mathrm{mV}$, that peak $\mathrm{I}_{\mathrm{CaL}}$ is observed at $0 \mathrm{mV}$, and $V_{0.5}$ lies between -20 to $0 \mathrm{mV}$ (Rose et al., 1992; Magyar et al., 2000; Liao et al., 2007). 

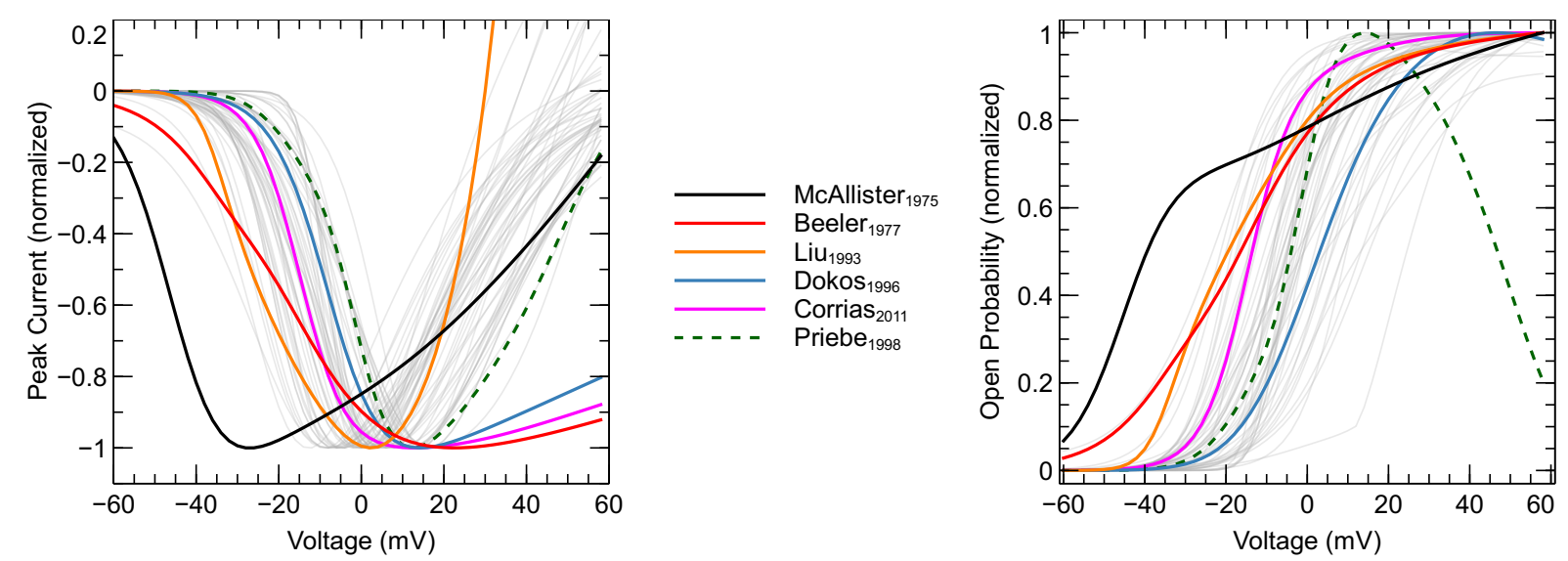

Figure 8: Left: I-V curve and Right: Normalised peak-open probability plotted against test potential for all 60 models. The 5 outlier models are labelled here along with the model by Priebe and Beuckelmann (1998); all 6 of these models are discussed in the main text while the rest are shown in grey. The simulation results for all of the models can be compared on the Cardiac Electrophysiology Web Lab at https://bit. Iy/LtypeCa.

We now take a closer look at the outlier models not included in Figure 7. Figure 8 (left) shows the I-V curve for all 60 models, including the outliers. To investigate the possible reasons for the outlier behaviour, we dissected simulated $\mathrm{I}_{\mathrm{CaL}}$ into open probability $(\mathrm{O})$ and driving term $(\mathrm{D})$. Normalised peak-O $(\overline{\mathrm{O}})$ is plotted against the test potential (O-V curve) in Figure 8 (right), where normalisation was performed using $\overline{\mathrm{O}}=\mathrm{O} /|\max \mathrm{O}|$.

Of the 5 outlier models, only the McAllister et al. (1975) model has an unusual O-V curve, because of which the peak $\mathrm{I}_{\mathrm{CaL}}$ is reached at a lower voltage than other models. The model by Liu et al. (1993) has an exponentially increasing driving term leading to the unusual I-V curve. The models by Beeler and Reuter (1977), Dokos et al. (1996), and Corrias et al. (2011) continue to exhibit large current at higher voltages. For Beeler and Reuter (1970) and Corrias et al. (2011), this observation can be explained by the driving terms which do not approach a reversal potential within the physiological range of the membrane voltage (Figure 6, Table 3). The model by Priebe and Beuckelmann (1998) has a similar driving term, but this is compensated by an outlier O-V curve leading to a typical I-V curve.

From this dissection of $\mathrm{I}_{\mathrm{CaL}}$ into $\mathrm{O}$ and $\mathrm{D}$ we learn that sometimes irregularities in modelling of one aspect (e.g. O) have been compensated by irregularities in other aspects (e.g. D). 


\section{Voltage-dependent inactivation}
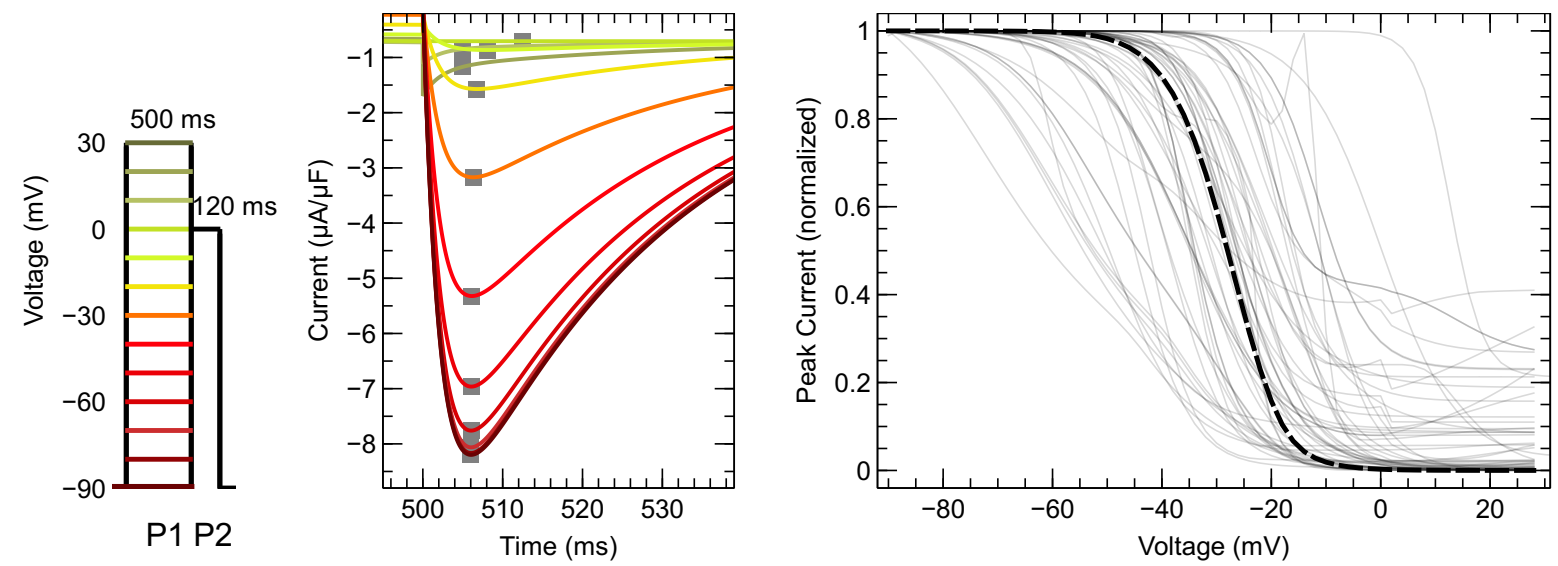

Figure 9: Left: Voltage-clamp protocol used to characterise inactivation (see main text for details). Centre: $\mathrm{I}_{\mathrm{CaL}}$ response during P2 as predicted by the Grandi et al. (2010) model. Traces from successive sweeps are overlaid and colour-coded to match the $\mathrm{P} 1$ steps in the left panel. The peak $\mathrm{I}_{\mathrm{CaL}}$ at each voltage step (marked with grey squares) is used to construct the I-V curves on the right. This process of constructing an I-V curve is shown in the animation online at https://github.com/CardiacModelling/ical-model-comparison. Right: Normalised peak $\mathrm{I}_{\mathrm{CaL}}$ versus step voltage curve for 60 models. The I-V curve from Kurata et al. (2002), which is close to the median response over all models, is highlighted with a black dashed line. The simulation results for all of the models can be compared on the Cardiac Electrophysiology Web Lab at https://bit.1y/LtypeCa.

A protocol to characterise voltage-dependent inactivation (VDI) was adapted from Magyar et al. (2000) and is shown in Figure 9 (left). Each sweep in this protocol starts with $20 \mathrm{~s}$ at a holding potential of $-90 \mathrm{mV}$, followed by a $500 \mathrm{~ms}$ step (P1) to a variable conditioning potential and a $120 \mathrm{~ms}$ step (P2) to a fixed test potential of $0 \mathrm{mV}$. The conditioning potential at $\mathrm{P} 1$ is $-90 \mathrm{mV}$ for the first sweep and increases by $2 \mathrm{mV}$ per sweep up to $30 \mathrm{mV}$ for the final sweep (a subset of which is shown in the figure).

Current was recorded during P2 to measure peak $\mathrm{I}_{\mathrm{CaL}}$ (I) (Figure 9, centre) which was normalised as $\overline{\mathrm{I}}=\mathrm{I} / \mathrm{min} \mathrm{I}$. Normalised peak $\mathrm{I}_{\mathrm{CaL}}(\overline{\mathrm{I}})$ was plotted against conditioning potential to construct the $\mathrm{I}-\mathrm{V}$ curves shown in Figure 9 (right).

This figure shows that most models predict inactivation to set in at around $-60 \mathrm{mV}$ or greater. The conditioning potential after which the peak $\mathrm{I}_{\mathrm{CaL}}$ is halved $\left(\mathrm{V}_{0.5}\right)$ was identified as the first voltage at which the I-V curve crosses 0.5 . The $\mathrm{V}_{0.5}$ varies between -31 to $10 \mathrm{mV}$ for the models in this study while the median $\mathrm{V}_{0.5}$ is $-29.8 \mathrm{mV}$. By comparison, examples from ventricular cells at physiological temperature show that $\mathrm{I}_{\mathrm{CaL}}$ channels begin to inactivate after a conditioning voltage of around $-60 \mathrm{mV}$ and that $\mathrm{V}_{0.5}$ lies between -30 and $-24 \mathrm{mV}$ (Li et al., 1999; Kim et al., 2016). 


\section{Recovery from voltage-dependent inactivation}
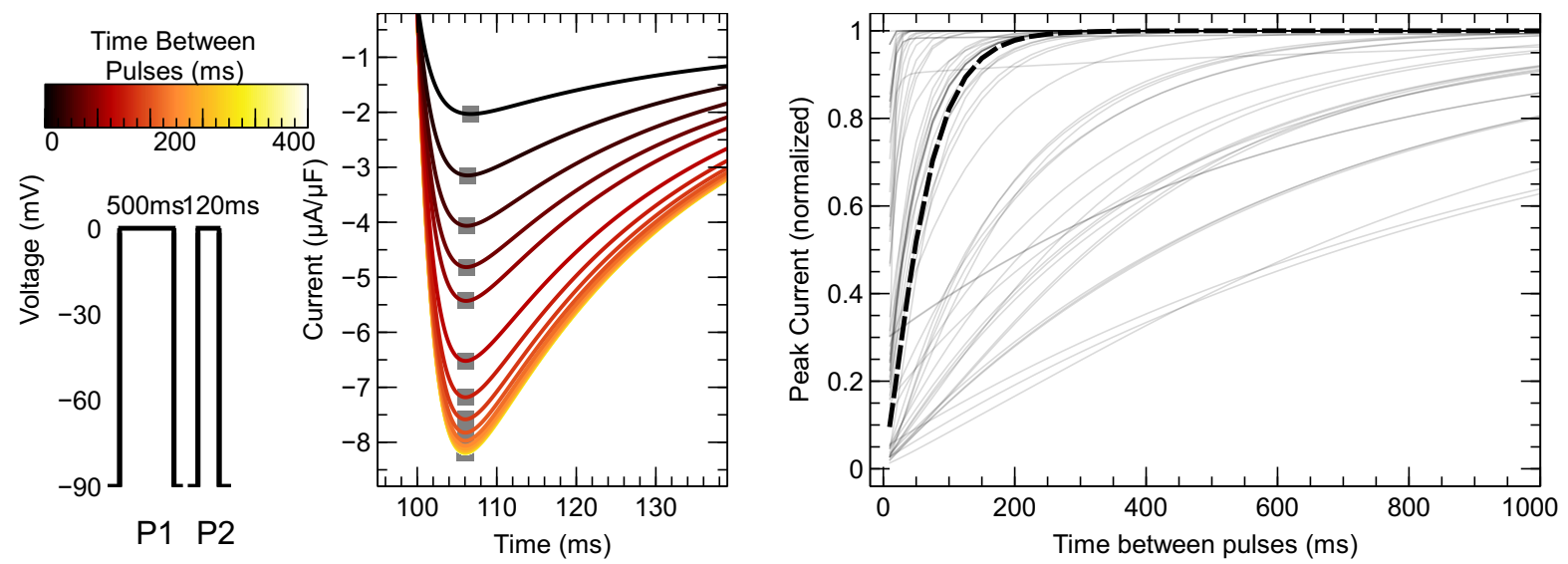

Figure 10: Left: Voltage-clamp used to characterise recovery from inactivation with a variable time interval between P1 and P2 of 10, 20,30,40, $50 \mathrm{~ms}$ and increment steps of $25 \mathrm{~ms}$ thereafter until $1000 \mathrm{~ms}$ (see main text for details). Centre: Example of $\mathrm{I}_{\mathrm{CaL}}$ predictions during P2, using the model by Grandi et al. (2010). The colours of each line match the colour shown above the interval length in the left panel. Traces from successive sweeps are overlaid and the peak $\mathrm{I}_{\mathrm{CaL}}$ is marked at each sweep which is used to construct the curves on the right. This process of constructing a peak $\mathrm{I}_{\mathrm{CaL}}$ versus time curve is shown in the animation online at https://github.com/CardiacModelling/ical-model-comparison. Right: Normalised peak $\mathrm{I}_{\mathrm{CaL}}$ versus time curves for all 60 models. The prediction from Fink et al. (2008) is close to the median response across all models and is highlighted with a black dashed line. The simulation results for all of the models can be compared on the Cardiac Electrophysiology Web Lab at https://bit.ly/LtypeCa.

In the previous section we investigated the voltage at which the $\mathrm{I}_{\mathrm{CaL}}$ channels inactivate. In this section, we look at the time $\mathrm{I}_{\mathrm{CaL}}$ channels take to recover from inactivation, using a protocol adapted from Fülöp et al. (2004) and shown in Figure 10 (left). Each sweep starts with $10 \mathrm{~s}$ at a holding potential of $-90 \mathrm{mV}$, followed by a $500 \mathrm{~ms}$ step (P1) to a conditioning potential of $0 \mathrm{mV}$. The potential is then set back to $-90 \mathrm{mV}$ for a duration that varies from sweep to sweep, followed by a $120 \mathrm{~ms}$ second step (P2) to the conditioning potential. The interval duration is $10 \mathrm{~ms}$ for the first sweep and increases by $10 \mathrm{~ms}$ per sweep up to $50 \mathrm{~ms}$, after which it increases by $25 \mathrm{~ms}$ per sweep up to $1000 \mathrm{~ms}$ (a subset of which are shown in the figure).

Peak $\mathrm{I}_{\mathrm{CaL}}$ was recorded during P1 ( $\left.\mathrm{I}_{\text {conditioning }}\right)$ and P2 $\left(\mathrm{I}_{\text {test }}\right)$ for all sweeps (Figure 10, centre). This was normalised as $\overline{\mathrm{I}}=\mathrm{I}_{\text {test }} / \mathrm{I}_{\text {conditioning }}$ and the normalised peak $\mathrm{I}_{\mathrm{CaL}}(\overline{\mathrm{I}})$ was plotted against interval length to construct the current-time curves shown in figure 10 (right).

An exponential function $1-\exp (-t / \tau)$ was fitted to each model's current-time curve to yield the time constant of recovery from inactivation $\tau$. This $\tau$ varies between 1.4 to $995.7 \mathrm{~ms}$ for the models in this study while the median $\tau$ is $51.2 \mathrm{~ms}$. This is much faster than examples from ventricular cells at physiological temperature, in which $\tau$ ranged from 50 to $700 \mathrm{~ms}$ (Li et al., 1999; Kim et al., 2016). 
bioRxiv preprint doi: https://doi.org/10.1101/2021.10.04.462988; this version posted October 7, 2021. The copyright holder for this preprint

\section{Calcium-dependent inactivation}
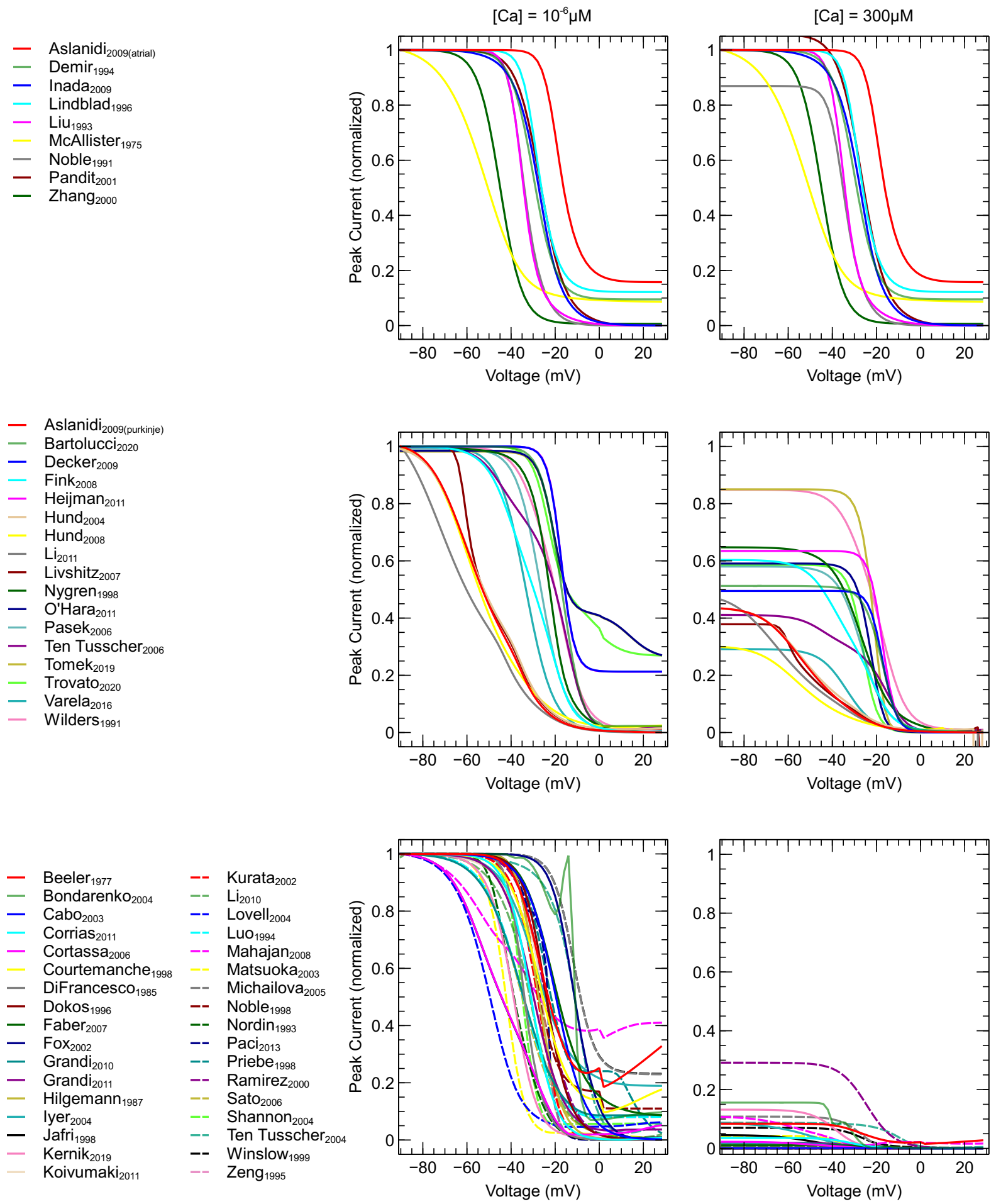

Figure 11: Models predict substantial variation in inactivation levels for the same change in $\left[\mathrm{Ca}^{2+}\right]$ as shown by the simulation to the inactivation protocol using Left: internal $\left[\mathrm{Ca}^{2+}\right]$ of $10^{-6} \mu \mathrm{M}$ and Right: internal $\left[\mathrm{Ca}^{2+}\right]$ of $300 \mu \mathrm{M}$. The models have been grouped intro three categories Top: insensitive or weakly sensitive to $\left[\mathrm{Ca}^{2+}\right](9$ models), Middle: mildly sensitive to $\left[\mathrm{Ca}^{2+}\right]$ (17 models), and Bottom: strongly sensitive to $\left[\mathrm{Ca}^{2+}\right]$ (34 models). The simulation results for all of the models can be compared on the Cardiac Electrophysiology Web Lab at https://bit.1y/LtypeCa. 
To study calcium-dependent inactivation (CDI), we compared the predicted response of the inactivation protocol shown in Figure 9 at internal calcium concentrations of $10^{-6} \mu \mathrm{M}$ and $300 \mu \mathrm{M}$. These concentrations are representative of the wide physiological variation of $\left[\mathrm{Ca}^{2+}\right]$ in cardiomyocytes, which ranges from 1-10 $\mu \mathrm{M}$ during low activity but may be greater than $100 \mu \mathrm{M}$ in the dyadic space during high activity (Fearnley et al., 2011). As before, the peak $\mathrm{I}_{\mathrm{CaL}}$ was identified at each sweep for both experiments, but the normalisation was performed using the maximum magnitude of peak $\mathrm{I}_{\mathrm{CaL}}$ measured across both concentrations.

Figure 11 shows the resulting I-V curves for the two experimental conditions split into three categories: 1 ) insensitive or weakly sensitive to $\left.\left[\mathrm{Ca}^{2+}\right], 2\right)$ mildly sensitive, and 3 ) strongly sensitive to $\left[\mathrm{Ca}^{2+}\right]$. To make these categories, we introduce a mathematical quantity that measures the change in $\mathrm{I}_{\mathrm{CaL}}$ predictions at the two $\left[\mathrm{Ca}^{2+}\right]$

$$
\mathrm{RMSD}=\sqrt{\frac{\sum_{i=1}^{n}\left(\overline{\mathrm{I}}_{300}-\overline{\mathrm{I}}_{10^{-6}}\right)^{2}}{n}},
$$

where RMSD stands for root mean squared difference and $n$ is the total number of sweeps. We classified a model as weakly sensitive if RMSD $<0.1$, mildly sensitive if $0.1 \leq \mathrm{RMSD} \leq 0.5$, and strongly sensitive if RMSD > 0.5. We thus identified 17 models in this study that show mild sensitivity to [ $\mathrm{Ca}^{2+}$ ] and 34 models that show strong sensitivity. Of the remaining 9 models, only Noble et al. (1991) and Pandit et al. (2001) account for $\left[\mathrm{Ca}^{2+}\right]$ in their equations and so are weakly sensitive, while the remaining 7 are $\left[\mathrm{Ca}^{2+}\right]$ insensitive and do not have any $\left[\mathrm{Ca}^{2+}\right]$ terms in O or D (see Table 1 , Row 1 ).

Although most models show CDI, there is large variation in the degree of CDI to the same change in $\left[\mathrm{Ca}^{2+}\right]$. To investigate this further, we examined the $\left[\mathrm{Ca}^{2+}\right]$ that induces the same level of inactivation in the models sensitive to $\left[\mathrm{Ca}^{2+}\right]$. For this purpose, we used a protocol consisting of only the first sweep of the inactivation protocol shown in Figure 9. As before, peak $\mathrm{I}_{\mathrm{CaL}}$ was recorded during P2, but now the experiment was repeated for increasing $\left[\mathrm{Ca}^{2+}\right]$ until a $50 \%$ drop in the peak $\mathrm{I}_{\mathrm{CaL}}$ was observed; we termed this concentration the $\mathrm{IC}_{50}\left[\mathrm{Ca}^{2+}\right]$. In this manner, we calculated the $\mathrm{IC}_{50}$ concentration for 49 models. No $\mathrm{IC}_{50}$ could be obtained for the model by Wilders et al. (1991) and Nygren et al. (1998), which did not produce a $50 \%$ drop at any of the levels we tested.

Calcium flowing into a subspace will induce a change in local $\left[\mathrm{Ca}^{2+}\right]$ with a rate that depends inversely on the subspace volume $V_{\text {local }}$ (assuming there is no buffering or diffusion of $\left[\mathrm{Ca}^{2+}\right]$ ). We may therefore expect models in which $\mathrm{I}_{\mathrm{CaL}}$ flows into large subspaces to compensate for the slower local $\left[\mathrm{Ca}^{2+}\right]$-change with a more sensitive CDI, and vice versa. This is affirmed by Figure 12, in which the $\mathrm{IC}_{50}$ concentration is plotted against $V_{\text {local }}$. For models in which $\mathrm{I}_{\mathrm{CaL}}$ channels are present in multiple biological subspaces, the volume was calculated as a weighted average. For example, $80 \%$ of the $\mathrm{I}_{\mathrm{CaL}}$ channels in the model by Tomek et al. (2019) lie in the dyadic space, whereas only $20 \%$ lie in the submembrane space, leading to a weighted average volume $V_{\text {local }}=0.8 V_{d}+0.2 V_{s}$. The models by Beeler and Reuter (1977) and Mahajan et al. (2008) were omitted as the volume of their localisation space could not be determined from the manuscripts.

Figure 12 shows a weak correlation between the predicted $\mathrm{IC}_{50}$ and the corresponding $V_{\text {local }}$, suggesting that modelled CDI is to some limited extent influenced by the size of the compartment that $\mathrm{I}_{\mathrm{CaL}}$ flows into. This is another example where we observe that one aspect of the model can compensate for another. 


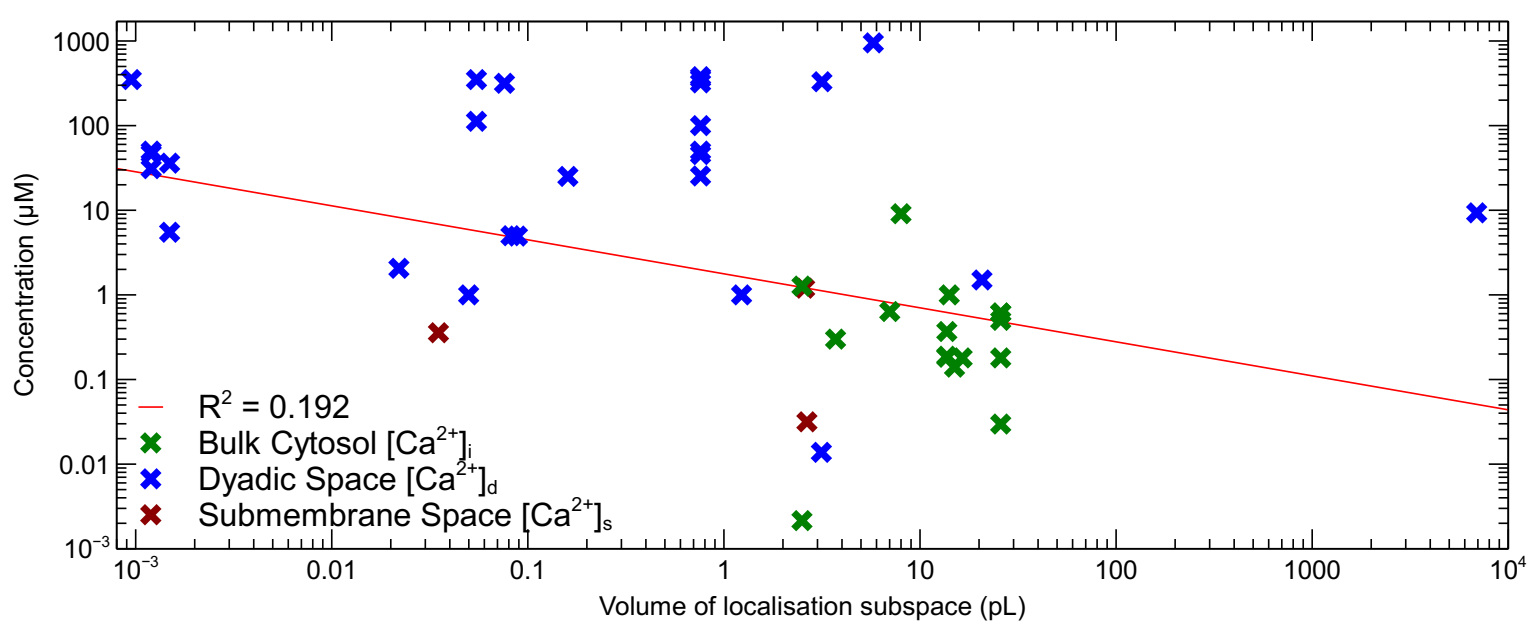

Figure 12: $\mathrm{IC}_{50}$ concentration plotted against the volume of the biological subspace assumed to contain L-type calcium channels by 47 models (see main text for details). Colours indicate the subspace containing $\mathrm{I}_{\mathrm{CaL}}$ channels, or the subspace containing the majority of channels in models where $\mathrm{I}_{\mathrm{CaL}}$ is spread over multiple spaces.

\section{Action potential clamp}

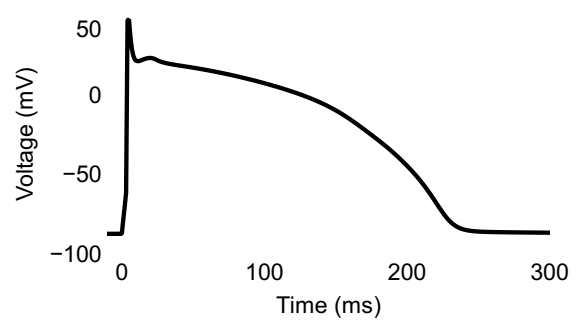

Figure 13: The AP waveform used in AP- and AP-CaT-clamp simulations. This action potential was derived from a $1 \mathrm{~Hz}$ simulation of the model by Grandi et al. (2010).

The experiments simulated so far use voltage-step protocols which bring out a wide range of $\mathrm{I}_{\mathrm{CaL}}$ kinetics but are very different from the voltage signals experienced by L-type calcium channels in situ. To compare predictions of $\mathrm{I}_{\mathrm{CaL}}$ in more physiological conditions, we simulated experiments in which the membrane potential $\left(V_{m}\right)$ is clamped to an action potential (AP) trace.

As noted before, assumptions about internal calcium dynamics will impact the (estimated or calibrated) parameters governing $\mathrm{I}_{\mathrm{CaL}}$ kinetics, and so to show the $\mathrm{I}_{\mathrm{CaL}}$ predictions from a whole AP model as fairly as possible, the internal calcium concentrations in these simulations should be allowed to vary as defined by the model equations. If, however, we are interested only in the models' $\mathrm{I}_{\mathrm{CaL}}$ equations, it is preferable to force an identical internal calcium transient in each model.

To address these conflicting aims, we performed a series of three complementary simulations. First, we simulated an AP-clamp in which we allowed the internal $\left[\mathrm{Ca}^{2+}\right]$ to vary according to the model's internal $\left[\mathrm{Ca}^{2+}\right]$ equations (AP clamp 1). These simulations were performed only for models in which a CellML file for the full AP model was available. For AP models with epi-, endo-, and mid-myocardial variants, the epicardial version was used. Secondly, we performed a dual AP-CaT-clamp, in which all internal $\left[\mathrm{Ca}^{2+}\right]$ (including the subspaces) were clamped to the same pre-calculated bulk cytosolic CaT (AP clamp 2). Thirdly, we performed a combined AP-CaT-clamp in which bulk cytosol, submembrane space, and dyadic 
space $\left[\mathrm{Ca}^{2+}\right]$ were clamped to pre-calculated transients appropriate to the subspace (AP clamp 3). We chose to use the AP and CaT measurements from the Grandi et al. (2010) human ventricle model during $1 \mathrm{~Hz}$ at steady pacing of the model (Figure 13,3), as this is the earliest human model in which all three subspaces are defined. In all three experiments, the simulated $\mathrm{I}_{\mathrm{CaL}}$ was normalised with respect to the total charge carried: $\overline{\mathrm{I}}(t)=\mathrm{I}(t) /\left|\int_{t} I(t) d t\right|$. The resulting normalised currents for all three simulations are shown in Figure 14.
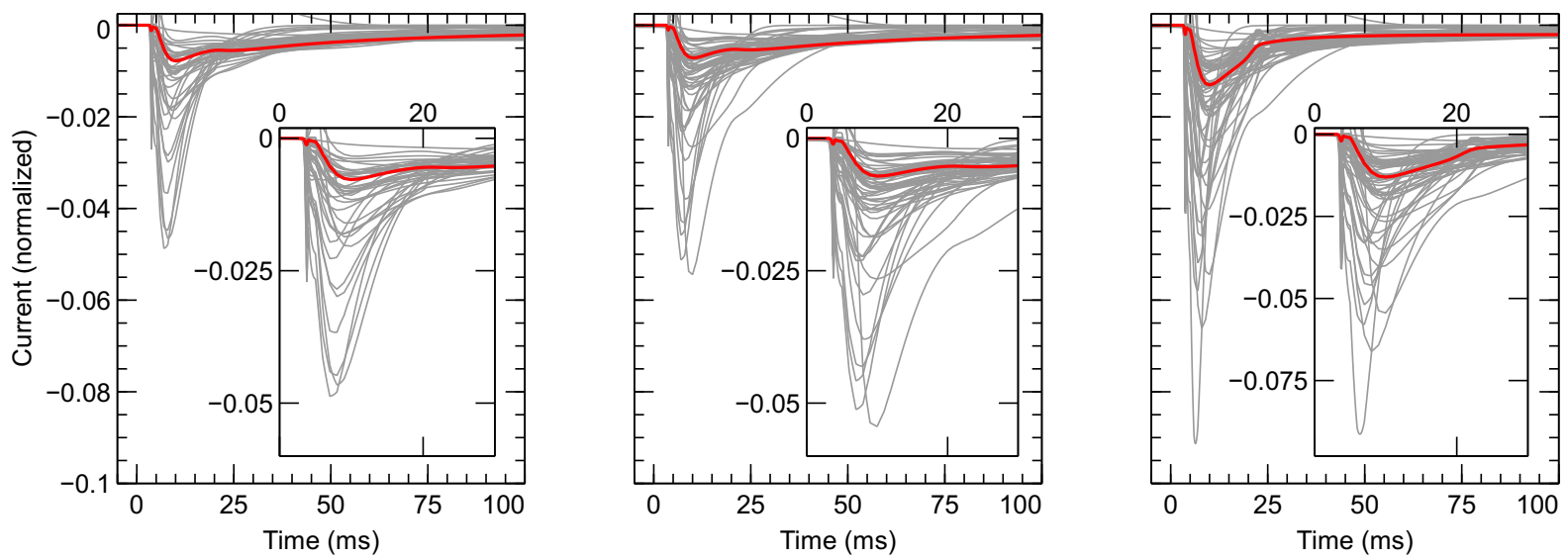

Figure 14: Variation in the $\mathrm{I}_{\mathrm{CaL}}$ predictions in response to AP and AP-CaT clamp. Left: Simulated response to AP clamp 1, in which internal $\left[\mathrm{Ca}^{2+}\right]$ are determined by the model equations, shown for the $44 \mathrm{I}_{\mathrm{CaL}}$-models implemented in a whole-cell model. Centre: Simulated response to AP clamp 2, in which all internal $\left[\mathrm{Ca}^{2+}\right]$ are clamped to a pre-calculated bulk cytosolic CaT. Right: Simulated response to AP clamp 3, in which $\left[\mathrm{Ca}^{2+}\right]_{i}$, $\left[\mathrm{Ca}^{2+}\right]_{s}$, and $\left[\mathrm{Ca}^{2+}\right]_{d}$ are clamped to pre-calculated bulk cytosolic, submembrane, and dyadic CaT respectively. Predictions from Grandi et al. (2010), which was used to derive the calcium transients, is highlighted in red. The simulation results for all of the models can be compared on the Cardiac Electrophysiology Web Lab at https://bit.1y/LtypeCa.

All three AP clamps in Figure 14 show considerable variation in predicted (normalised) $\mathrm{I}_{\mathrm{CaL}}$ between models. Some of this variation may be explained as a result of differences in species, cell-type, and other factors. To test this assumption, we divided the 60 models into groups according to several criteria (e.g. species, cell-type) and investigated whether this resulted in groups with reduced variation. We chose the "compromise" protocol AP Clamp 3 for this purpose. To remove effects of varying driving terms and maximal conductances, we compared the predicted open probability $(\mathrm{O})$ rather than $\mathrm{I}_{\mathrm{CaL}}$.

To give an indication of the variation within a group, we used the "normalised root mean square difference" (NRMSD) of the observed open probabilities of all models in the group, according to:

$$
\hat{O}_{i}=\frac{1}{n} \sum_{j=1}^{n} O_{i j} ; \text { NRMSD }_{\text {group }}=\sqrt{\frac{1}{m \cdot n} \sum_{i=1}^{m} \sum_{j=1}^{n}\left(O_{i j}-\hat{O}_{i}\right)^{2}} .
$$

Here, $O_{i j}$ represents the open probability measured in response to the "AP-CaT clamp 3" protocol at the $i^{\text {th }}$ time step for the $j^{\text {th }}$ model, $m$ is the total number of time points, and $n$ is the total number of models within the group.

If grouping by a particular category reduces variability, we expect the NRMSD within each group to be lower than the NRMSD of the original group-of-all-models $\left(\mathrm{NRMSD}_{\text {total }}=0.139\right)$. This can be quantified by defining a relative measure $\mathrm{NRMSD}_{\text {relative }}=\mathrm{NRMSD}_{\text {group }} / \mathrm{NRMSD}_{\text {total }}$. A grouping is considered to be better than baseline if its NRMSD relative is less than one. 
First, we investigate the effects of grouping models chronologically by grouping each model into one of four categories depending on the year of publication. This is shown in Figure 15, where we can observe some convergence in model predictions over time, indicated by a decreasing NRMSD relative. Although this is encouraging, some degree of convergence should be expected as more recent models are often refinements of previous models in the same age category. Large variability should also expected from the models published before the 1990s, which depend on data obtained from a wider range of experimental techniques.
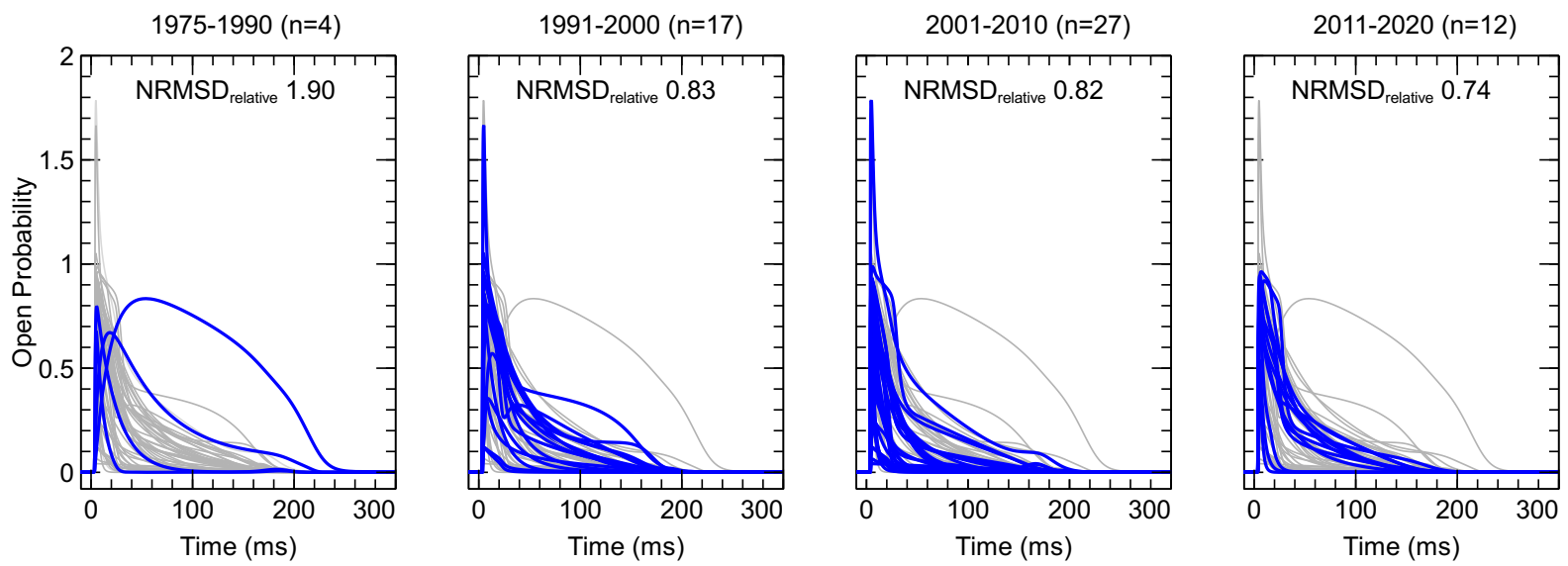

Figure 15: Open probability in response to AP clamp 3, grouped according to date of publication, shows a degree of convergence over time. Blue curves in each panel correspond to $\mathrm{I}_{\mathrm{CaL}}$ predictions of models within the corresponding period, while the remaining predictions are shown in grey.

Next, we grouped models according to the approach used to model how the calcium concentrations affect the open probability, depicted by the rows in Table 1. On this basis, Figure 16 shows the models grouped into 6 classes: no $\left[\mathrm{Ca}^{2+}\right]$ (row 1, 2), $\left[\mathrm{Ca}^{2+}\right]_{i}\left(\right.$ row 3, 6), $\left[\mathrm{Ca}^{2+}\right]_{s}\left(\right.$ row 4, 7), $\left[\mathrm{Ca}^{2+}\right]_{d}$ (row 5, 8, 11, 12), $\left[\mathrm{Ca}^{2+}\right]_{i}$ and $\left[\mathrm{Ca}^{2+}\right]_{d}$ (row 9), and $\left[\mathrm{Ca}^{2+}\right]_{s}$ and $\left[\mathrm{Ca}^{2+}\right]_{d}$ (row 10). It shows that that most groups formed on the basis of the local $\left[\mathrm{Ca}^{2+}\right]$ near the $\mathrm{I}_{\mathrm{CaL}}$ channel have at least $20 \%$ less disagreement amongst the predictions across models than the baseline. This indicates that the modelled localisation of the $\mathrm{I}_{\mathrm{CaL}}$ channels plays an important role in determining model predictions. However, only the model by Tomek et al. (2019) is shown in class 5 and thus the NRMSD ${ }_{\text {relative }}$ calculated here is not relevant. Similarly, all three models in class 6 (Shannon et al., 2004; Grandi et al., 2010, 2011) were developed by the same group. 

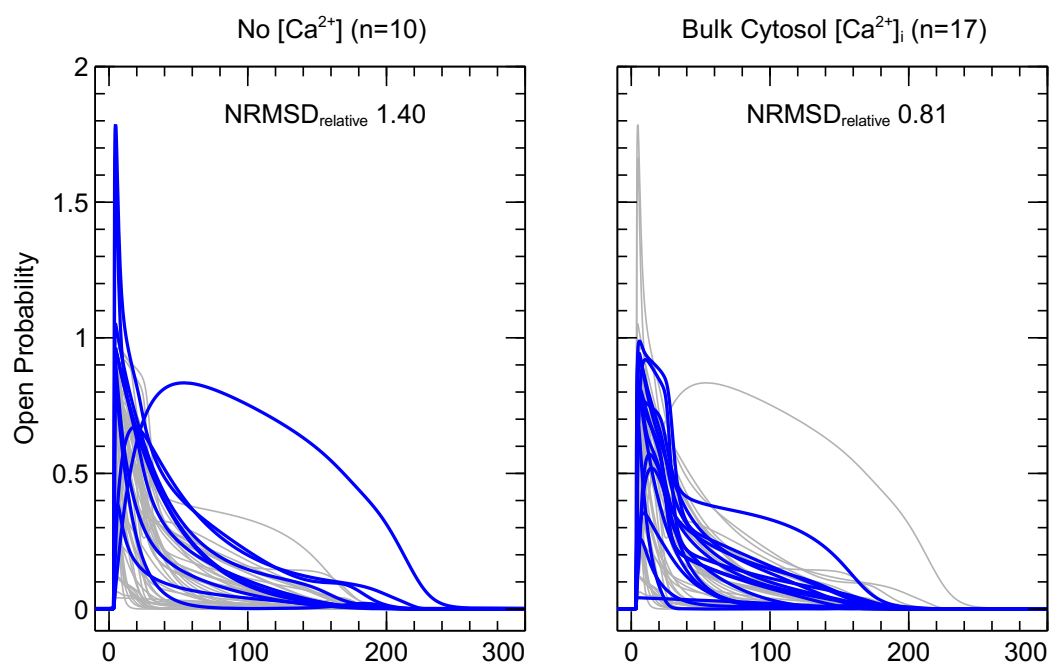

Submembrane Space $\left[\mathrm{Ca}^{2+}\right]_{\mathrm{s}}(\mathrm{n}=4)$
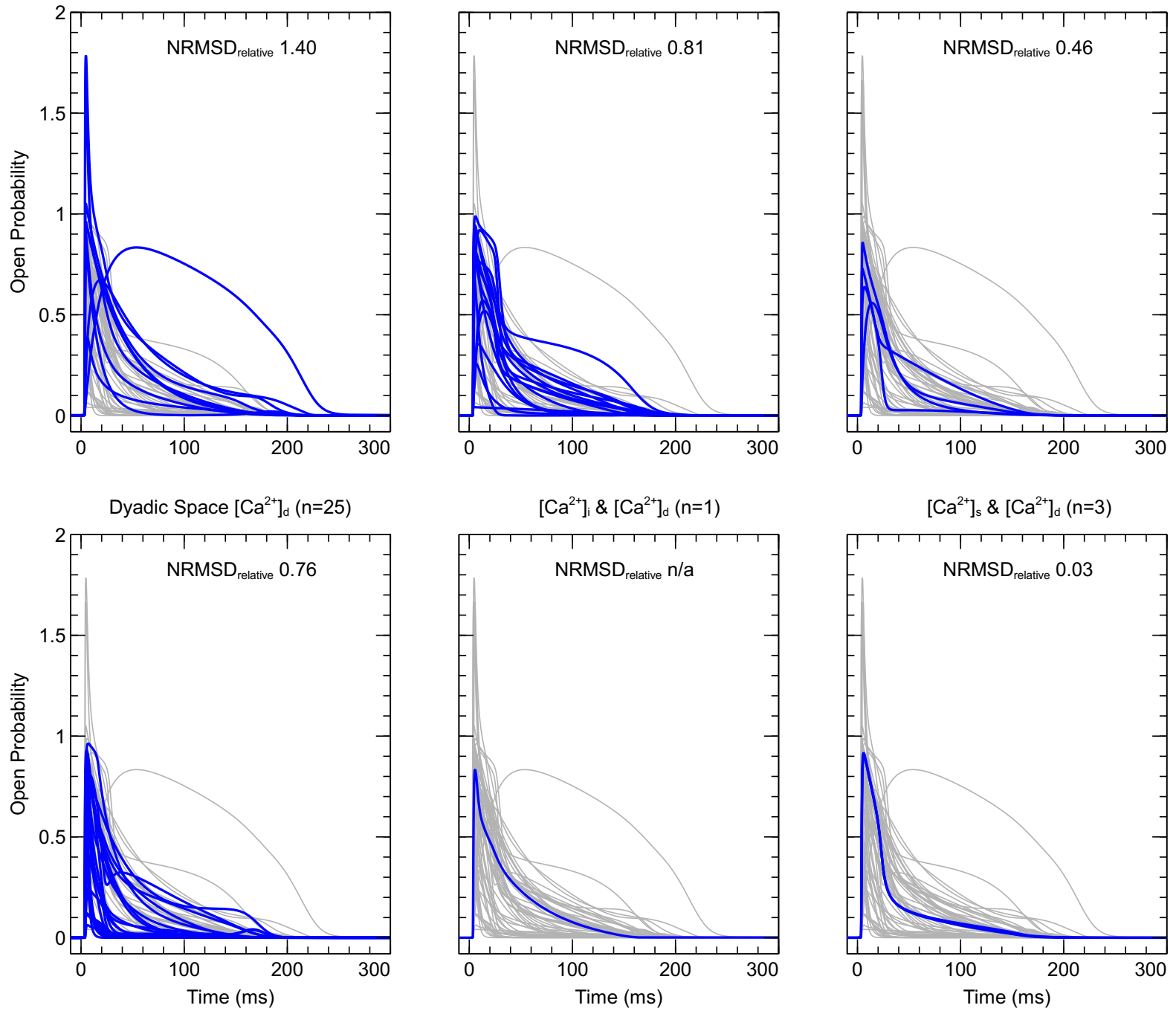

Figure 16: Open probability $(O)$ in response to AP Clamp 3, grouped by local $\left[\mathrm{Ca}^{2+}\right]$ as shown by the rows in Table 1 where each row represents an $O$ or driving term dependence on different local $\left[\mathrm{Ca}^{2+}\right]$. In this figure each panel includes the models in 1 ) row $1 \& 2,2)$ row $3 \& 6,3)$ row $4 \& 7,4)$ row $5,8,11, \& 12,5$ ) row 9 , and 6 ) row 10 (where the model is implemented quantitatively) of Table 4 . In each panel, blue curves show $\mathrm{I}_{\mathrm{CaL}}$ predictions from models within the corresponding group, while the remaining predictions are shown in grey.

We also investigated grouping the models by species (e.g. human, canine), cell type (e.g. ventrical, purkinje), and gating kinetics (e.g. Type A, C). Groups on the basis of these factors led to small improvements on the baseline, but no major reductions in the NMRSD relative were seen except in the group of canine models $(\mathrm{n}=14)$ which had $\mathrm{NMRSD}_{\text {relative }}=0.62$. Of all tested criteria, grouping by local $\left[\mathrm{Ca}^{2+}\right]$ near the $\mathrm{I}_{\mathrm{CaL}}$ channels exhibited the most consistent predictions. 


\section{Discussion}

In this study we have undertaken a qualitative comparison of $71 \mathrm{I}_{\mathrm{CaL}}$ models, and simulated experimental protocols with 60 models to enable a quantitative comparison. In our qualitative analysis, we found 15 major categories of $\mathrm{I}_{\mathrm{CaL}}$ gating models, and a smaller but similar lack of consensus on how to model $\mathrm{I}_{\mathrm{CaL}}$ 's electrochemical driving force and the myocyte's spatial organisation. Accordingly, the 60 models studied quantitatively made very different predictions about activation, inactivation, recovery, and CDI, with only limited convergence emerging with year of publication. So, despite decades of intensive and careful research, it is still very much an open question as to how to formulate a model of $\mathrm{I}_{\mathrm{CaL}}$ for use in electrophysiology simulations.

Interestingly, and despite its critical role in cardiac function, very little work has been published that compares models of $\mathrm{I}_{\mathrm{CaL}}$ or shows the benefits of a newly introduced model over its predecessors (but see Luo and Rudy, 1994, for an example). Therefore, when undertaking a new study involving $\mathrm{I}_{\mathrm{CaL}}$, there is a need to carefully assess which of the existing 71 models most accurately represents the experimental record on the current of interest (e.g. human non-diseased left-ventricular $\mathrm{I}_{\mathrm{CaL}}$ ). This is a time-consuming and daunting task, especially if we consider that the model that best matches the data "out of the box" may be surpassed by other models after re-parameterisation. Clearly, it would be of great benefit to the field of (computational) electrophysiology if a well-tested consensus model or at least a "gold-standard" model were to emerge.

In this section, we show how dissecting $\mathrm{I}_{\mathrm{CaL}}$ models into smaller components can facilitate model comparison, but can also expose problems in individual parts. We then highlight open questions in models of the driving term, calcium-sensitivity and voltage-dependent kinetics and speculate on possible solutions.

\section{Compensation}

A major difficulty when comparing $\mathrm{I}_{\mathrm{CaL}}$ models is that, although they share a common structure, their driving term (D), voltage-dependent kinetics, and calcium sensitivity interact in ways that allow irregularities in one aspect to be compensated in another. For example the unusual open probability (O) of the model by Priebe and Beuckelmann (1998) (Figure 8) was shown to be compensated by a large reversal potential in its driving term (Figure 6). Similarly, the models by Demir et al. (1994), Lindblad et al. (1996), and Aslanidi et al. (2009a) allow O to be greater than one (so that the usual interpretation of open probability does not apply), which can be compensated for in either $\mathrm{D}$ or the maximal conductance. The model by Beeler and Reuter (1970) has a strong sensitivity to $\left[\mathrm{Ca}^{2+}\right]$ (Figure 11) but does not include CDI, deriving its $\left[\mathrm{Ca}^{2+}\right]$-dependence from an unusually strong driving force (Figure 6) instead. Finally, Figure 12 shows how a high sensitivity to calcium can be compensated by postulating a bigger subspace near the L-type calcium channels, leading to a lower local $\left[\mathrm{Ca}^{2+}\right]$.

Compensation effects also come into play when creating new AP models, which often require calibration of the sub-models (e.g. the $\mathrm{I}_{\mathrm{CaL}}$ model) to cell-level observations (Whittaker et al., 2020). Even when carried out with care, this process may hide defects in one part of a model by introducing them in another. A model built in this way may reproduce many electrophysiological phenomena seen in the experimental data, but through mechanisms that do not reflect those in the real cell. As a result, when extrapolating to new (e.g. patho-physiological) situations, there is a likelihood that its predictions will be unreliable. 


\section{Driving term}

The study of the electrochemical force driving $\mathrm{I}_{\mathrm{CaL}}$ flux through the open channels is complicated by the wide range of calcium concentrations in a myocyte and by the L-type calcium channel's significant permeability to potassium and sodium. Different models have been proposed as a result (Ohmic and several GHK variants), but we were unable to find studies that show the benefit of one form over another. The relative permeability to different ionic species also varies between models (Table 4), as do the activity coefficients used in some GHK models. It is important to note that, while almost all these models used the same activity coefficients, their values depend on experimental conditions (ionic strength and temperature), for different intracellular and extracellular ionic compositions. They can also be calculated as part of the model, as was done by Tomek et al. (2019) (although this model erroneously used a natural logarithm instead of a base-10 logarithm for the Davies activity coefficient calculation, see https://bit.1y/3tqD4gP), however, within physiological ranges of temperature and ionic concentrations, they change by less than $0.1 \%$ during an action potential.

To decide between driving force models, specialised experiments may be required that can separate driving force from kinetics and CDI. For example, if some way can be found to fix the channels in their open state (e.g. a drug or mutation) it may be possible to measure an open-state I-V relationship directly in a whole-cell configuration. If noise levels can be made sufficiently low then single-channel experiments, (in which the kinetics do not affect the current level) may also be useful for this purpose (Greenstein and Winslow, 2002). Excised-patch experiments could have additional advantages, in that they could allow rapid variation of internal (inside-out) or external calcium concentrations (outside-out), to levels that a whole cell may not tolerate, and in removing obfuscating effects from intracellular buffers and transporters (Gradogna et al., 2009). Finally, it is worth noting that the Ohmic and GHK models are both approximations, and so it may be possible to fit them to predictions from (or use) more sophisticated models of ionic permeation (Roux et al., 2004).

\section{CDI and calcium dynamics}

Calcium-dependent inactivation (CDI) is one of the most challenging aspects of modelling $\mathrm{I}_{\mathrm{CaL}}$. Accordingly, the degree of CDI predicted by different models varies very widely (Figure 11). That this is not just a quantitative difference can be seen in Figure 5, which shows examples where CDI is treated as an independent process and examples where voltage and calcium-dependent gating are intermixed. CDI depends on the (fluctuating) calcium concentration at the cytosolic channel side, and so model assumptions about channel localisation and cell geometry have a strong impact on modelled CDI. This is evidenced by the relationship between subspace volume and $\mathrm{IC}_{50}$ (Figure 12) and by the reduction in NMRSD when grouping models by channel localisation.

Experimentally, CDI can be separated from voltage-dependent kinetics and driving term to some degree by using voltage protocols with a single repeating step, so that voltage effects are consistent - if still unknown. However, the local calcium concentration is difficult to control, as the very low $\left[\mathrm{Ca}^{2+}\right]$ maintained in living cells means the calcium influx through $\mathrm{I}_{\mathrm{CaL}}$ causes a significant change. In myocytes, a bewildering array of processes affect and are affected by local $\left[\mathrm{Ca}^{2+}\right]$ (Bers, 2008). In heterologous expression systems, calcium-buffers are required to keep $\left[\mathrm{Ca}^{2+}\right]$ at levels the cells can tolerate (You et al., 1997). Bulk cytosolic $\left[\mathrm{Ca}^{2+}\right]$ can be measured optically using fluorescent dyes (Herron et al., 2012) but measuring local calcium elevations in subspaces (or "microdomains") is technically challenging (Acsai et al., 2011). As a result, there is no 'simple' set-up in which CDI can be studied, and analysing data from experiments targeting CDI requires consideration of intracellular $\left[\mathrm{Ca}^{2+}\right]$ gradients, diffusion, and buffering. Although analytical solutions exist for simplified scenarios (Smith, 1996), it is likely that 
numerical simulations (e.g. Rice et al., 1999; Greenstein and Winslow, 2002; Koivumäki et al., 2011; Nivala et al., 2012) will be required for this purpose.

\section{Voltage-dependent kinetics}

The equations for (voltage and calcium-dependent) open probability vary more from model to model than those for any other aspect of $\mathrm{I}_{\mathrm{CaL}}$ : we identified 15 distinct gating mechanisms, several of which had further sub-types. Some mechanisms have clearly developed over time to account for novel experimental information: for example, the transition of gating type $\mathrm{A}$ to $\mathrm{B}$ to $\mathrm{C}$ in Table 2 directly relates to the discovery of calcium-dependent inactivation (CDI) in $\mathrm{I}_{\mathrm{CaL}}$ channels. However, we found that the introduction of new gating models is not commonly accompanied by a published critical comparison of the old and new models on the data set of interest. In part 2 of this study we showed that there is large variability in the predicted response to voltage-clamp protocols, which cannot be explained by differences in species or cell type. Without further systematic analysis it is unclear how much of this variability is due to modelling challenges, and how much is due to variability in the underlying experimental data sets.

While most studies of $\mathrm{I}_{\mathrm{CaL}}$ kinetics have used conventional voltage-step protocols (such as shown in Figures 7, 9, and 10), recent advances in protocol design for $\mathrm{I}_{\mathrm{Kr}}$ (Beattie et al., 2018; Clerx et al., 2019) may be translatable to $\mathrm{I}_{\mathrm{CaL}}$. Application of such protocols in high-throughput settings (Lei et al., 2019) with careful consideration of experimental artefacts (Lei et al., 2020a,b) may help produce rich data sets that will allow us to distinguish between the different proposed gating mechanisms and study (biological or experimental) variability. Such an approach, however, would require that voltage and calcium effects are independent (or at least can be studied independently) and may rely on accurate CDI and driving term models already being available. Alternatively, it may be possible to derive gating models as simplifications of more detailed molecular dynamics models (Silva, 2018; Ramasubramanian and Rudy, 2018). In either case, care must be taken to create independent training and validation data sets, so that the most crucial part of the gating model, its predictive power, can be assessed (Whittaker et al., 2020).

\section{Data sharing}

Finally, we have surveyed and compared models of $\mathrm{I}_{\mathrm{CaL}}$ without much referral to what is perhaps the most important criterion: do they match the data. As we have chosen the broad field of "mammalian models" of $\mathrm{I}_{\mathrm{CaL}}$, from anywhere in the heart, there is no single data set that all models should match. However, L-type calcium channel genes are strongly conserved, so that it seems likely that cell-type differences and even species differences may be accommodated by modifying parameter values, rather than requiring different equations. This way, a systematic comparison could be carried out that tested the ability of the 60 sets of model equations to fit a specific data set.

An immediate issue here is the lack of publicly available data. Although the need for sharing data (and sufficient meta data) is widely acknowledged (Quinn et al., 2011) and technical barriers have all but disappeared in the last two decades, it is still uncommon for electrophysiological recordings to be published in digital, unprocessed, form. As a result, modellers have frequently resorted to digitising published figures and then fitting to "summary curves" (e.g. I-V curves) that represent averaged data from several cells in a condensed form. Both averaging (Golowasch et al., 2002) and fitting to summary curves (Clerx et al., 2019) can lead to inaccuracies, so there is an evident need for more widespread sharing of experimental data, perhaps in a systematic form such as the Physionet database for ECG signals (Goldberger et al., 2000). 


\section{Conclusion}

Five decades of careful research has resulted in a list of over 71 mammalian $\mathrm{I}_{\mathrm{CaL}}$ models, which make varying assumptions and predictions about the electrochemical driving force, voltage and calcium-dependent gating, and channel localisation. Despite this impressive body of work, there are still several, fundamental, open questions on how to model $\mathrm{I}_{\mathrm{CaL}}$. We believe that this study is the first to systematically survey and compare $\mathrm{I}_{\mathrm{CaL}}$ models and hope that it can serve as a starting point for a critical re-assessment of L-type calcium current modelling from which a synthesised, consensus model may emerge.

\section{Additional information}

\section{Data availability}

Code for all models and simulations is freely available at https://github.com/CardiacModelling/ ical-model-comparison.

\section{Funding}

This work was supported by the UK Engineering and Physical Sciences Research Council [grant numbers EP/L016044/1, EP/S024093/1]; the Biotechnology and Biological Sciences Research Council [grant number BB/P010008/1]; and the Wellcome Trust [grant number 212203/Z/18/Z]. A.A. acknowledges EPSRC and F. Hoffmann-La Roche Ltd. for studentship support via the Centre for Doctoral Training in Systems Approaches to Biomedical Science. D.J.G. acknowledges support from the EPSRC Centres for Doctoral Training Programme. J.C., G.R.M., M.C. and D.J.G. acknowledge support from a BBSRC project grant. G.R.M. and M.C. acknowledge support from the Wellcome Trust via a Wellcome Trust Senior Research Fellowship to G.R.M. This research was funded in whole, or in part, by the Wellcome Trust $[212203 / \mathrm{Z} / 18 / \mathrm{Z}]$.

\section{Competing interests}

K.W. and L.P. are employees of F.Hoffman-La Roche Ltd. and K.W. is a shareholder. 


\section{References}

Acsai K, Antoons G, Livshitz L, Rudy Y \& Sipido KR (2011). Microdomain $\left[\mathrm{Ca}^{2+}\right.$ ] near ryanodine receptors as reported by L-type $\mathrm{Ca}^{2+}$ and $\mathrm{Na}^{+} / \mathrm{Ca}^{2+}$ exchange currents. The Journal of Physiology $\mathbf{5 8 9}$, $2569-2583$.

Aggarwal R \& Boyden PA (1995). Diminished $\mathrm{Ca}^{2+}$ and $\mathrm{Ba}^{2+}$ currents in myocytes surviving in the epicardial border zone of the 5-day infarcted canine heart. Circulation Research 77, 1180-1191.

Aggarwal R \& Boyden PA (1996). Altered pharmacologic responsiveness of reduced L-type calcium currents in myocytes surviving in the infarcted heart. Journal of Cardiovascular Electrophysiology $\mathbf{7}$, $20-35$.

Asakura K, Cha CY, Yamaoka H, Horikawa Y, Memida H, Powell T, Amano A \& Noma A (2014). EAD and DAD mechanisms analyzed by developing a new human ventricular cell model. Progress in Biophysics and Molecular Biology 116, 11-24.

Aslanidi OV, Boyett MR, Dobrzynski H, Li J \& Zhang H (2009a). Mechanisms of transition from normal to reentrant electrical activity in a model of rabbit atrial tissue: interaction of tissue heterogeneity and anisotropy. Biophysical Journal 96, 798-817.

Aslanidi OV, Stewart P, Boyett MR \& Zhang H (2009b). Optimal velocity and safety of discontinuous conduction through the heterogeneous Purkinje-ventricular junction. Biophysical Journal 97, 20-39.

Bartolucci C, Passini E, Hyttinen J, Paci M \& Severi S (2020). Simulation of the effects of extracellular calcium changes leads to a novel computational model of human ventricular action potential with a revised calcium handling. Frontiers in Physiology 11, 314.

Bassingthwaithe JB \& Reuter H (1972). Calcium movements and excitation-contraction coupling in cardiac cells In De Mello WC, editor, Electrical Phenomena in the Heart, chapter 13, pp. 266-290. Academic Press.

Beattie KA, Hill AP, Bardenet R, Cui Y, Vandenberg JI, Gavaghan DJ, de Boer TP \& Mirams GR (2018). Sinusoidal voltage protocols for rapid characterisation of ion channel kinetics. The Journal of Physiology 596, 1813-1828.

Beeler GW \& Reuter H (1970). Membrane calcium current in ventricular myocardial fibres. The Journal of Physiology 207, 191-209.

Beeler GW \& Reuter H (1977). Reconstruction of the action potential of ventricular myocardial fibres. The Journal of Physiology 268, 177-210.

Bénitah JP, Bailly P, D'Agrosa MC, Da Ponte JP, Delgado C \& Lorente P (1992). Slow inward current in single cells isolated from adult human ventricles. Pflügers Archiv-European Journal of Physiology 421, $176-187$.

Bers DM (2008). Calcium cycling and signaling in cardiac myocytes. Annual Review of Physiology 70, $23-49$.

Beuckelmann DJ, Näbauer M \& Erdmann E (1992). Intracellular calcium handling in isolated ventricular myocytes from patients with terminal heart failure. Circulation 85, 1046-1055.

Beuckelmann DJ, Näbauer M \& Erdmann E (1991). Characteristics of calcium-current in isolated human ventricular myocytes from patients with terminal heart failure. Journal of Molecular and Cellular Cardiology 23, 929-937. 
Bondarenko VE, Szigeti GP, Bett GC, Kim SJ \& Rasmusson RL (2004). Computer model of action potential of mouse ventricular myocytes. American Journal of Physiology-Heart and Circulatory Physiology 287, H1378-H1403.

Boyett MR, Honjo H, Harrison SM, Zang WJ \& Kirby MS (1994). Ultra-slow voltage-dependent inactivation of the calcium current in guinea-pig and ferret ventricular myocytes. Pflügers Archiv-European Journal of Physiology 428, 39-50.

Cabo C \& Boyden PA (2003). Electrical remodeling of the epicardial border zone in the canine infarcted heart: a computational analysis. American Journal of Physiology-Heart and Circulatory Physiology 284, H372-H384.

Campbell DL, Giles WR, Hume JR, Noble D \& Shibata EF (1988). Reversal potential of the calcium current in bull-frog atrial myocytes. The Journal of Physiology 403, 267-286.

Catterall WA (2011). Voltage-gated calcium channels. Cold Spring Harbor Perspectives in Biology 3, a003947.

Cavalié A, Pelzer D \& Trautwein W (1986). Fast and slow gating behaviour of single calcium channels in cardiac cells. Pflügers Archiv-European Journal of Physiology 406, 241-258.

Clerx M, Beattie KA, Gavaghan DJ \& Mirams GR (2019). Four ways to fit an ion channel model. Biophysical Journal 117, 2420-2437.

Clerx M, Collins P, de Lange E \& Volders PGA (2016). Myokit: a simple interface to cardiac cellular electrophysiology. Progress in Biophysics and Molecular Biology 120, 100-114.

Cooper J, Mirams GR \& Niederer SA (2011). High-throughput functional curation of cellular electrophysiology models. Progress in Biophysics and Molecular Biology 107, 11-20.

Cooper J, Scharm M \& Mirams GR (2016). The cardiac electrophysiology web lab. Biophysical Journal 110, 292-300.

Corrias A, Giles W \& Rodriguez B (2011). Ionic mechanisms of electrophysiological properties and repolarization abnormalities in rabbit Purkinje fibers. American Journal of Physiology-Heart and Circulatory Physiology 300, H1806-H1813.

Cortassa S, Aon MA, O’Rourke B, Jacques R, Tseng HJ, Marbán E \& Winslow RL (2006). A computational model integrating electrophysiology, contraction, and mitochondrial bioenergetics in the ventricular myocyte. Biophysical Journal 91, 1564-1589.

Courtemanche M, Ramirez RJ \& Nattel S (1998). Ionic mechanisms underlying human atrial action potential properties: insights from a mathematical model. American Journal of Physiology-Heart and Circulatory Physiology 275, H301-H321.

Daly AC, Clerx M, Beattie KA, Cooper J, Gavaghan DJ \& Mirams GR (2018). Reproducible model development in the cardiac electrophysiology Web Lab. Progress in Biophysics and Molecular Biology 139, 3-14.

Davies CW \& Malpass VE (1964). Ion association and the viscosity of dilute electrolyte solutions. Transactions of the Faraday Society 60, 2075-2084.

Decker KF, Heijman J, Silva JR, Hund TJ \& Rudy Y (2009). Properties and ionic mechanisms of action potential adaptation, restitution, and accommodation in canine epicardium. American Journal of Physiology-Heart and Circulatory Physiology 296, H1017-H1026. 
Demir SS, Clark JW \& Giles WR (1999). Parasympathetic modulation of sinoatrial node pacemaker activity in rabbit heart: a unifying model. American Journal of Physiology-Heart and Circulatory Physiology 276, H2221-H2244.

Demir SS, Clark JW, Murphey CR \& Giles WR (1994). A mathematical model of a rabbit sinoatrial node cell. American Journal of Physiology-Cell Physiology 266, C832-C852.

DiFrancesco D \& Noble D (1985). A model of cardiac electrical activity incorporating ionic pumps and concentration changes. Philosophical Transactions of the Royal Society of London. B, Biological Sciences 307, 353-398.

Dokos S, Celler B \& Lovell N (1996). Ion currents underlying sinoatrial node pacemaker activity: a new single cell mathematical model. Journal of Theoretical Biology 181, 245-272.

Dolphin AC (2016). Voltage-gated calcium channels and their auxiliary subunits: physiology and pathophysiology and pharmacology. The Journal of Physiology 594, 5369-5390.

Egan TM, Noble D, Noble SJ, Powell T, Spindler AJ \& Twist VW (1989). Sodium-calcium exchange during the action potential in guinea-pig ventricular cells. The Journal of Physiology 411, 639-661.

Ehrlich JR, Cha TJ, Zhang L, Chartier D, Melnyk P, Hohnloser SH \& Nattel S (2003). Cellular electrophysiology of canine pulmonary vein cardiomyocytes: action potential and ionic current properties. The Journal of Physiology 551, 801-813.

Eisner DA, Caldwell JL, Kistamás K \& Trafford AW (2017). Calcium and excitation-contraction coupling in the heart. Circulation Research 121, 181-195.

Escande D, Coulombe A, Faivre JF \& Coraboeuf E (1986). Characteristics of the time-dependent slow inward current in adult human atrial single myocytes. Journal of Molecular and Cellular Cardiology 18, $547-551$.

Faber GM \& Rudy Y (2000). Action potential and contractility changes in $\left[\mathrm{Na}^{+}\right]_{\mathrm{i}}$ overloaded cardiac myocytes: a simulation study. Biophysical Journal 78, 2392-2404.

Faber GM, Silva J, Livshitz L \& Rudy Y (2007). Kinetic properties of the cardiac L-type $\mathrm{Ca}^{2+}$ channel and its role in myocyte electrophysiology: a theoretical investigation. Biophysical Journal 92, $1522-1543$.

Fearnley CJ, Roderick HL \& Bootman MD (2011). Calcium signaling in cardiac myocytes. Cold Spring Harbor Perspectives in Biology 3, a004242.

Fermini B \& Nathan RD (1991). Removal of sialic acid alters both T-and L-type calcium currents in cardiac myocytes. American Journal of Physiology-Heart and Circulatory Physiology 260, H735-H743.

Findlay I (2002). Voltage-and cation-dependent inactivation of L-type $\mathrm{Ca}^{2+}$ channel currents in guineapig ventricular myocytes. The Journal of Physiology 541, 731-740.

Findlay I (2004). Physiological modulation of inactivation in L-type $\mathrm{Ca}^{2+}$ channels: one switch. The Journal of Physiology 554, 275-283.

Fink M, Noble D, Virag L, Varro A \& Giles WR (2008). Contributions of HERG K ${ }^{+}$current to repolarization of the human ventricular action potential. Progress in Biophysics and Molecular Biology 96, $357-376$.

Fox JJ, McHarg JL \& Gilmour Jr RF (2002). Ionic mechanism of electrical alternans. American Journal of Physiology-Heart and Circulatory Physiology 282, H516-H530. 
Fozzard HA (2002). Cardiac sodium and calcium channels: a history of excitatory currents. Cardiovascular Research 55, 1-8.

Frankenhaeuser B (1960). Sodium permeability in toad nerve and in squid nerve. The Journal of Physiology 152, 159-166.

Friedman N, Vinet A \& Roberge F (1996). A study of a new model of the cardiac ventricular cell incorporating myoplasmic calcium regulation In $22^{\text {nd }}$ Canadian Medical and Biological Engineering Society Conference, pp. 92-93.

Fülöp L, Bányász T, Magyar J, Szentandrássy N, Varró A \& Nánási PP (2004). Reopening of L-type calcium channels in human ventricular myocytes during applied epicardial action potentials. Acta Physiologica Scandinavica 180, 39-47.

Gaborit N, Le Bouter S, Szuts V, Varro A, Escande D, Nattel S \& Demolombe S (2007). Regional and tissue specific transcript signatures of ion channel genes in the non-diseased human heart. The Journal of Physiology 582, 675-693.

Gettes LS \& Reuter H (1974). Slow recovery from inactivation of inward currents in mammalian myocardial fibres. The Journal of Physiology 240, 703-724.

Goldberger AL, Amaral LA, Glass L, Hausdorff JM, Ivanov PC, Mark RG, Mietus JE, Moody GB, Peng CK \& Stanley HE (2000). PhysioBank, PhysioToolkit, and PhysioNet: components of a new research resource for complex physiologic signals. Circulation 101, e215-e220.

Goldman DE (1943). Potential, impedance, and rectification in membranes. The Journal of General Physiology 27, 37-60.

Golowasch J, Goldman MS, Abbott LF \& Marder E (2002). Failure of averaging in the construction of a conductance-based neuron model. Journal of Neurophysiology 87, 1129-1131.

Goonasekera SA, Hammer K, Auger-Messier M, Bodi I, Chen X, Zhang H, Reiken S, Elrod JW, Correll RN, York AJ et al. (2012). Decreased cardiac L-type $\mathrm{Ca}^{2+}$ channel activity induces hypertrophy and heart failure in mice. The Journal of Clinical Investigation 122, 280-290.

Gradogna A, Scholz-Starke J, Gutla PVK \& Carpaneto A (2009). Fluorescence combined with excised patch: measuring calcium currents in plant cation channels. The Plant Journal 58, 175-182.

Grandi E, Pandit SV, Voigt N, Workman AJ, Dobrev D, Jalife J \& Bers DM (2011). Human atrial action potential and $\mathrm{Ca}^{2+}$ model: sinus rhythm and chronic atrial fibrillation. Circulation Research $\mathbf{1 0 9}$, $1055-1066$.

Grandi E, Pasqualini FS \& Bers DM (2010). A novel computational model of the human ventricular action potential and Ca transient. Journal of Molecular and Cellular Cardiology 48, 112-121.

Greenstein JL, Hinch R \& Winslow RL (2006). Mechanisms of excitation-contraction coupling in an integrative model of the cardiac ventricular myocyte. Biophysical Journal 90, 77-91.

Greenstein JL \& Winslow RL (2002). An integrative model of the cardiac ventricular myocyte incorporating local control of $\mathrm{Ca}^{2+}$ release. Biophysical Journal 83, 2918-2945.

Habuchi Y, Noda T, Nishimura M \& Watanabe Y (1990). Recovery of the slow inward current from $\mathrm{Ca}^{2+}$-mediated and voltage-dependent inactivation in the rabbit sinoatrial node. Journal of Molecular and Cellular Cardiology 22, 469-482. 
Hadley RW \& Lederer WJ (1991). $\mathrm{Ca}^{2+}$ and voltage inactivate $\mathrm{Ca}^{2+}$ channels in guinea-pig ventricular myocytes through independent mechanisms. The Journal of Physiology 444, 257-268.

Hagiwara N, Irisawa H \& Kameyama M (1988). Contribution of two types of calcium currents to the pacemaker potentials of rabbit sino-atrial node cells. The Journal of Physiology 395, 233-253.

Han W, Chartier D, Li D \& Nattel S (2001). Ionic remodeling of cardiac Purkinje cells by congestive heart failure. Circulation 104, 2095-2100.

Hashambhoy YL, Winslow RL \& Greenstein JL (2009). CaMKII-induced shift in modal gating explains L-type $\mathrm{Ca}^{2+}$ current facilitation: a modeling study. Biophysical Journal 96, 1770-1785.

Hedley WJ, Nelson MR, Bellivant DP \& Nielsen PF (2001). A short introduction to CellML. Philosophical Transactions of the Royal Society of London A: Mathematical, Physical and Engineering Sciences 359, 1073-1089.

Heijman J (2012). Computational analysis of $\beta$-adrenergic stimulation and its effects on cardiac ventricular electrophysiology Ph.D. diss., Maastricht University.

Heijman J, Volders PGA, Westra RL \& Rudy Y (2011). Local control of $\beta$-adrenergic stimulation: effects on ventricular myocyte electrophysiology and $\mathrm{Ca}^{2+}$-transient. Journal of Molecular and Cellular Cardiology 50, 863-871.

Herron TJ, Lee P \& Jalife J (2012). Optical imaging of voltage and calcium in cardiac cells \& tissues. Circulation Research 110, 609-623.

Hess P, Lansman JB \& Tsien RW (1986). Calcium channel selectivity for divalent and monovalent cations. voltage and concentration dependence of single channel current in ventricular heart cells. The Journal of General Physiology 88, 293-319.

Hilgemann DW \& Noble D (1987). Excitation-contraction coupling and extracellular calcium transients in rabbit atrium: reconstruction of basic cellular mechanisms. Proceedings of the Royal Society of London B: Biological Sciences 230, 163-205.

Himeno Y, Asakura K, Cha CY, Memida H, Powell T, Amano A \& Noma A (2015). A human ventricular myocyte model with a refined representation of excitation-contraction coupling. Biophysical Journal 109, 415-427.

Hinch R, Greenstein JL, Tanskanen AJ, Xu L \& Winslow RL (2004). A simplified local control model of calcium-induced calcium release in cardiac ventricular myocytes. Biophysical Journal 87, 3723-3736.

Hirano Y, Fozzard HA \& January CT (1989). Characteristics of L-and T-type $\mathrm{Ca}^{2+}$ currents in canine cardiac Purkinje cells. American Journal of Physiology-Heart and Circulatory Physiology 256, H1478-H1492.

Hodgkin AL \& Huxley AF (1952). A quantitative description of membrane current and its application to conduction and excitation in nerve. The Journal of Physiology 117, 500-544.

Hodgkin AL \& Katz B (1949). The effect of sodium ions on the electrical activity of the giant axon of the squid. The Journal of Physiology 108, 37-77.

Hoefen R, Reumann M, Goldenberg I, Moss AJ, Jin O, Gu Y, McNitt S, Zareba W, Jons C, Kanters JK et al. (2012). In silico cardiac risk assessment in patients with long QT syndrome: type 1: clinical predictability of cardiac models. Journal of the American College of Cardiology 60, 2182-2191. 
Höfer GF, Hohenthanner K, Baumgartner W, Groschner K, Klugbauer N, Hofmann F \& Romanin C (1997). Intracellular $\mathrm{Ca}^{2+}$ inactivates L-type $\mathrm{Ca}^{2+}$ channels with a Hill coefficient of $\sim 1$ and an inhibition constant of $\sim 4$ microM by reducing channel's open probability. Biophysical Journal 73, $1857-1865$.

Hofmann F, Flockerzi V, Kahl S \& Wegener JW (2014). L-type Cav1.2 calcium channels: from in vitro findings to in vivo function. Physiological Reviews 94, 303-326.

Hund TJ, Decker KF, Kanter E, Mohler PJ, Boyden PA, Schuessler RB, Yamada KA \& Rudy Y (2008). Role of activated CaMKII in abnormal calcium homeostasis and $\mathrm{I}_{\mathrm{Na}}$ remodeling after myocardial infarction: Insights from mathematical modeling. Journal of Molecular and Cellular Cardiology 45, $420-428$.

Hund TJ \& Rudy Y (2004). Rate dependence and regulation of action potential and calcium transient in a canine cardiac ventricular cell model. Circulation 110, 3168-3174.

Imredy JP \& Yue DT (1994). Mechanism of $\mathrm{Ca}^{2+}$-sensitive inactivation of L-type $\mathrm{Ca}^{2+}$ channels. Neuron 12, 1301-1318.

Inada S, Hancox JC, Zhang H \& Boyett MR (2009). One-dimensional mathematical model of the atrioventricular node including atrio-nodal, nodal, and nodal-his cells. Biophysical Journal 97, 2117-2127.

Iyer V, Mazhari R \& Winslow RL (2004). A computational model of the human left-ventricular epicardial myocyte. Biophysical Journal 87, 1507-1525.

Jafri MS, Rice JJ \& Winslow RL (1998). Cardiac $\mathrm{Ca}^{2+}$ dynamics: the roles of ryanodine receptor adaptation and sarcoplasmic reticulum load. Biophysical Journal 74, 1149-1168.

Kääb S, Nuss HB, Chiamvimonvat N, O'Rourke B, Pak PH, Kass DA, Marban E \& Tomaselli GF (1996). Ionic mechanism of action potential prolongation in ventricular myocytes from dogs with pacing-induced heart failure. Circulation Research 78, 262-273.

Kamp TJ, Hu H \& Marban E (2000). Voltage-dependent facilitation of cardiac L-type Ca channels expressed in HEK-293 cells requires $\beta$-subunit. American Journal of Physiology-Heart and Circulatory Physiology 278, H126-H136.

Kass RS \& Sanguinetti MC (1984). Inactivation of calcium channel current in the calf cardiac Purkinje fiber. Evidence for voltage-and calcium-mediated mechanisms. The Journal of General Physiology 84, $705-726$.

Katsube Y, Yokoshiki H, Nguyen L, Yamamoto M \& Sperelakis N (1998). L-type Ca ${ }^{2+}$ currents in ventricular myocytes from neonatal and adult rats. Canadian Journal of Physiology and Pharmacology $\mathbf{7 6}$, $873-881$.

Kawano S \& Hiraoka M (1991). Transient outward currents and action potential alterations in rabbit ventricular myocytes. Journal of Molecular and Cellular Cardiology 23, 681-693.

Keener JP \& Sneyd J (1998). Mathematical Physiology I: Cellular Physiology Vol. 1 Springer.

Kernik DC, Morotti S, Wu H, Garg P, Duff HJ, Kurokawa J, Jalife J, Wu JC, Grandi E \& Clancy CE (2019). A computational model of induced pluripotent stem-cell derived cardiomyocytes incorporating experimental variability from multiple data sources. The Journal of Physiology 597, 4533-4564.

Kim JG, Sung DJ, Kim Hj, Park SW, Won KJ, Kim B, Shin HC, Kim KS, Leem CH, Zhang YH et al. (2016). Impaired inactivation of L-Type $\mathrm{Ca}^{2+}$ current as a potential mechanism for variable arrhythmogenic liability of HERG $\mathrm{K}^{+}$channel blocking drugs. PloS One 11. 
Ko JH, Park WS, Kim SJ \& Earm YE (2006). Slowing of the inactivation of voltage-dependent sodium channels by staurosporine, the protein kinase $\mathrm{C}$ inhibitor, in rabbit atrial myocytes. European Journal of Pharmacology 534, 48-54.

Kodama I, Boyett MR, Nikmaram MR, Yamamoto M, Honjo H \& Niwa R (1999). Regional differences in effects of E-4031 within the sinoatrial node. American Journal of Physiology-Heart and Circulatory Physiology 276, H793-H802.

Koivumäki JT, Korhonen T \& Tavi P (2011). Impact of sarcoplasmic reticulum calcium release on calcium dynamics and action potential morphology in human atrial myocytes: a computational study. PLoS Computational Biology 7, e1001067.

Kurata Y, Hisatome I, Imanishi S \& Shibamoto T (2002). Dynamical description of sinoatrial node pacemaking: improved mathematical model for primary pacemaker cell. American Journal of PhysiologyHeart and Circulatory Physiology 283, H2074-H2101.

Le Grand B, Hatem S, Deroubaix E, Couetil JP \& Coraboeuf E (1991). Calcium current depression in isolated human atrial myocytes after cessation of chronic treatment with calcium antagonists. Circulation Research 69, 292-300.

Le Grand BL, Hatem S, Deroubaix E, Couétil JP \& Coraboeuf E (1994). Depressed transient outward and calcium currents in dilated human atria. Cardiovascular Research 28, 548-556.

Lei C, Clerx M, Gavaghan DJ, Polonchuk L, Mirams GR \& Wang K (2019). Rapid characterization of hERG channel kinetics I: using an automated high-throughput system. Biophysical Journal 117, 2438-2454.

Lei C, Clerx M, Whittaker DG, Gavaghan DJ, de Boer TP \& Mirams GR (2020a). Accounting for variability in ion current recordings using a mathematical model of artefacts in voltage-clamp experiments. Philosophical Transactions of the Royal Society A: Mathematical, Physical and Engineering Sciences 378, 20190348.

Lei C, Fabbri A, Whittaker DG, Clerx M, Windley MJ, Hill AP, Mirams GR \& de Boer TP (2020b). A nonlinear and time-dependent leak current in the presence of calcium fluoride patch-clamp seal enhancer. Wellcome Open Research 5, 152.

Li GR \& Nattel S (1997). Properties of human atrial $\mathrm{I}_{\mathrm{Ca}}$ at physiological temperatures and relevance to action potential. American Journal of Physiology-Heart and Circulatory Physiology 272, H227-H235.

Li GR, Yang B, Feng J, Bosch RF, Carrier M \& Nattel S (1999). Transmembrane $\mathrm{I}_{\mathrm{Ca}}$ contributes to rate-dependent changes of action potentials in human ventricular myocytes. American Journal of Physiology-Heart and Circulatory Physiology 276, H98-H106.

Li L, Niederer SA, Idigo W, Zhang YH, Swietach P, Casadei B \& Smith NP (2010). A mathematical model of the murine ventricular myocyte: a data-driven biophysically based approach applied to mice overexpressing the canine NCX isoform. American Journal of Physiology-Heart and Circulatory Physiology 299, H1045-H1063.

Li M, Kanda Y, Ashihara T, Sasano T, Nakai Y, Kodama M, Hayashi E, Sekino Y, Furukawa T \& Kurokawa J (2017). Overexpression of KCNJ2 in induced pluripotent stem cell-derived cardiomyocytes for the assessment of QT-prolonging drugs. Journal of Pharmacological Sciences 134, 75-85.

Li P \& Rudy Y (2011). A model of canine Purkinje cell electrophysiology and $\mathrm{Ca}^{2+}$ cycling: rate 
dependence, triggered activity, and comparison to ventricular myocytes. Circulation Research 109, $71-79$.

Liao P, Yu D, Li G, Yong TF, Soon JL, Chua YL \& Soong TW (2007). A smooth muscle Cav1.2 calcium channel splice variant underlies hyperpolarized window current and enhanced state-dependent inhibition by nifedipine. Journal of Biological Chemistry 282, 35133-35142.

Lindblad DS, Murphey CR, Clark JW \& Giles WR (1996). A model of the action potential and underlying membrane currents in a rabbit atrial cell. American Journal of Physiology-Heart and Circulatory Physiology 271, H1666-H1696.

Linz KW \& Meyer R (1997). Modulation of L-type calcium current by internal potassium in guinea pig ventricular myocytes. Cardiovascular Research 33, 110-122.

Liu Y, Zeng W, Delmar M \& Jalife J (1993). Ionic mechanisms of electronic inhibition and concealed conduction in rabbit atrioventricular nodal myocytes. Circulation 88, 1634-1646.

Livshitz LM \& Rudy Y (2007). Regulation of $\mathrm{Ca}^{2+}$ and electrical alternans in cardiac myocytes: role of CAMKII and repolarizing currents. American Journal of Physiology-Heart and Circulatory Physiology 292, H2854-H2866.

Lovell NH, Cloherty SL, Celler BG \& Dokos S (2004). A gradient model of cardiac pacemaker myocytes. Progress in Biophysics and Molecular Biology 85, 301-323.

Luo CH \& Rudy Y (1994). A dynamic model of the cardiac ventricular action potential II. Afterdepolarizations, triggered activity, and potentiation. Circulation Research 74, 1097-1113.

Ma J, Guo L, Fiene SJ, Anson BD, Thomson JA, Kamp TJ, Kolaja KL, Swanson BJ \& January CT (2011). High purity human-induced pluripotent stem cell-derived cardiomyocytes: electrophysiological properties of action potentials and ionic currents. American Journal of Physiology-Heart and Circulatory Physiology 301, H2006-H2017.

Magyar J, Iost N, Körtvély Á, Bányász T, Virág L, Szigligeti P, Varró A, Opincariu M, Szécsi J, Papp JG et al. (2000). Effects of endothelin-1 on calcium and potassium currents in undiseased human ventricular myocytes. Pflügers Archiv-European Journal of Physiology 441, 144-149.

Magyar J, Szentandrássy N, Bányász T, Fülöp L, Varró A \& Nánási PP (2002). Effects of thymol on calcium and potassium currents in canine and human ventricular cardiomyocytes. British Journal of Pharmacology 136, 330-338.

Mahajan A, Shiferaw Y, Sato D, Baher A, Olcese R, Xie LH, Yang MJ, Chen PS, Restrepo JG, Karma A et al. (2008). A rabbit ventricular action potential model replicating cardiac dynamics at rapid heart rates. Biophysical Journal 94, 392-410.

Matsuoka S, Sarai N, Kuratomi S, Ono K \& Noma A (2003). Role of individual ionic current systems in ventricular cells hypothesized by a model study. The Japanese Journal of Physiology 53, 105-123.

McAllister RE, Noble D \& Tsien RW (1975). Reconstruction of the electrical activity of cardiac Purkinje fibres. The Journal of Physiology 251, 1-59.

McDonald TF, Cavalié A, Trautwein W \& Pelzer D (1986). Voltage-dependent properties of macroscopic and elementary calcium channel currents in guinea pig ventricular myocytes. Pflügers Archiv-European Journal of Physiology 406, 437-448.

Mesirca P, Torrente AG \& Mangoni ME (2014). T-type channels in the sino-atrial and atrioventricular pacemaker mechanism. Pflügers Archiv-European Journal of Physiology 466, 791-799. 
Mewes T \& Ravens U (1994). L-type calcium currents of human myocytes from ventricle of non-failing and failing hearts and from atrium. Journal of Molecular and Cellular Cardiology 26, 1307-1320.

Michailova A, Saucerman J, Belik ME \& McCulloch AD (2005). Modeling regulation of cardiac $\mathrm{K}_{\mathrm{ATP}}$ and L-type $\mathrm{Ca}^{2+}$ currents by ATP, ADP, and $\mathrm{Mg}^{2+}$. Biophysical Journal 88, 2234-2249.

Mirams GR, Davies MR, Cui Y, Kohl P \& Noble D (2012). Application of cardiac electrophysiology simulations to pro-arrhythmic safety testing. British journal of pharmacology 167, 932-945.

Miyoshi S, Mitamura H, Fujikura K, Fukuda Y, Tanimoto K, Hagiwara Y, Ita M \& Ogawa S (2003). A mathematical model of phase 2 reentry: role of L-type Ca current. American Journal of PhysiologyHeart and Circulatory Physiology 284, H1285-H1294.

Nakayama T, Kurachi Y, Noma A \& Irisawa H (1984). Action potential and membrane currents of single pacemaker cells of the rabbit heart. Pflügers Archiv-European Journal of Physiology 402, 248-257.

Niederer SA, Fink M, Noble D \& Smith NP (2009). A meta-analysis of cardiac electrophysiology computational models. Experimental Physiology 94, 486-495.

Nilius B (1986). Possible functional significance of a novel type of cardiac Ca channel. Biomedica Biochimica Acta 45, K37-45.

Nivala M, de Lange E, Rovetti R \& Qu Z (2012). Computational modeling and numerical methods for spatiotemporal calcium cycling in ventricular myocytes. Frontiers in Physiology 3, 114.

Noble D, Noble SJ, Bett GC, Earm YE, Ho WK \& So IK (1991). The role of sodium-calcium exchange during the cardiac action potential. Annals of the New York Academy of Sciences 639, 334-353.

Noble D, Garny A \& Noble PJ (2012). How the Hodgkin-Huxley equations inspired the cardiac physiome project. The Journal of Physiology 590, 2613-2628.

Noble D \& Rudy Y (2001). Models of cardiac ventricular action potentials: iterative interaction between experiment and simulation. Philosophical Transactions of the Royal Society of London A: Mathematical, Physical and Engineering Sciences 359, 1127-1142.

Noble D, Varghese A, Kohl P \& Noble P (1998). Improved guinea-pig ventricular cell model incorporating a diadic space, $\mathrm{I}_{\mathrm{Kr}}$ and $\mathrm{I}_{\mathrm{Ks}}$, and length-and tension-dependent processes. The Canadian Journal of Cardiology 14, 123-134.

Noma A \& Shibasaki T (1985). Membrane current through adenosine-triphosphate-regulated potassium channels in guinea-pig ventricular cells. The Journal of Physiology 363, 463-480.

Nordin C (1993). Computer model of membrane current and intracellular $\mathrm{Ca}^{2+}$ flux in the isolated guinea pig ventricular myocyte. American Journal of Physiology-Heart and Circulatory Physiology 265, H2117-H2136.

Nordin C, Siri F \& Aronson RS (1989). Electrophysiologic characteristics of single myocytes isolated from hypertrophied guinea-pig hearts. Journal of Molecular and Cellular Cardiology 21, 729-739.

Nygren A, Fiset C, Firek L, Clark JW, Lindblad DS, Clark RB \& Giles WR (1998). Mathematical model of an adult human atrial cell: the role of $\mathrm{K}^{+}$currents in repolarization. Circulation Research 82, 63-81.

O’Hara T, Virág L, Varró A \& Rudy Y (2011). Simulation of the undiseased human cardiac ventricular action potential: model formulation and experimental validation. PLoS Computational Biology $\mathbf{7}$, e1002061. 
Ortner NJ \& Striessnig J (2016). L-type calcium channels as drug targets in CNS disorders. Channels 10, $7-13$.

Paci M, Hyttinen J, Aalto-Setälä K \& Severi S (2013). Computational models of ventricular-and atriallike human induced pluripotent stem cell derived cardiomyocytes. Annals of Biomedical Engineering 41, 2334-2348.

Pandit SV, Clark RB, Giles WR \& Demir SS (2001). A mathematical model of action potential heterogeneity in adult rat left ventricular myocytes. Biophysical Journal 81, 3029-3051.

Pásek M, Šimurda J \& Christé G (2006). The functional role of cardiac T-tubules explored in a model of rat ventricular myocytes. Philosophical Transactions of the Royal Society A: Mathematical, Physical and Engineering Sciences 364, 1187-1206.

Pelzmann B, Schaffer P, Bernhart E, Lang P, Mächler H, Rigler B \& Koidl B (1998). L-type calcium current in human ventricular myocytes at a physiological temperature from children with tetralogy of Fallot. Cardiovascular Research 38, 424-432.

Pitzer KS \& Mayorga G (1973). Thermodynamics of electrolytes. II. Activity and osmotic coefficients for strong electrolytes with one or both ions univalent. The Journal of Physical Chemistry 77, 2300-2308.

Pohl A, Wachter A, Hatam N \& Leonhardt S (2016). A computational model of a human single sinoatrial node cell. Biomedical Physics \& Engineering Express 2, 035006.

Priebe L \& Beuckelmann DJ (1998). Simulation study of cellular electric properties in heart failure. Circulation Research 82, 1206-1223.

Puglisi JL, Yuan W, Bassani JW \& Bers DM (1999). $\mathrm{Ca}^{2+}$ influx through $\mathrm{Ca}^{2+}$ channels in rabbit ventricular myocytes during action potential clamp: influence of temperature. Circulation Research $\mathbf{8 5}$, e7-e16.

Quinn TA, Granite S, Allessie MA, Antzelevitch C, Bollensdorff C, Bub G, Burton RAB, Cerbai E, Chen PS, Delmar M et al. (2011). Minimum Information about a Cardiac Electrophysiology Experiment (MICEE): Standardised reporting for model reproducibility, interoperability, and data sharing. Progress in Biophysics and Molecular Biology 107, 4-10.

Ramasubramanian S \& Rudy Y (2018). The structural basis of IKs ion-channel activation: Mechanistic insights from molecular simulations. Biophysical Journal 114, 2584-2594.

Ramirez RJ, Nattel S \& Courtemanche M (2000). Mathematical analysis of canine atrial action potentials: rate, regional factors, and electrical remodeling. American Journal of Physiology-Heart and Circulatory Physiology 279, H1767-H1785.

Rasmusson RL, Clark JW, Giles WR, Robinson K, Clark RB, Shibata EF \& Campbell DL (1990). A mathematical model of electrophysiological activity in a bullfrog atrial cell. American Journal of Physiology-Heart and Circulatory Physiology 259, H370-H389.

Restrepo JG, Weiss JN \& Karma A (2008). Calsequestrin-mediated mechanism for cellular calcium transient alternans. Biophysical Journal 95, 3767-3789.

Reuter H (1968). Slow inactivation of currents in cardiac Purkinje fibres. The Journal of Physiology 197, $233-253$.

Reuter H (1974). Localization of beta adrenergic receptors, and effects of noradrenaline and cyclic nucleotides on action potentials, ionic currents and tension in mammalian cardiac muscle. The Journal of Physiology 242, 429-451. 
Reuter H \& Scholz H (1977). A study of the ion selectivity and the kinetic properties of the calcium dependent slow inward current in mammalian cardiac muscle. The Journal of Physiology 264, 17-47.

Reuter H (1973). Divalent cations as charge carriers in excitable membranes. Progress in Biophysics and Molecular Biology 26, 1-43.

Rice JJ, Jafri MS \& Winslow RL (1999). Modeling gain and gradedness of $\mathrm{Ca}^{2+}$ release in the functional unit of the cardiac diadic space. Biophysical Journal 77, 1871-1884.

Rice JJ \& Jafri MS (2001). Modelling calcium handling in cardiac cells. Philosophical Transactions of the Royal Society of London. Series A: Mathematical, Physical and Engineering Sciences 359, 1143-1157.

Ridder BJ, Leishman DJ, Bridgland-Taylor M, Samieegohar M, Han X, Wu WW, Randolph A, Tran P, Sheng J, Danker T et al. (2020). A systematic strategy for estimating hERG block potency and its implications in a new cardiac safety paradigm. Toxicology and Applied Pharmacology 394, 114961.

Rose WC, Balke CW, Wier WG \& Marban E (1992). Macroscopic and unitary properties of physiological ion flux through L-type $\mathrm{Ca}^{2+}$ channels in guinea-pig heart cells. The Journal of Physiology 456 , 267-284.

Roux B, Allen T, Berneche S \& Im W (2004). Theoretical and computational models of biological ion channels. Quarterly Reviews of Biophysics 37, 15-103.

Rovetti R, Cui X, Garfinkel A, Weiss JN \& Qu Z (2010). Spark-induced sparks as a mechanism of intracellular calcium alternans in cardiac myocytes. Circulation Research 106, 1582.

Rubart M, Lopshire JC, Fineberg NS \& Zipes DP (2000). Changes in left ventricular repolarization and ion channel currents following a transient rate increase superimposed on bradycardia in anesthetized dogs. Journal of Cardiovascular Electrophysiology 11, 652-664.

Rudy Y \& Silva JR (2006). Computational biology in the study of cardiac ion channels and cell electrophysiology. Quarterly Reviews of Biophysics 39, 57-116.

Sato D, Shiferaw Y, Garfinkel A, Weiss JN, Qu Z \& Karma A (2006). Spatially discordant alternans in cardiac tissue: role of calcium cycling. Circulation Research 99, 520-527.

Satoh H (1994). Elevation of intracellular $\mathrm{Ca}^{2+}$ concentration by protein kinase $\mathrm{C}$ stimulation in isolated single rabbit sino-atrial node cells. General Pharmacology: The Vascular System 25, 325-332.

Schulz DJ, Goaillard JM \& Marder E (2006). Variable channel expression in identified single and electrically coupled neurons in different animals. Nature Neuroscience 9, 356-362.

Shannon TR, Wang F \& Bers DM (2005). Regulation of cardiac sarcoplasmic reticulum Ca release by luminal $[\mathrm{Ca}]$ and altered gating assessed with a mathematical model. Biophysical Journal 89, 4096-4110.

Shannon TR, Wang F, Puglisi J, Weber C \& Bers DM (2004). A mathematical treatment of integrated Ca dynamics within the ventricular myocyte. Biophysical Journal 87, 3351-3371.

Shirokov R, Levis R, Shirokova N \& Ríos E (1993). Ca ${ }^{2+}$-dependent inactivation of cardiac L-type Ca ${ }^{2+}$ channels does not affect their voltage sensor. The Journal of General Physiology 102, 1005-1030.

Silva JR (2018). How to connect cardiac excitation to the atomic interactions of ion channels. Biophysical Journal 114, 259-266.

Smith GD (1996). Analytical steady-state solution to the rapid buffering approximation near an open $\mathrm{Ca}^{2+}$ channel. Biophysical Journal 71, 3064-3072. 
Stern MD (1992). Theory of excitation-contraction coupling in cardiac muscle. Biophysical Journal 63, $497-517$.

Striessnig J, Pinggera A, Kaur G, Bock G \& Tuluc P (2014). L-type Ca ${ }^{2+}$ channels in heart and brain. Wiley Interdisciplinary Reviews: Membrane Transport and Signaling 3, 15-38.

Sun H, Leblanc N \& Nattel S (1997). Mechanisms of inactivation of L-type calcium channels in human atrial myocytes. American Journal of Physiology-Heart and Circulatory Physiology 272, H1625-H1635.

Sun L, Fan JS, Clark JW \& Palade PT (2000). A model of the L-type $\mathrm{Ca}^{2+}$ channel in rat ventricular myocytes: ion selectivity and inactivation mechanisms. The Journal of Physiology 529, 139-158.

Szabó G, Szentandrássy N, Bíró T, Tóth BI, Czifra G, Magyar J, Bányász T, Varró A, Kovács L \& Nánási PP (2005). Asymmetrical distribution of ion channels in canine and human left-ventricular wall: epicardium versus midmyocardium. Pflügers Archiv-European Journal of Physiology 450, 307-316.

Takagi S, Kihara Y, Sasayama S \& Mitsuiye T (1998). Slow inactivation of cardiac L-type $\mathrm{Ca}^{2+}$ channel induced by cold acclimation of guinea pig. American Journal of Physiology-Regulatory, Integrative and Comparative Physiology 274, R348-R356.

Taniguchi J, Noma A \& Irisawa H (1983). Modification of the cardiac action potential by intracellular injection of adenosine triphosphate and related substances in guinea pig single ventricular cells. Circulation Research 53, 131-139.

Ten Tusscher KHWJ, Noble D, Noble PJ \& Panfilov AV (2004). A model for human ventricular tissue. American Journal of Physiology-Heart and Circulatory Physiology 286, H1573-H1589.

Ten Tusscher KHWJ \& Panfilov AV (2006). Alternans and spiral breakup in a human ventricular tissue model. American Journal of Physiology-Heart and Circulatory Physiology 291, H1088-H1100.

Tomek J, Bueno-Orovio A, Passini E, Zhou X, Minchole A, Britton O, Bartolucci C, Severi S, Shrier A, Virag L et al. (2019). Development, calibration, and validation of a novel human ventricular myocyte model in health, disease, and drug block. eLife $\mathbf{8}$.

Trovato C, Passini E, Nagy N, Varró A, Abi-Gerges N, Severi S \& Rodriguez B (2020). Human Purkinje in silico model enables mechanistic investigations into automaticity and pro-arrhythmic abnormalities. Journal of Molecular and Cellular Cardiology .

Tseng GN, Robinson RB \& Hoffman BF (1987). Passive properties and membrane currents of canine ventricular myocytes. The Journal of General Physiology 90, 671-701.

Tseng GN (1988). Calcium current restitution in mammalian ventricular myocytes is modulated by intracellular calcium. Circulation Research 63, 468-482.

Varela M, Colman MA, Hancox JC \& Aslanidi OV (2016). Atrial heterogeneity generates re-entrant substrate during atrial fibrillation and anti-arrhythmic drug action: mechanistic insights from canine atrial models. PLoS Computational Biology 12, e1005245.

Veerman CC, Mengarelli I, Guan K, Stauske M, Barc J, Tan HL, Wilde AAM, Verkerk AO \& Bezzina CR (2016). hiPSC-derived cardiomyocytes from Brugada Syndrome patients without identified mutations do not exhibit clear cellular electrophysiological abnormalities. Scientific Reports 6, 1-10.

Vitek M \& Trautwein W (1971). Slow inward current and action potential in cardiac Purkinje fibres. Pflügers Archiv-European Journal of Physiology 323, 204-218. 
Vornanen M \& Shepherd N (1997). Restitution of contractility in single ventricular myocytes of guinea pig heart. Cardiovascular Research 33, 611-622.

Whittaker DG, Clerx M, Lei CL, Christini DJ \& Mirams GR (2020). Calibration of ionic and cellular cardiac electrophysiology models. Wiley Interdisciplinary Reviews: Systems Biology and Medicine p. e1482.

Wilders R, Jongsma HJ \& Van Ginneken ACG (1991). Pacemaker activity of the rabbit sinoatrial node: A comparison of mathematical models. Biophysical Journal 60, 1202-1216.

Winslow RL, Rice J, Jafri S, Marban E \& O'Rourke B (1999). Mechanisms of altered excitationcontraction coupling in canine tachycardia-induced heart failure, II: model studies. Circulation Research 84, 571-586.

You Y, Pelzer DJ \& Pelzer S (1997). Modulation of L-type $\mathrm{Ca}^{2+}$ current by fast and slow $\mathrm{Ca}^{2+}$ buffering in guinea pig ventricular cardiomyocytes. Biophysical Journal 72, 175-187.

Yu T, Lloyd CM, Nickerson DP, Cooling MT, Miller AK, Garny A, Terkildsen JR, Lawson J, Britten RD, Hunter PJ et al. (2011). The Physiome model repository 2. Bioinformatics 27, 743-744.

Yue L, Feng J, Gaspo R, Li GR, Wang Z \& Nattel S (1997). Ionic remodeling underlying action potential changes in a canine model of atrial fibrillation. Circulation Research 81, 512-525.

Zahradníková A, Kubalová Z, Pavelková J, Gyorke S \& Zahradník I (2004). Activation of calcium release assessed by calcium release-induced inactivation of calcium current in rat cardiac myocytes. American Journal of Physiology-Cell Physiology 286, C330-C341.

Zamponi GW, Striessnig J, Koschak A \& Dolphin AC (2015). The physiology, pathology, and pharmacology of voltage-gated calcium channels and their future therapeutic potential. Pharmacological Reviews 67, 821-870.

Zeng J, Laurita KR, Rosenbaum DS \& Rudy Y (1995). Two components of the delayed rectifier $\mathrm{K}^{+}$ current in ventricular myocytes of the guinea pig type: Theoretical formulation and their role in repolarization. Circulation Research 77, 140-152.

Zhang H, Holden AV, Kodama I, Honjo H, Lei M, Varghese T \& Boyett MR (2000). Mathematical models of action potentials in the periphery and center of the rabbit sinoatrial node. American Journal of Physiology-Heart and Circulatory Physiology 279, H397-H421.

Zhou Z \& Bers DM (2000). $\mathrm{Ca}^{2+}$ influx via the L-type $\mathrm{Ca}^{2+}$ channel during tail current and above current reversal potential in ferret ventricular myocytes. The Journal of Physiology 523, 57-66. 